\title{
The structure and hydraulics of natural woody debris jams
}

\author{
Rebecca B. Manners
}

A thesis submitted to the faculty of the University of North Carolina at Chapel Hill in partial fulfillment of the requirements for the degree of Master of Arts in the Department of Geography

\section{Chapel Hill}

2006

Approved by:

Martin W. Doyle

Lawrence E. Band

Amilcare Porporato 


\begin{abstract}
REBECCA B. MANNERS: The structure and hydraulics of natural woody debris jams (Under the direction of Martin W. Doyle)
\end{abstract}

While the importance of woody debris in rivers has been well-studied within the past few decades, the dynamics of the woody debris jam is often overlooked. This study focuses on the woody debris jam treating it as a complex and porous accumulation of heterogeneous material. Accounting for the momentum extracted as flow passes a debris jam, the drag force on three jams with differing structures, representing varying degrees of porosity, is quantified. Utilizing the drag force equation along with the volume and surface area of the jam, the effect of structure on hydraulics is investigated. A theoretical model for debris jam evolution is hypothesized based on these results and a review of the literature. The results from this study show that 1) natural debris jams are porous structures and 2) piece-size distributions may dictate the evolution of a debris jam and therefore its rate of change in hydraulics. 


\section{ACKNOWLEDGEMENTS}

This thesis would not have been possible without the help from a variety of people and organizations. Funding throughout this project was provided by a NSF grant to Martin Doyle. The Geography Department provided me with additional funds while working towards my degree.

I would like to thank Martin Doyle for his role as my advisor offering me guidance and support. The members of my committee, Martin Doyle, Larry Band and Amilcare Porporato read this thesis and supplied valuable feedback. Melanie Small gave me insight during the duration of this project and played an instrumental role in the collection of data. Arjun Dongre and Chelsea Lane-Miller's field support aided in the successful collection of a complete data set within a limited timeframe. Additional support was provided by the staff of Cornell's Little Moose field station, Randy Fuller, Wild Water Outdoor Center, and NYDEC. 


\section{TABLE OF CONTENTS}

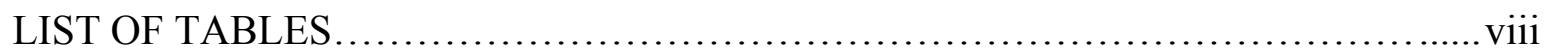

LIST OF FIGURES .........................................................

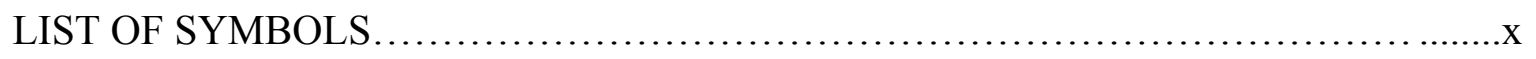

Chapter

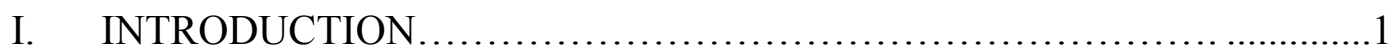

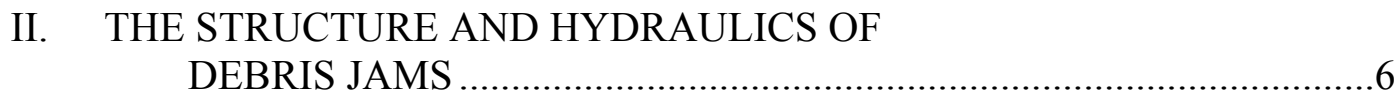

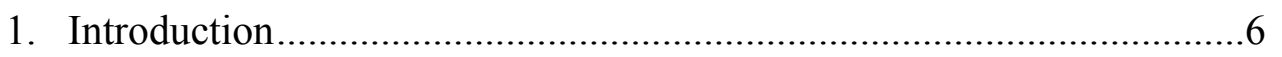

1.1 Hydraulics of Debris Jams ................................................ 8

1.2 Goals and Structure ........................................................ 9

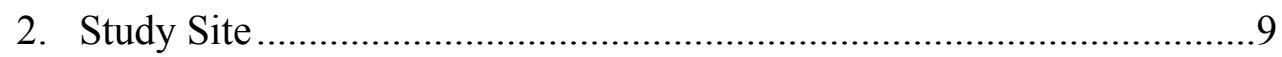

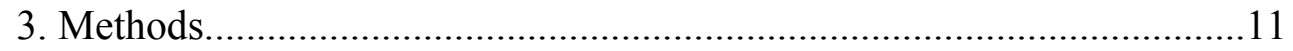

3.1 Experimental Design........................................................11

3.2 Determining Drag Force through Momentum Extraction .........15

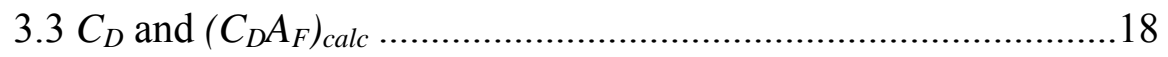

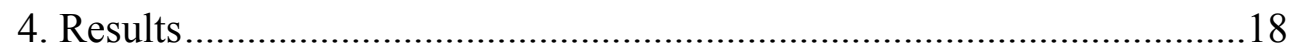

4.1 Jam Structure and Composition .............................................. 18

4.1.1 Key Member(s) and Total Accumulation ................18

4.1.2 Volume and Surface Area of Accumulated ...............19

Pieces 
4.1.3 Soil and Leaf Litter

4.2 Velocity and Shear Stress Distributions ...............................21

4.2.1 Upstream ..........................................................22

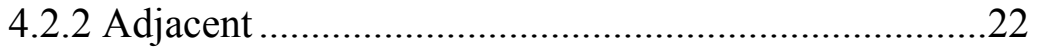

4.2.3 Downstream ......................................................23

4.2.4 Excess Shear Stress.............................................23

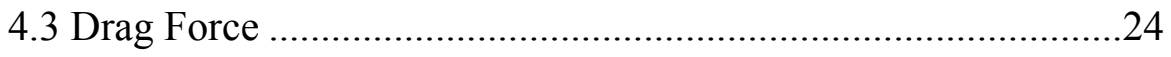

4.3.1 The Drag Force Equation: $F_{D}, A_{F(e m p)}, C_{D}$,

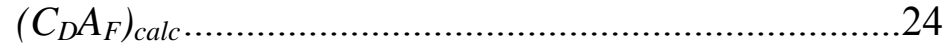

4.3.2 Relationship between $A_{F(e m p)}, F_{D},\left(C_{D} A_{F}\right)_{c a l c}$

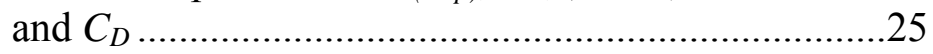

4.3.3 The Influence of Jam Structure and Composition: $A_{F(e m p)}, V, A_{\text {surf, }}$ and Porosity ..................................25

5. Discussion .26

5.1 A Detailed Look at Jams in a Mountain River in the Northeast U.S. .26

5.1.1 Jam Composition .26

5.1.2 Effects of a Debris Jam on the Channel Bed .27

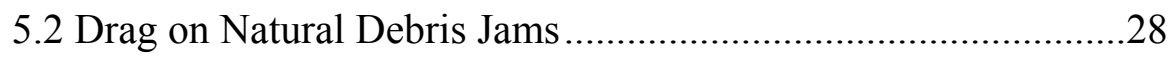

5.2.1 Drag Coefficient and the Drag Equation ..................28

5.2.2 Surface Area and Porosity .....................................30

5.2.3 Theoretical Predictions between Debris Jam Types ...32

6. Implications of Findings .34

7. Conclusion . .35 


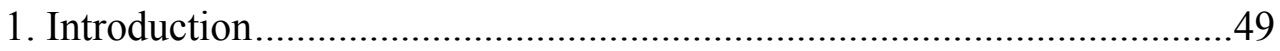

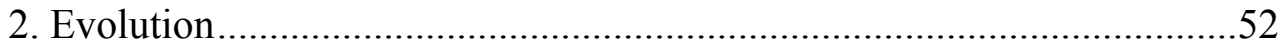

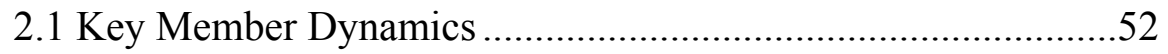

2.1.1 Key Member Stability ...............................................52

2.1.2 Key Member Recruitment...........................................53

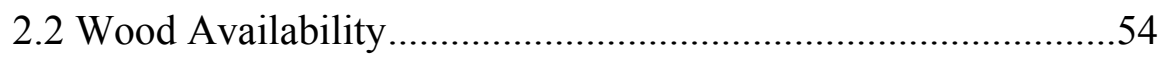

2.2.1 Watershed-Scale: Wood Loadings................................54

2.2.2 Reach-Scale: Wood Loadings and Fluvial Transport.57 2.2.3 Jam-Scale: Accumulation of Wood ..............................58

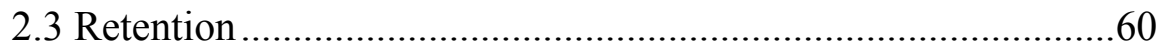

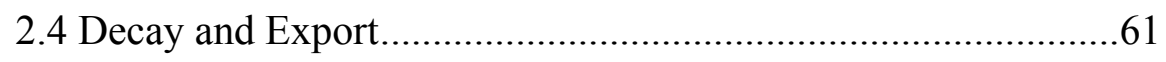

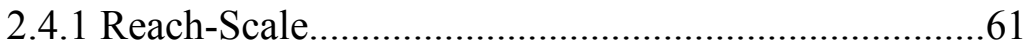

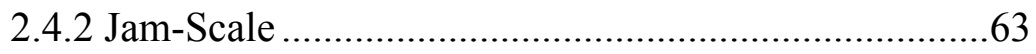

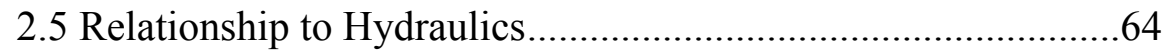

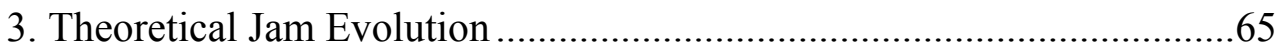

4. Case Study: Jam Evolution and the Change in Hydraulics.......................66

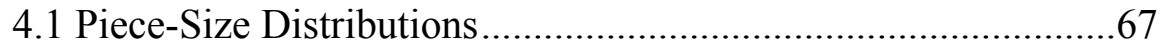

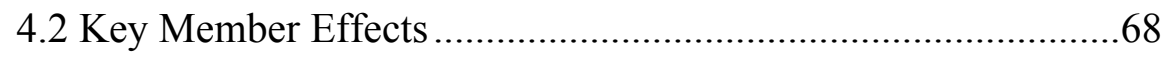

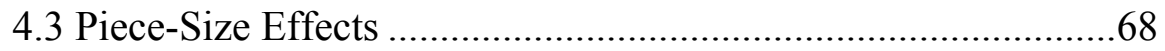

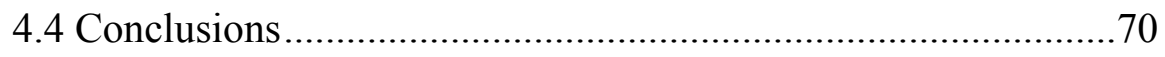

5. Management and Restoration Recommendations......................................71

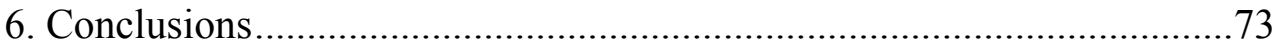


IV. SUMMARY OF FINDINGS AND FUTURE RESEARCH DIRECTIONS

APPENDIX I: PHOTO-DOCUMENTATION OF THE STAGES OF REMOVAL FOR THE THREE JAMS STUDIED ALONG THE INDIAN RIVER, NEW YORK .88

APPENDIX II: PEBBLE COUNT DISTRIBUTIONS

APPENDIX III: MAGNITUDE AND DIRECTION OF DEPTH-AVERAGED VELOCITIES AND NEAR-BED SHEAR STRESS VALUES FROM PROFILES TAKEN AT FIXED SAMPLING LOCATIONS FOR EACH JAM

APPENDIX IV: MEAN VELOCITY AND SHEAR STRESS FOR JAMS 1 AND 3 ......101

APPENDIX V: VELOCITY AND SHEAR STRESS DISTRIBUTIONS AROUND JAMS 1 AND 3

REFERENCES .104 


\section{LIST OF TABLES}

Table

2.1 Volume, surface area, and total number of individual pieces on each jam for each stage of removal

2.2 Drag force and the drag force equation variables

2.3 Multivariate linear regression results

3.1 Wood vocabulary

3.2 Wood piece distributions

3.3 Drag force $(\mathrm{kN})$ on each jam for each phase 
Figure

\section{LIST OF FIGURES}

2.1 Study sites along the Indian River, Adirondack Mountains, New York

2.2 Schematic of the control volume defined by the local hydraulic effects of a debris jam

2.3 Definition of stages of removal

2.4 Surface area and volume relationships by stage of removal

2.5 Velocity and shear stress distributions at jam 2 for all stages of removal

2.6 Spatially divided mean velocity and shear stress values for each stage at both low and high flow conditions for jam 2

2.7 Excess shear stress distributions for jam 2

2.8 Proportion of $\left(C_{D} A_{F}\right)_{\text {calc }}$ made up by $A_{F(e m p)}$ and $C_{D}$ for jams 1 and 2

2.9 Contour plot of $\left(C_{D} A_{F}\right)_{\text {calc }}$ based on the $A_{\text {surf }}-V$ relationship for each stage of removal

3.1 Schematic of the controls on the evolution of a debris jam

3.2 Piece-size distributions from various studies

3.3 Theoretical evolution of a debris jam

3.4 Photographs of jam 1 at the different phases of evolution

3.5 Piece-size distributions for wood pieces with diameter greater than $1 \mathrm{~cm}$ found on the three jams studied on the Indian River

3.6 Evolution of jams 1 and 2 


\section{LIST OF SYMBOLS}

\begin{tabular}{|c|c|c|}
\hline $\mathrm{a}$ & coefficient in surface area-volume relationship & - \\
\hline A & area of control volume boundary & $\mathrm{m}^{2}$ \\
\hline$A_{\text {bed }}$ & area of bed within control volume & $\mathrm{m}^{2}$ \\
\hline $\mathrm{A}_{\mathrm{F}(\mathrm{emp})}$ & empirical debris jam frontal area & $\mathrm{m}^{2}$ \\
\hline$A_{\text {surf }}$ & surface area of wood pieces & $\mathrm{m}^{2}$ \\
\hline $\mathrm{b}$ & exponent in surface area-volume relationship & - \\
\hline $\mathrm{C}_{\mathrm{D}}$ & drag coefficient & - \\
\hline$\left(\mathrm{C}_{\mathrm{D}} \mathrm{A}_{\mathrm{F}}\right)_{\mathrm{calc}}$ & drag character & $\mathrm{m}^{2}$ \\
\hline $\mathrm{C}_{\mathrm{S}}$ & sorting coefficient & - \\
\hline $\mathrm{F}$ & external forces & $\mathrm{N}$ \\
\hline $\mathrm{F}_{1,2,3}$ & hydrostatic force across control volume surface & $\mathrm{N}$ \\
\hline $\mathrm{F}_{\text {boundary }}(\mathrm{x}, \mathrm{y})$ & force components exerted on bed and banks & $\mathrm{N}$ \\
\hline $\mathrm{F}_{\mathrm{D}}$ & drag force & $\mathrm{N}$ \\
\hline $\mathrm{F}_{\mathrm{D}(\mathrm{x}, \mathrm{y})}$ & drag force components & $\mathrm{N}$ \\
\hline $\mathrm{F}_{\text {total }(\mathrm{x}, \mathrm{y})}$ & force components exerted on the control volume & $\mathrm{N}$ \\
\hline $\mathrm{h}$ & water depth & $\mathrm{m}$ \\
\hline $\mathrm{k}$ & decay rate constant & - \\
\hline $\mathrm{k}_{\mathrm{b}}$ & biological decay rate constant & - \\
\hline $\mathrm{k}_{\mathrm{f}}$ & fragmentation decay rate constant & - \\
\hline$\kappa$ & von Karman’s constant & - \\
\hline $\mathrm{p}$ & pressure & $\mathrm{N} \mathrm{m}^{-2}$ \\
\hline$\rho$ & density of water & $\mathrm{kg} \mathrm{m}^{-3}$ \\
\hline$\tau_{\text {bed }}$ & local shear stress & $\mathrm{N} \mathrm{m}^{-2}$ \\
\hline$\tau_{\text {bed(x,y) }}$ & local shear stress components & $\mathrm{N} \mathrm{m}^{-2}$ \\
\hline$\tau_{\mathrm{c}} *$ & Shields value & $\mathrm{N} \mathrm{m}^{-2}$ \\
\hline$\tau_{\mathrm{c} 50}$ & critical shear stress for the $D_{50}$ & $\mathrm{~N} \mathrm{~m}^{-2}$ \\
\hline $\mathrm{u}^{*}$ & shear velocity & $\mathrm{m} \mathrm{s}^{-1}$ \\
\hline $\mathrm{U}$ & depth-averaged velocity & $\mathrm{m} \mathrm{s}^{-1}$ \\
\hline $\mathrm{U}_{1,2,3}$ & depth-averaged velocity across control volume surface & $\mathrm{m} \mathrm{s}^{-1}$ \\
\hline $\mathrm{U}_{\mathrm{Ap}}$ & far-field approach velocity & $\mathrm{m} \mathrm{s}^{-1}$ \\
\hline $\mathrm{U}_{\mathrm{x}}$ & longitudinal velocity component & $\mathrm{m} \mathrm{s}^{-1}$ \\
\hline $\mathrm{U}_{\mathrm{y}}$ & lateral velocity component & $\mathrm{m} \mathrm{s}^{-1}$ \\
\hline $\mathrm{V}$ & volume of wood pieces & $\mathrm{m}^{3}$ \\
\hline $\mathrm{V}_{\mathrm{CJ}}$ & volume of the complete jam & $\mathrm{m}^{3}$ \\
\hline$V_{\text {phase }}$ & volume of wood at the phase & $\mathrm{m}^{3}$ \\
\hline $\mathrm{Y}_{0}$ & initial volume of material & $\mathrm{m}^{3}$ \\
\hline$Y_{t}$ & volume of material left after time $t$ & $\mathrm{~m}^{3}$ \\
\hline $\mathrm{z}_{0}$ & bed roughness length & $\mathrm{mm}$ \\
\hline
\end{tabular}




\section{CHAPTER 1:}

\section{INTRODUCTION}

After decades of removing wood from rivers, the acknowledgement of woods' morphological and ecological role has led to its ubiquitous use in in-stream habitat improvement projects, one of the most common types of restoration in the U.S.(Bernhardt et al 2005). The presence of woody debris jams in rivers provides a whole suite of adjustments, and those channels with wood have been shown to be morphologically distinct (Keller and Swanson 1979; Montgomery et al. 1996). An understanding of the role of wood in rivers begins with its associated change in hydraulics (Gippel 1995).

On a reach-scale, woody debris increases channel roughness. Manga and Kirchner (2000) used theoretical models to estimate the partitioning of stress between woody debris and the bed and found that in a gravel bed river in the Central Oregon Cascades, woody debris covers less than $2 \%$ of the streambed but provides roughly half of the total flow resistance (Manga and Kirchner 2000). Buffington and Montgomery (1999) applied similar models to show how the roughness added by wood results in finer bed surfaces due to the lower bed-transport rates.

Alterations to the sediment-transport rates by woody debris result in localized areas of scour and deposition. Commonly, woody debris is associated with the presence of pools where increased wood loadings decrease the spacing between pools and increase the 
average pool depth (Montgomery et al 1995; Lisle 1995). Woody debris may also change flow patterns deflecting flow away from bank and to the centerline thereby narrowing the channel (Daniels and Rhoads 2004; Wallerstein and Thorne 2004). Conversely, woody debris may deflect flow towards a bank resulting in erosion and channel widening (Smith et al 1993). These hydraulic and geomorphic adjustments create habitat (Angermeir and Karr 1984; Flebbe 1999; Shields et al. 2003) and alter many ecological processes in rivers (Bilby and Likens 1980).

While wood affects rivers at the reach-scale, a mechanistic understanding of its influence on hydraulic, geomorphic and ecological processes requires studies to focus in on the effects of individual elements of wood. Numerous studies have focused on the hydraulics of single logs investigating the effect of the size of the log (Wallerstein et al 2002), the position of the log with respect to the channel bed and to the flow (Gippel et al. 1996; Hygelund and Manga 2003) and the Reynolds and Froude numbers (Wallerstein et al. 2001) on the drag force. Other studies have then investigated how these factors affect the patterns of scour and deposition (Cherry and Beschta 1989; Marsh et al 2001). The outcome of this work is a thorough understanding of the hydraulic and geomorphic effects of individual logs whose applicability is limited in natural settings where wood tends to aggregate to form debris jams (Keller and Swanson 1979).

In environments capable of transporting woody debris, large stable pieces called key members (Abbe and Montgomery 2003) capture and retain woody debris. Through time, a wide variety of wood pieces ranging from twigs to trunks accumulate on the key member becoming lodged against one another and forming a complex structure. The interaction of the jam structure with the surrounding flow dictates the local hydraulics and the treatment of the 
debris jam as a single-solid element may oversimplify these processes. Therefore a deficiency in knowledge exists on the hydraulics of natural debris jams. Given that debris jams can retain as much as $90 \%$ of the wood in a reach (Collins and Montgomery 2002) and that woody debris jams are a popular tool in restoration projects for protecting banks and creating habitat (Abbe et al 2003; Bernhardt et al 2005), this gap in the literature prohibits a complete understanding of the hydraulic, geomorphic and ecologic influence of woody debris.

The above review of the pertinent literature and current issues regarding woody debris in rivers lays the foundation for the remaining chapters. I have shown that while we know a good deal about the dynamics of woody debris, there is still a deficiency in our understanding, especially when it comes to the hydraulics of debris jams. This document is based on the idea that a debris jam is a complex and porous structure formed through the accumulation of a variety of wood piece sizes whose structure and composition are related to its hydraulics. The nature of debris jam formation means that both the composition and hydraulics of a debris jam will change through time. Through a mixture of field-based experiments, modeling, and a literature review, this document adds to our understanding of the natural dynamics of woody debris. By treating debris jams as accumulations of material, instead of single-solid objects, this document provides a unique way of conceptualizing their hydraulics, the controls on their formation, and persistence as influential structures in the fluvial environment.

In chapter two, I present data on the structure and hydraulics of three debris jams which were systematically removed to represent varying porosities. Working on a regulated river, I was able to account for the hydraulics of the debris jams at both base flow and 
bankfull. Velocity fields were measured around each jam during each stage of removal. From this data I present the velocity fields and shear stress distributions associated with varying degrees of porosity and total jam volume. I quantify the drag force on each jam for each stage of removal utilizing the velocity fields and solving for the momentum extracted as the water flowed past the debris jam. With these values of drag, I back-calculate the drag coefficient in order to compare my findings with those reported for single-log models in a controlled setting. My data suggest that the drag coefficient may not be the best way to represent the drag character of natural debris jams and instead a combination of the frontal area and the drag coefficient are better representative. Additionally, the data shows that assumptions of non-porosity result in an over-prediction of the hydraulics of natural debris jams and that assumptions of jams as single key members leaves significant alterations to the local hydraulics unaccounted for. A version of this chapter has been submitted to Water Resources Research for publication.

Chapter three addresses the temporal component of debris jams by presenting a conceptual model for their evolution. I hypothesize in this chapter that the trajectory from a single key member to a complete jam is a predictable one and is mediated by the wood available in the reach (notably the piece-size distribution) and the hydraulics. A review of the literature on the controls of key member dynamics, wood availability, the decay and export of wood and the hydraulics of single wood elements highlights our understanding of the controls on debris jam evolution as well as the gaps. A case study presents data on the piecesize distributions of the three jams (from chapter two) at the various phases in the evolution model and relates the sorting and size of pieces on each jam and the jam's porosity to their drag force. This model is then related to management and restoration projects where the 
value of conceptualizing debris jams as temporally dynamic structures whose composition and hydraulics are a function of their current state could result in more successful and costeffective designs. A version of this chapter will be submitted to River Research and Applications for publication.

Chapter four summarizes the findings of this thesis, highlighting how my research has fit into current issues in the fields of geomorphology, ecology and the science of restoration. I then make recommendations for future research on woody debris hydraulics based on questions that have arisen from my research. 


\section{CHAPTER 2}

\section{THE STRUCTURE AND HYDRAULICS OF DEBRIS JAMS}

\section{Introduction}

Woody debris jams substantially influence river geomorphology and ecology, and rivers with debris jams are distinct from those without (Bilby and Likens 1980; Keller and Swanson 1979; Montgomery et al. 1996). The natural formation of wood into debris jams, defined as the build-up of woody material of variable sizes and quantities into a distinctive unit, has been imitated by the river restoration industry (Abbe et al., 2003; Bernhardt et al. 2005). Debris jams are often used in restoration channel design to alter channel hydraulics and morphology for specific goals such as bank protection or habitat formation. Successful restoration projects require an understanding of the relationship between the structure of debris jams, resultant hydraulic processes, and eventual geomorphic forms. This relationship is based on the hydraulics of jams beginning with an alteration of flow.

Shifting flow patterns due to a single log, multiple logs or an entire debris jam, alter the spatial distribution of shear stress (Manga and Kirchner 2000). At the reach scale, woody debris repartitions boundary shear stress, resulting in finer bed material (Buffington and Montgomery 1999). Woody debris also decreases the spacing between pools (Gurnell and Sweet 1998), increases pool area (Lisle 1995), and increases overall channel width (Smith et al. 1993). At the patch scale, the addition of woody debris alters the spatial distribution of shear stress, creating patches of scour and deposition (Smith et al. 1993). Scour around woody debris is caused by flow convergence where diverted flow intersects 
the main unaffected flow, forming pools at the outer tip of the wood piece or jam (Cherry and Beschta, 1989). Flow separation upstream of woody debris causes backwater effects, and blockage of flow causes reduced velocities downstream, resulting in reduced shear stress on the bed and deposition of fines (Wallerstein et al. 1997) (Figure 2.2).

The specific effects of a debris jam first depend on the magnitude of flow. Despite our current understanding that little geomorphic change occurs during base flows (Wolman and Miller 1960), past research is limited to data collected at low flows. Daniels and Rhoads (2004) studied the three-dimensional flow structures around large woody debris for two stages, the higher of which was still below bankfull.

Second, debris jams alter channel morphology and hydraulics based on the distinctive geometry of the wood piece or pieces (Lisle 1986). Currently, our understanding of the localized hydraulics of wood in rivers is limited to single solid objects (Gippel 1995), often treated as individual or multiple cylinders. However, woody debris often accumulates into jams, which can be combinations of wood pieces from the nearby bank and those transported fluvially from upstream sources (Abbe and Montogomery 2003). Beginning with a single key member, these "combination jams" evolve into intricate matrices of wood pieces of widely variable sizes. Therefore, to define the relationship between jam structure and composition and hydraulic changes associated with debris jams, it is necessary to treat them as complex and dynamic accumulations of material ranging in size from leaves and twigs to entire tree trunks. Jam composition is defined by the number and size of wood pieces, the volume and surface area of these pieces, and the open space between wood pieces also referred to as the jam's porosity. 


\subsection{Hydraulics of Debris Jams}

The relationship between jam structure and hydraulic function is quantified through drag force $\left(F_{D}\right)$, which is the difference in pressure the water exerts on the jam from upstream to downstream. Empirically, $F_{D}$ is given by:

$$
\mathrm{F}_{\mathrm{D}}=1 / 2 \rho \mathrm{C}_{\mathrm{D}} A_{F(e m p)} \mathrm{U}_{\mathrm{Ap}}{ }^{2}
$$

where $\rho$ is the density of water, $A_{F(\text { emp })}$ is the submerged frontal area of the obstruction normal to flow, $U_{A p}$ is the approach velocity measured as the mean free-stream velocity and $C_{D}$ is the drag coefficient of the obstruction. When woody debris is modeled as a cylinder, $A_{F(e m p)}$ is simply the diameter of the object multiplied by its length measured normal to flow. The approach velocity is independent of the object, and may be manipulated in a controlled setting or measured in a natural one. Therefore, the contribution of $C_{D}$ to $F_{D}$ can be directly quantified.

Natural debris jams are poorly described as cylinders; instead they are irregular, porous, and three-dimensional. Therefore, $A_{F(\text { (emp) }}$ loses its meaning. Similarly, $C_{D}$ previously has been solved for a two-dimensional non-porous object (eg. cylindrical rods), which may misrepresent a debris jam. Isolating the influences of $A_{F(e m p)}$ and $C_{D}$ cannot easily be done because they are interrelated, thus separating the terms may misrepresent their contributions to the drag force. Instead, we use the combined term $\left(C_{D} A_{F}\right)_{c a l c}$ in order to bridge the hydraulic and the structural realities of the jam. This term describes a jam's drag form defined as the shape and size of a jam as it dictates its drag force. It has the potential to take into account the entire depth of accumulated material including total roughness within the jam (i.e. surface area of woody pieces) and the open space, or porosity. 


\subsection{Goals and Structure}

The goal of this study is to define the relationship between jam composition and the hydraulics of debris jams, document the hydraulic drag on natural debris jams at high flow, and illustrate the utility of the combined term $\left(C_{D} A_{F}\right)_{c a l c}$ in analyzing the hydraulics of natural debris jams. We work at the scale of a single jam in order to expand upon the single-log model used in previous studies. By using naturally formed and manipulated debris jams, we investigated the local hydraulics associated with these complex structures. We systematically altered debris jam porosity via targeted removal of specified size classes of wood, isolating the effects of differing structure and composition.

In this paper, we first examine the composition of three natural jams in a high gradient mountain river in the Northeast United States. Second, we report velocity and shear stress distributions, focusing on their adjustments as jam structure and composition change. Third, we predict the potential shifts in areas of scour and deposition. Fourth, we quantify at various stages of manipulation the drag force $\left(F_{D}\right)$, the drag coefficient $\left(C_{D}\right)$ and the combined term $\left(C_{D} A_{F}\right)_{\text {calc. }}$. Fifth, we explore the influence of total volume, surface area and porosity on $F_{D}$ and $\left(C_{D} A_{F}\right)_{\text {calc. }}$. Finally, we compare our results to those reported for single$\log$ models.

\section{Study Site}

The Indian River is located within the Hudson River system in the Adirondack Mountains in New York State (Figure 2.1). The geology is dominated by metamorphic rock recently $(\sim 10,000$ yrs B.P.) scoured and modified by the Laurentian glacier during the Wisconsin glaciation. Deposition of glacial till and glacial erratics define the current 
landscape. Regional hydrology is characterized by snowmelt peak flows in April or May, low flow in July and August and large frontal systems associated with hurricanes in the fall.

The Indian River is a high gradient (1\% slope) cobble and boulder-bed tributary of the Hudson River. Four and half km upstream of the confluence with the Hudson, the Abanakee Dam, alters the hydrology of the Indian and Hudson Rivers. Water is released from Abanakee Dam 4 days a week from April to October. Releases increase flow by nearly an order of magnitude (from $5 \mathrm{~m}^{3} \mathrm{~s}^{-1}$ to $40 \mathrm{~m}^{3} \mathrm{~s}^{-1}$ ), transitioning from very low base-flow to near-bankfull in minutes. These releases reproduced a consistent bankfull event and remained constant around $40 \mathrm{~m}^{3} \mathrm{~s}^{-1}$ for approximately 90 minutes.

Steep hillslopes and bedrock controlled valley walls minimize floodplain surfaces. Extensive logging in the late $19^{\text {th }}$ century and two major fires in the early part of the $20^{\text {th }}$ century converted the majority of the forests in the Adirondacks from spruce-fir to Northern hardwoods. The hillslopes along the Indian River are primarily populated by yellow birch, sugar maple and ash. Safety concerns from the rafting industry result in the clearing of the main channel of most large trees and trunks.

We studied three naturally occurring bank-deflector jams (sensu Abbe and Montgomery 2003) as combination jams of in-situ key members whose surface serves to collect large quantities of fluvially transported wood pieces (Figure 2.1). The key members of all three jams were anchored on the bank and stabilized naturally by large boulders. Jam 1 was located $1.4 \mathrm{~km}$ downstream of the dam in a steep $(\mathrm{s}=1.5 \%)$ and narrow reach (width $=$ $40 \mathrm{~m}$ ) with coarse bed material $\left(\mathrm{D}_{50}=150-280 \mathrm{~mm}\right)$. Jams 2 and 3 were located 2.3 and 1.8 $\mathrm{km}$ downstream of the dam in a wide $($ width $=60 \mathrm{~m})$ lower gradient reach $(\mathrm{s}=0.5 \%)$ with finer bed material $\left(\mathrm{D}_{50}=100-150 \mathrm{~mm}\right)$. 
The jams of the Indian River are potentially affected by three anthropogenic modifications. First, according to the local rafting guides, large logs in the Indian River are frequently removed or cut. However, the initial key members of the studied jams had no sign of human intervention and all accumulated material appeared to be the result of natural processes. Second, the study reaches may receive less wood than other un-dammed sections due to the cutoff of supply upstream by the dams. Third, any material present in the river is frequently remobilized during releases.

\section{Methods}

\subsection{Experimental Design}

We sought to study natural woody debris jams at both high and low flows at various stages of removal and treatment. For each jam, the key member was defined as that piece or pieces which initiated the formation of the debris jam (Abbe and Montgomery 1996). We established a classification for all accumulated woody debris with small woody debris (SWD, diameter $\leq 1 \mathrm{~cm}$ ), medium woody debris (MWD, $1 \mathrm{~cm}<$ diameter $<10 \mathrm{~cm}$ ), and large woody debris (LWD diameter $\geq 10 \mathrm{~cm}$ ). We used this classification to organize stages of removal.

Four stages were defined by size of material on the jam, representing differing degrees of porosity, volume of material and frontal area (Figure 2.3). For stage A (the wrapped jam), we covered the entire surface of the natural jam with a plastic tarp taking care to not change the dimensions. This simulated the non-porous condition assumed in previous modeling studies. Stage B (the natural jam) was porous with all accumulated material including all sizes of woody debris as well as soil and leaf litter. For stage $\mathrm{C}$ (partial jam), all SWD, soil, leaf litter and other pieces deemed unstable were removed. This resulted in a 
framework of the key member, MWD and LWD, and represents a highly porous debris jam. For stage D (key member), the remaining woody debris was removed, leaving only the key member(s). While systematically removing the wood, soil and leaf litter between stages B, C, and $\mathrm{D}$, we measured the length and diameter of each wood piece and accounted for the volume of soil and leaf litter using a graduated bucket. We calculated volume $(V)$ surface area $\left(A_{\text {surf }}\right)$ for each piece of wood removed by treating each individual piece as a cylinder, assigning it a single length and diameter. Key member dimensions were measured in greater detail accounting for any tapering or branching. We related $A_{\text {surf }}$ to $V$ for each stage of removal using the power function

$\mathrm{A}_{\text {surf }}=\mathrm{aV}^{\mathrm{b}}$.

Volume was used as the predictor variable because it is generally reported as an indicator of wood loading in a reach (Erskine and Webb 2003; Gregory et al 1993; Fox et al. 2003). A multivariate linear regression model without an intercept (Littell et al. 1996) was run for the independent variables that we used to define jam composition $\left(A_{F(e m p)}, A_{\text {surf }}\right.$ and $\left.V\right)$ in order to predict the drag force $\left(F_{D}\right)$ and drag form $\left(C_{D} A_{F}\right)_{\text {calc }}$ for each jam and at each stage of removal. While porosity was an important variable, it could not be empirically quantified. We used a fixed-effects model (Littell et al. 1996) to account for the within and between jams effects.

We separated the hydraulic effects of the LWD jams into three patches: upstream, adjacent, and downstream (Figure 2.2). We defined each patch by the high flow flow-fields and local morphologic features at each jam. In its natural state, part of the upstream patch was backwatered, had a strong lateral component due to flow deflection and slightly finer bed material than the approach patch. The upstream patch also included non-affected flow 
and bed material. The adjacent patch encompassed the flow convergence zone and was characterized by increased lateral velocity components, extremely high velocities, scour holes and coarser bed material. The downstream patch, in the hydraulic shadow of the jams, had greatly reduced velocities, shallow water depths, and finer bed material.

To characterize each jam site, we surveyed cross-sections and the local slope and measured the key member angle relative to the main flow (Figure 2.1). We quantified grainsize distribution in each of the four patches via pebble counts (after Wolman 1954). The dimensions of each jam were measured for each stage of removal including total length, height and width. We calculated the blockage ratio for each jam as the total channel width divided by the projection length of the jam (Gippel et al. 1996), where projection length is the total length of the jam normal to flow.

Two 1.2 by $2.4 \mathrm{~m}$ free-standing platforms were installed at each site making data collection at high flows possible without obstructing flow. We placed one platform upstream of the jam for access to both the upstream and approach patches. The other platform was placed at the adjacent patch. The downstream patch was wadeable during high flows. For each site, we established 22-25 fixed locations at which velocity profiles (4 points per location) were measured during high and low flow at each stage of removal. Longitudinal $\left(U_{X}\right)$ and lateral $\left(U_{Y}\right)$ velocity components were measured at each location using a Sontek FlowTracker Acoustic Doppler Velocimeters (ADV) or Marsh McBirney Flow Mate Electromagnetic Current Meter (ECM). Since the ECM is one-dimensional, the operator held the probe in the $\mathrm{X}$ and $\mathrm{Y}$ direction.

Velocity profiles were obtained for each location by measuring the velocity at 80,60 , and 40 percent depth. Additionally, we measured near-bed velocities by lowering the probe 
down as far as possible without interference from the bed (signal to noise ratio- SNR greater than 10 and a boundary adjustment value of good or better). Each point in the profile was averaged over a 60 -second sampling period. Only $54 \%$ of the velocity profiles fit a logarithmic curve $(\mathrm{p}<0.01)$. To create consistency in our analysis, we instead determined depth-averaged velocities for each profile by integrating the velocity point measurements over the entire depth (Byrd et al. 2000).

The resultant depth-averaged velocities were used to calculate near-bed local shear stress $\left(\tau_{\text {bed }}\right)$ using the law of the wall (Wilcock 1996). While the depth-averaged method of solving for shear stress assumes a logarithmic profile, Wilcock (1996) found that the alternate method of using a single near-bed measurement is less precise. We did not use the single near-bed measurement due to large bed material and associated inaccuracies with nearbed measurements. Thus, to calculate $\tau_{\text {bed }}$, we first solved for the shear velocity $\left(u^{*}\right)$

$$
\mathrm{U} / \mathrm{u} *=1 / \kappa \ln \left(\mathrm{h} / \mathrm{e}^{\mathrm{z}}\right)
$$

where $U$ is the depth averaged velocity from the measured profile, $\kappa$ is von Karman's constant $(0.40), h$ is the total water depth and $z_{0}$ is the bed roughness length (estimated as $z_{0}=$ $\left.0.1 \mathrm{D}_{90}\right)$. The local shear stress is then equal to

$$
\tau_{\text {bed }}=\rho u^{2}
$$

Depth-averaged velocities and shear stress values were grouped by patch (upstream, adjacent and downstream) and averaged for each stage of removal at both high and low flow in order to quantitatively evaluate the spatial trends. For each stage of removal, the flow fields and shear stress distributions were interpolated by kriging using Surfer (8.0). 
Using the grain-size distributions for each patch at each jam, we applied the Shields equation to calculate the critical shear stress $\left(\tau_{c} 50, \tau_{c}{ }^{*}=0.06\right)$ needed to mobilize the $\mathrm{D}_{50}$ (Buffington and Montgomery 1997). Excess shear stress (i.e. $\tau_{\text {bed }} / \tau_{c} 50>1$ ) was mapped to evaluate the localized areas of high shear stress. Values greater than 1 indicated potential particle entrainment.

\subsection{Determining Drag Force through Momentum Extraction}

We quantified the drag force on each jam at high flow for each stage of removal using the momentum principle: the sum of the external forces on a system is equal to the rate of change of momentum (Roberson and Crowe 1993). Applying this principle to a control volume (Figure 2.2), the difference in momentum between the inflow and outflow surfaces is equal to the force exerted on the surface of the control volume. In the case of a debris jam, the external forces changing the fluid momentum are forces exerted by the debris jam and the shear stress exerted by the bed and banks.

A control volume (Figure 2.2) was defined based on the spatial extent of a jam's influence on the local velocities. We isolated the effect of the longitudinal and lateral forces on the jam by solving for their components separately. Assuming steady flow, the momentum equation simplifies to:

$$
\sum \mathrm{F}=\int_{\mathrm{cs}} \mathrm{U} \rho \mathbf{U} \bullet d \mathbf{A},
$$

where $F$ is the external forces, $U$ is depth-averaged velocity and $A$ is the area vector that has the magnitude of the area and is directed normal to the control surface (inflow or outflow) in question, and the right term is integrated over that control surface. 
Solving for the longitudinal (x) direction only, the sum of the forces is given by:

$$
\sum \mathrm{F}=\mathrm{F}_{1}-\mathrm{F}_{2}+\mathrm{F}_{\text {total( }(\mathrm{x})},
$$

where $F_{1}$ is the hydrostatic force across the inflow surface (surface 1 ), $F_{2}$ is the hydrostatic force across the outflow surface (surface 2), and $F_{\text {total(x) }}$ is the force exerted on the entire control volume in the x-direction, including the jam, bed, and banks. The hydrostatic force is equal to the pressure exerted by the water integrated over the area of flow:

$$
\begin{aligned}
& \mathrm{F}_{1}=\int \mathrm{p}_{1} d \mathrm{~A}_{1}, \\
& \mathrm{~F}_{2}=\int \mathrm{p}_{2} d \mathrm{~A}_{2},
\end{aligned}
$$

where $p_{1}$ is the pressure at surface 1 and $p_{2}$ is the pressure at surface 2 .

The total force is a function of the forces exerted by the debris jam, the resistance of the channel boundary.

$$
\mathrm{F}_{\text {total }(\mathrm{x})}=\mathrm{F}_{\text {boundary }(\mathrm{x})}+\mathrm{F}_{\mathrm{D}(\mathrm{x})} \Rightarrow \mathrm{F}_{\mathrm{D}(\mathrm{X})}=\mathrm{F}_{\text {total }(\mathrm{x})}-\mathrm{F}_{\text {boundary }(\mathrm{x}) \text {. }}
$$

The force exerted by the debris jam is the drag force. In order to separate out the drag force on the debris jam, we applied the concept of shear-stress partitioning (Buffington and Montgomery 1999), accounting for all the roughness elements in the control volume contributing to the total boundary shear stress. Since the extent of our control volume is very small in proportion to the entire channel (about $20 \%$ of the width), we can neglect large-scale roughness factors such as sinuosity. Skin friction (grain resistance from the bed and banks) and bed-form drag are relevant, and we quantified these through our velocity profiles and calculations of $\tau_{\text {bed. }}$. Integrating $\tau_{\text {bed }}$ over the bed surface of the control volume gives $F_{\text {boundary }(x) \text {, which is the total force exerted in the momentum extraction within the control }}$ volume which equals: 


$$
\mathrm{F}_{\text {boundary(x) }}=\int \tau_{\text {bed(x) }} d \mathrm{~A}_{\text {bed }}
$$

where $A_{b e d}$ is the area of the bed within the control volume. This approach assumes that the shear stress measured on the bed also reflects the roughness exerted by the banks.

Returning to the momentum equation (equation (4)) we sum the forces:

$$
\mathrm{F}_{1}-\mathrm{F}_{2}-\mathrm{F}_{\text {total }(\mathrm{x})}=-\int \rho \mathrm{U}_{1}^{2} d \mathrm{~A}_{1}+\int \rho \mathrm{U}_{2}^{2} d \mathrm{~A}_{2}
$$

noting that the first term on the right side is negative because of the definition of the control surface relative to the direction of flow.

In order to solve for the lateral force on the jam (y-direction) the definition of the terms changes slightly. Under the assumption that with no jam the flow would be completely in the x-direction (i.e., $U_{y}<<U_{x}$ ), then in the presence of a jam in the control volume, ydirectional flow across surface 3 (Figure 2.2) is due to the force exerted by the jam. Assuming no pressure gradient existed between the bank and surface 3, then the momentum equation in the $\mathrm{y}$-direction is given by:

$$
\mathrm{F}_{\text {total }(\mathrm{y})}=\int \rho \mathrm{U}_{3}^{2} d \mathrm{~A}_{3}
$$

where

$$
\mathrm{F}_{\text {total }(\mathrm{y})}=\mathrm{F}_{\mathrm{D}(\mathrm{y})}-\mathrm{F}_{\text {boundary }(\mathrm{y})} \Rightarrow \mathrm{F}_{\mathrm{D}(\mathrm{y})}=\mathrm{F}_{\text {total }(\mathrm{y})}+\mathrm{F}_{\text {boundary }(\mathrm{y})}
$$

Equations (10) and (12) provide the total resultant drag force on the jam:

$$
\left.\mathrm{F}_{\mathrm{D}}=\left(\mathrm{F}_{\mathrm{D}(\mathrm{x})}{ }^{2}+\mathrm{F}_{\mathrm{D}(\mathrm{y})}\right)^{2}\right)^{1 / 2}
$$




\section{3 $C_{D}$ and $\left(C_{D} A_{F}\right)_{\text {calc }}$}

Finally, we sought to use the field quantification of $F_{D}, A_{F(\text { emp })}$ and $U_{A p}$ to backcalculate $C_{D}$ using equation (1). With equation (12), we calculated $F_{D}$ for high flow conditions. Using measurements and surveys, we calculated $A_{F(e m p)}$ for each debris jam at each stage of removal. The approach velocity, $U_{A p}$, was measured in the field during each stage and was defined as the far-field velocity not affected by the jam or the changes we made to the jam (values of $U_{A p}$ did not differ greatly at each site due to the consistent nature

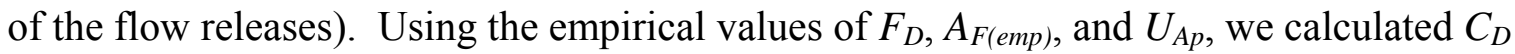
for each jam at each stage of removal. We calculated $C_{D}$ to compare our values of porous, natural debris jams to published values from modeled, simplified woody debris.

Because $C_{D}$ and $A_{F(e m p)}$ in previous cases assumes a solid, non-porous object which is not reflective of our natural debris jams, we also used empirical values of only $F_{D}$ and $U_{A p}$ to back-calculate $\left(C_{D} A_{F}\right)_{c a l c}$, i.e., not isolating the individual contribution of $C_{D}$ or $A_{F(e m p)}$ to $F_{D}$. Therefore the calculation of $\left(C_{D} A_{F}\right)_{c a l c}$ does not contain any predetermined value of $A_{F(e m p)}$ and the influence of the surface of the debris jam is intertwined with $C_{D}$. We hypothesized that this term is more useful for implementing equation (1) in natural debris jam settings in which neither $C_{D}$ nor $A_{F(e m p)}$ have clear meanings.

\section{Results}

\subsection{Jam Structure and Composition}

\subsubsection{Key Member(s) and Total Accumulation}

While the three jams studied ranged in their key member sizes, overall dimensions and total volume of material (Table 2.1), the ratio of key member volume to accumulated material volume was similar. The key member or members contributed, on average, $45 \pm 4 \%$ 


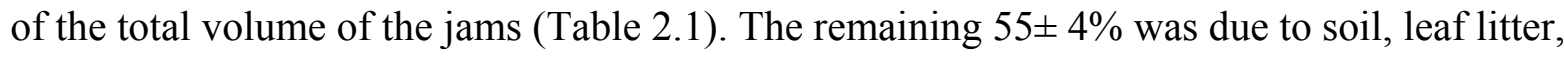
twigs, sticks and other fluvial transported pieces of woody debris.

Jam 1 had two key members with lengths of 14.0 and $18.4 \mathrm{~m}$ and diameters of 50 and $30 \mathrm{~cm}$, respectively. These two key members had a total volume of $5.16 \mathrm{~m}^{3}$. Transported from upstream, $7.54 \mathrm{~m}^{3}$ of material accumulated on jam 1 resulting in a total jam volume of $12.70 \mathrm{~m}^{3}$. Jam 2 had one key member derived from the adjacent bank and another deposited from upstream. The locally derived key member had a length extending from the bank out into flow of $7.4 \mathrm{~m}$ and a diameter of $25 \mathrm{~cm}$, and the secondary key member was $4.0 \mathrm{~m}$ long with a diameter of $48 \mathrm{~cm}$. The two key members of jam 2 had a total volume of $1.44 \mathrm{~m}^{3}$ with an additional $1.53 \mathrm{~m}^{3}$ of material accumulated for a total of $2.97 \mathrm{~m}^{3}$. Jam 3 had one key member with a length of $7.4 \mathrm{~m}$ and diameter of $17 \mathrm{~cm}$. The key member on jam $3 \mathrm{had} \mathrm{a}$ volume of $0.26 \mathrm{~m}^{3}$ and $0.32 \mathrm{~m}^{3}$ of accumulated material totaling $0.58 \mathrm{~m}^{3}$.

\subsubsection{Volume and Surface Area of Accumulated Pieces}

The range in total jam volume resulted in a large variation in the number of pieces on each jam, changing by an order of magnitude between jams (Table 2.1), from $10^{2}$ on Jam 3 , to $10^{3}$ for Jam 2 , and $10^{4}$ on Jam 4 . Relative proportions of woody debris piece size classes (e.g. SWD, MWD, LWD) were similar across all three jams in terms of total composition of the debris jams, total number of pieces, total surface area and total volume.

We removed 14,439 pieces of wood from Jam 1, the majority $(13,681$ pieces, $95 \%)$ of which were SWD. These pieces made up only $6 \%\left(0.73 \mathrm{~m}^{3}\right)$ of the total volume $\left(12.70 \mathrm{~m}^{3}\right)$ but $51 \%\left(292.9 \mathrm{~m}^{2}\right)$ of total surface area. Jam 2 held 2,767 pieces of wood, $93 \%(2,560)$ of which were SWD. Totaling $0.15 \mathrm{~m}^{3}$, these pieces made up only $5 \%$ of the total volume $(2.97$ 
$\left.\mathrm{m}^{3}\right)$ but $56 \%\left(67.0 \mathrm{~m}^{2}\right)$ of the total surface area. Jam 3 had a total of 577 pieces of wood. The proportion of these pieces in the SWD size class was slightly less than but comparable to the other two jams $(527,91 \%)$. This translated into a smaller proportion of the surface area contributable to these pieces, only $35 \%\left(7.9 \mathrm{~m}^{2}\right)$.

Similarly, MWD contributed comparable proportions of both volume and surface area. While MWD still accounts for more of the total surface area than total volume, this relationship is much less than that seen for SWD. On jam 1, the 687 pieces made up 19\% $\left(2.58 \mathrm{~m}^{3}\right)$ of the total volume and $29 \%\left(166.2 \mathrm{~m}^{2}\right)$ of the total surface area. Jam 2's 190 pieces comprised $16 \%\left(0.46 \mathrm{~m}^{3}\right)$ of the volume and $27 \%\left(32.2 \mathrm{~m}^{2}\right)$ of the surface area. Jam 3's 43 pieces were $16 \%\left(0.09 \mathrm{~m}^{3}\right)$ of the volume and $24 \%\left(5.5 \mathrm{~m}^{2}\right)$ of the surface area.

LWD adds more volume than surface area. All three jams have a relatively small number of large pieces $(69,15$ and 6 respectively), yet these pieces add a large proportion of volume (27\%-3.43 $\mathrm{m}^{3}, 18 \%-0.55 \mathrm{~m}^{3}$ and $27 \%-0.16 \mathrm{~m}^{3}$ respectively). While jam 2 adds less to the total volume than do jams 1 and 3, its contribution of surface area is similar, $12 \%(70.3$ $\left.\mathrm{m}^{2}\right), 12 \%\left(14.7 \mathrm{~m}^{2}\right)$ and $16 \%\left(3.5 \mathrm{~m}^{2}\right)$ on jams 1,2 and 3 respectively.

The surface area to volume relationships were distinct and defined by the size classes of wood pieces on the jams (SWD, MWD, LWD, and key members). These size classes were used to define the stages of removal, where stage B had all classes, stage $\mathrm{C}$ was lacking the SWD, and stage D was only a key member. Therefore the stages of removal have distinct relationships between surface area and volume (Figure 2.4). Predicted power-law functions between surface area and volume (equation 2) explained the observed points well $\left(\mathrm{R}^{2}=0.72\right.$ 1.00). The rate at which $A_{\text {surf }}$ varied with volume was greatest for stage $\mathrm{B}(b=1.05)$, then stage $\mathrm{C}(b=0.75)$ and least for stage $\mathrm{D}(b=0.66)$. According to the predicted $A_{\text {surf }}-V$ 
relationships, for a volume of approximately $1 \mathrm{~m}^{3}$, stages $\mathrm{B}$ and $\mathrm{C}$ had similar surface areas (38.3 and $39.3 \mathrm{~m}^{2}$ respectively) which was much greater than stage $\mathrm{D}\left(10.0 \mathrm{~m}^{2}\right)$. At the maximum volume found in this study $\left(12.5 \mathrm{~m}^{3}\right)$, surface area on stage B increases an order of magnitude above stage $\mathrm{D}\left(556.4 \mathrm{~m}^{2}\right.$ and $52.3 \mathrm{~m}^{2}$ respectively).

\subsubsection{Soil and Leaf Litter}

Compared to wood, soil and leaf litter played a very different role in the composition of jams. While wood pieces are rigid and irregularly shaped, soil and leaf litter can be compressed and molded. At the studied jams, soil and/or leaf litter filled gaps within the matrices of wood. Jam 2 had the most significant amount of soil $\left(0.19 \mathrm{~m}^{3}\right)$ (Table 2.1). Jam 1 also had soil found in pockets of regularly dry sheltered areas totaling $0.08 \mathrm{~m}^{3}$. Jam 3 had no soil.

\subsection{Velocity and Shear Stress Distributions}

Spatial patterns of velocity and shear stress were consistent among all three jams, with the greatest values at the adjacent patch and the lowest downstream. As woody debris was removed, velocities and shear stress increased at the downstream patches as more flow passed directly through the jams, decreasing velocities in the adjacent patch. Velocities and shear stress values in the upstream patch increased as backwater effects were dampened with the removal of material.

Since we observed similar spatial patterns among the three jams, we present the results for velocity and shear stress from jam 2 (section 4.2). Velocity and shear stress results for jams 1 and 3 can be found in Appendix A, B and C in the supplemental material. 
Additionally, we focus on the high flow results as differences between stages of removal are more pronounced and geomorphic changes are known to occur during these higher flows.

\subsubsection{Upstream}

Upstream velocity fields remained fairly constant between stages and were mostly spatially homogenous (Figures 2.5 and 2.6a,d). Small changes in mean velocity occurred between stages of removal, the most significant of which was between stage $\mathrm{D}\left(92 \mathrm{~cm} \mathrm{~s}^{-1}\right)$ and the other three stages $\left(75,76\right.$ and $81 \mathrm{~cm} \mathrm{~s}^{-1}$ respectively) (Figure 2.6a). Similarly, the mean shear stress values of the first three stages do not differ $\left(18,19,21 \mathrm{~N} \mathrm{~m}^{-2}\right.$ respectively), yet are all statistically different $(\mathrm{p}<0.01)$ than stage $\mathrm{D}\left(28 \mathrm{~N} \mathrm{~m}^{-2}\right)$. The increase in shear stress for stage $\mathrm{D}$ did not exceed the critical shear for the $\mathrm{D}_{50}$ (Figure 2.6d).

\subsubsection{Adjacent}

Throughout all stages of removal, velocities and shear stress values were higher in the adjacent patch than they were in the upstream and downstream patches. Shear stress values were relatively large (from 84 to $49 \mathrm{~N} \mathrm{~m}^{-2}$ ) compared to other areas. Upstream had a maximum mean shear stress value of $28 \mathrm{~N} \mathrm{~m}^{-2}$ and downstream's maximum was $21 \mathrm{~N} \mathrm{~m}^{-2}$.

During stage A (wrapped jam), almost no flow passed through the jam, rather flow was routed around the jam. With increased porosity of the jam (stages B - D), flow became more streamlined (reduced lateral velocity components; Figure 2.5 ) as greater flow passed directly through the jam. Mean velocities in the adjacent patch changed little between stages, ranging from $140 \mathrm{~cm} \mathrm{~s}^{-1}$ to $127 \mathrm{~cm} \mathrm{~s}^{-1}$ (Figure 2.6b), but shear stress values decreased 
significantly from $84 \mathrm{~N} \mathrm{~m}^{-2}$ at stage $\mathrm{A}$ to $49 \mathrm{~N} \mathrm{~m}^{-2}$ at stage $\mathrm{B}$, and remained consistent for stages $\mathrm{C}$ and $\mathrm{D}$ (52 and $53 \mathrm{~N} \mathrm{~m}^{-2}$; Figure 2.6e).

\subsubsection{Downstream}

Contrary to the abrupt changes in velocity and shear stress in the upstream and adjacent patches, values in the downstream patch increased gradually in response to the changing stages of removal, corresponding to the changing porosity. With no flow passing through the jam during stage A, there were extremely low velocities in the downstream patch. The only flow moving through the structure was close to the bank where the key member was perched on a boulder creating space between the jam and the bed. With increased porosity, velocities increased progressively from stages A to B (from 22 to $40 \mathrm{~cm} \mathrm{~s}^{-}$

${ }^{1}$ ), and from $\mathrm{B}$ to $\mathrm{C}\left(62 \mathrm{~cm} \mathrm{~s}^{-1}\right)$. In stage $\mathrm{D}$, velocities were nearly consistent from upstream $\left(92 \mathrm{~cm} \mathrm{~s}^{-1}\right)$ to downstream $\left(78 \mathrm{~cm} \mathrm{~s}^{-1} ;\right.$ Figures 2.5 and 2.6). Similar to velocity, there were gradual changes in shear stress between stages of removal $\left(4,9,14,21 \mathrm{~N} \mathrm{~m}^{-2}\right.$ for stages $\mathrm{A}$, $\mathrm{B}, \mathrm{C}$, and D respectively).

\subsubsection{Excess Shear Stress}

We measured shear stresses that were in excess of critical shear for $\mathrm{D}_{50}$. Excess shear stresses were concentrated and in localized cores determined by the relative dominance of different flowpaths around or through the jam. The dominance of flowpaths was a function of the porosity of the jam. As porosity of the jam decreased, the dominant flowpath shifted from around the jam (adjacent patch) to through the jam (downstream patch). 
Two cores of excess shear stress were present in stage B, one at the adjacent patch localized around the flow convergence zone, and the other in the downstream patch where flow was accelerated under the jam (Figure 2.7). At low porosity (stage A), the high stress area was fully concentrated at the flow convergence zone off the tip of the jam. As porosity increased and the dominant flow path shifted away from the tip and through the jam, the size of the core of excess shear adjacent to the jam decreased, and a new core of excess shear formed downstream. The size of this core increased as porosity of the jam increased.

\subsection{Drag Force}

\subsubsection{The Drag Force Equation: $F_{D}, A_{F(e m p)}, C_{D},\left(C_{D} A_{F}\right)_{c a l c}$}

Between all three jams, $F_{D}$ varied from $62.7 \mathrm{kN}$ for stage B on Jam 1 to $0.8 \mathrm{kN}$ for stage $\mathrm{D}$ of Jam 3 (Table 2.2). The longitudinal component of drag force $\left(F_{D(x)}\right)$ contributed the majority to $F_{D}$ and ranged from $62.7 \mathrm{kN}$ for stage B on Jam 1 to $0.2 \mathrm{kN}$ for stage D of Jam 3. The lateral component $\left(F_{D(y)}\right)$ only contributed a small amount to the total force ranging from $0.4 \mathrm{kN}$ to $3.6 \mathrm{kN}$, and had no discernible pattern. Between jams, $F_{D}$ varied substantially, from 62.7 to $19.9 \mathrm{kN}$ for jam $1,18.2$ to $11.6 \mathrm{kN}$ for jam 2, and from 10.1 to 0.2 $\mathrm{kN}$ for jam 3. The decreases in $F_{D}$ at each jam were consistent with stage of removal, as the highest $F_{D}$ was associated with the greatest amount of material and lowest porosity for each jam.

Field-determined $A_{F(e m p)}$ is a function of the total amount of material on the jam, decreasing between stages of removal. Also between jams, $A_{F(e m p)}$ is larger at all stages for jam $1\left(14.6-6.7 \mathrm{~m}^{2}\right)$ then jam $2\left(6.3-3.0 \mathrm{~m}^{2}\right)$ and jam 2 is larger than jam $3\left(2.7-1.3 \mathrm{~m}^{2}\right)$. 
For all three jams, the $C_{D}$ back-calculated from empirical values of $F_{D}, A_{F(e m p))}$, and $U_{A p}$, ranged from 1.7 to 11.1 (Table 2.2), and showed little systematic variation. In stage A, jam 3 had a $C_{D}$ of 11.1 , decreasing to 9.4 for stage $\mathrm{B}$, and to 1.7 for stage $\mathrm{C}$. The drag coefficients for jams 1 and 2 did not decrease with stage of removal as we saw with Jam 3. Jam 1 had its highest $C_{D}$ in stage B (7.1) and lowest in stage C (5.0). In contrast, Jam 2 had the highest $C_{D}$ during stage $\mathrm{C}$ (7.7) and lowest in stage $\mathrm{B}(4.9)$.

Values of $\left(C_{D} A_{F}\right)_{\text {calc }}$ back-calculated from empirical values of $F_{D}$ and $U_{A p}$ decreased with stage of removal, within each jam: from 103.6 to $39.8 \mathrm{~m}^{2}$ for jam 1, 36.6 to $22.7 \mathrm{~m} 2$ for jam 2, and 29.9 to $2.1 \mathrm{~m}^{2}$ for jam 3. The highest $\left(103.6 \mathrm{~m}^{2}\right.$ for jam 1 stage B) and lowest values $\left(2.1 \mathrm{~m}^{2}\right.$ for jam 3 stage $\left.\mathrm{D}\right)$ corresponded to the highest and lowest $F_{D}$ values.

\subsubsection{Relationship between $A_{F(e m p)}, F_{D},\left(C_{D} A_{F}\right)_{c a l c}$ and $C_{D}$}

Drag force and $\left(C_{D} A_{F}\right)_{c a l c}$ were both related to $A_{F(\text { (emp) }}$ between stages and jams (Table 2.2). A further consideration of the connection of $A_{F(e m p)}$ with $\left(C_{D} A_{F}\right)_{c a l c}$ revealed that the systematic removal of material from the jams and reduction of $A_{F(e m p)}$ at the same jam, resulted in a greater proportion of $\left(C_{D} A_{F}\right)_{c a l c}$ due to $C_{D}$ (Figure 2.8). Therefore, while the magnitude of $C_{D}$, back-calculated from $F_{D}$, did not exhibit any consistent trends between stages of removal, it did gain importance in determining drag.

\subsubsection{The Influence of Jam Structure and Composition: $A_{F(e m p)}, V, A_{\text {surf }}$, and Porosity}

The values of $A_{F(\text { emp })}, V$ and $A_{\text {surf }}$ were used as the metrics for describing jam composition, including the range in the number and size of the wood pieces. Volume did not predict either $F_{D}$ or $\left(C_{D} A_{F}\right)_{c a l c}$ when using all three metrics of composition (run 1, Table 2.3). 
On the contrary, $A_{F(\text { emp })}$ was a significant predictor for both $F_{D}$ and $\left(C_{D} A_{F}\right)_{c a l c}$, when using all metrics of jam composition (run 1). Volume and $A_{F(\text { emp) }}$ were highly correlated within the first run of the model $\left(\mathrm{R}^{2}=0.82\right)$ which included $A_{\text {surf. }}$ However, $A_{F(\text { emp })}$ gained predictive power when $A_{\text {surf }}$ was excluded from the model (run 2). $A_{\text {surf }}$ was important for all runs for $F_{D}$, but was never significant for $\left(C_{D} A_{F}\right)_{c a l c}$. Therefore, because $A_{F(e m p)}$ and $V$ were highly correlated, and $A_{F(e m p)}$ was a better predictor for both $F_{D}$ and $\left(C_{D} A_{F}\right)_{c a l c}$, the model including only $A_{F(e m p)}$ and $A_{\text {surf }}$ (run 4) was sufficient for describing drag force and drag form.

The difference in hydraulics between stage A and B for jams 2 and 3 can be attributed solely to porosity (e.g., frontal area does not change). Lacking porosity, the $F_{D}$ was $\sim 20 \%$ greater in stage A for jams 2 and 3 than in stage B: the force on Jam 2 during stage A (wrapped) was $18.2 \mathrm{kN}$, decreasing to $15.1 \mathrm{kN}$ for stage B (natural), and the force on Jam 3 for stage A was $10.1 \mathrm{kN}$ and decreased to $17.8 \mathrm{kN}$ during stage B. Since frontal area remained the same between the two stages of removal, the drag coefficient accounted for the increase in $F_{D}$, increasing by $\sim 17 \%$.

\section{Discussion}

\subsection{A Detailed Look at Jams in a Mountain River in the Northeast U.S.}

\subsubsection{Jam Composition}

The results from this study provide a detailed description of individual debris jams in a high gradient mountain river in the Northeast United States. While our findings are limited to a single reach on a regulated river, they fill in a gap in the literature. Previous research has established a solid understanding of the reach-scale controls on wood debris recruitment, retention, and accumulation, highlighting the importance of wood material, hydrology, and 
geomorphology (see review by Gurnell et al. 2002). However, the current application of woody debris jams in river restoration (e.g., engineered log jams, Abbe et al., 1997) is inconsistent with the scale and focus of previous studies. Data on the formation and structure of individual woody debris jams therefore is critical, yet lacking.

Abbe and Montgomery (2003) provide a detailed physical inventory for single debris jams within a relatively pristine watershed in the Pacific Northwest, USA. Although we worked within a reach with different land use histories (heavily logged), hydrology (dam regulated), and geomorphology (constrained river), our jams were similar to those in a different physiographic region studied by Abbe and Montgomery (2003). We found that the type of jam we studied, the combination bank-deflector jam, had similar physical characteristics and were found in a similar location within the watershed. Abbe and Montgomery (2003) distinguish between three types of debris found on these jams: key members, racked pieces, and loose pieces. The key members are locally derived in situ pieces which serve to anchor debris and begin the accumulation of the racked pieces which are lodged against the key member and act as the framework in which the loose pieces fill in the open spaces. The jams in this study were constructed similarly. Most of the key members were locally-derived and had frameworks of large and medium woody debris on them. The similarity between their study and ours may indicate a consistency in jam form across watershed characteristics.

\subsubsection{Debris Jam's Affect on the Channel Bed}

This study has shown the localized effect of debris jams on the velocity and shear stress distributions. With changing jam composition, high shear stress cores exceeding $\tau_{c 50}$ 
shifted. Those locations of excess shear stress indicate potential scouring of the bed and may result in future pool formation or enhancement.

Previous studies of scour around debris jams have suggested that pool formation occurs in the convergence zone off the tip of the structure (Cherry and Beschta 1989; Buffington et al. 2002). In our study, we observed cores of high excess shear stress primarily at low porosity stages of removal (stages A and B, Figure 2.6). Therefore, only after a jam has accumulated enough material to substantially decrease its porosity will flow be sufficiently concentrated at the tip, thereby creating the predicted scour hole. For increasing porosities, flow accelerated through one or multiple holes under and/or through the debris jam, resulting in localized areas of scour immediately downstream of the jam. While previous studies guide us in general patterns of upstream and adjacent erosion and downstream deposition (Abbe and Montgomery 1996; Buffington and Montgomery 1999), our study suggests that the complex pattern of erosion and deposition associated with natural jams is first dependent on the degree of porosity. A jam with near-zero porosity will then default to a somewhat random spatial distribution of erosion and deposition around the debris jam based on the random nature of wood piece accumulation.

\subsection{Drag on Natural Debris Jams}

\subsubsection{Drag Coefficient and the Drag Equation}

Previous studies of hydraulic forces on wood jams have focused heavily on $C_{D}$ because the other variables in equation (1) are easily quantified for simple cylinders whereas $C_{D}$ cannot be measured directly. Studies of woody debris elements show trends in $C_{D}$ values with changing log submergence, log slenderness (Wallerstein et al. 2002), blockage, 
orientation, distance from the bed (Gippel et al. 1996; Hygelund and Manga 2003), and Reynolds and Froude numbers (Wallerstein et al. 2001). All of these studies have only used the single-log model resulting in a range of $C_{D}$ from $0.4-4.5$ in the flume (Gippel et al 1996) and 1.0 - 3.3 (Hygelund and Manga 2003) in the field. In contrast, this study has quantified the drag on natural debris jams in the field resulting in $C_{D}$ values from 1.7-11.1. $C_{D}$ did not change systematically with the amount of material and porosity (Table 2.3). While $C_{D}$ declined rapidly once the accumulated material was removed from Jam 3 (from 9.4 to 1.7), it increased for Jam 2 (4.9 to 7.5).

These differences observed at our site can most likely be attributed to some of the changes investigated in previously published studies. Removing material may alter the location of the jam in the water column. In Gippel et al's (1996) flume studies they found that the drag coefficient decreased as the relative depth of the "log" increased. Focusing on the change in $C_{D}$ for Jam 1 we can see this trend. From the natural to partially removed stage the drag coefficient dropped (Table 2.3). For this jam, the majority of the $3.09 \mathrm{~m}^{3}$ of material removed was below the key member. By creating space at the base of the jam, not only did the frontal area decrease but the relative depth also decreased. When the remaining material was removed, the frontal area decreased more drastically than the jam's placement from the bed, resulting in an increase in the drag coefficient. This example shows that the relationship between jam composition and the drag coefficient is not a simple one. As shown above, the drag coefficient will change in a predictable pattern for single logs. However, on natural jams, $C_{D}$ is much less predictable as its sensitivity to changing geometry and location in the water column becomes masked by changes in overall jam composition including $A_{F(e m p)}$. 
A complication in studying natural debris jams is separating $C_{D}$ from $A_{F(e m p)}$. In reality, natural debris jams have poorly defined frontal areas because of their irregular shape and their porosity, which also contributes to being poorly described by a single value of $C_{D}$ for all types of jams. Using $\left(C_{D} A_{F}\right)_{\text {calc }}$ acknowledges that they have a combined effect on drag, but their individual contributions are less important to know and likely to vary considerably between jams.

Surprisingly, our results showed that $\left(C_{D} A_{F}\right)_{\text {calc }}$ for natural debris jams can be explained by the simple measure of $A_{F(\text { emp })}$ (equation (1)) (Table 2.3). It is important that $A_{F(\text { emp })}$ did not explain all the variation in $\left(C_{D} A_{F}\right)_{c a l c}$, as would be the case for a simple log

model. Using both $A_{F(e m p)}$ and $A_{\text {surf }}$ provides greater information on the size (via $\left.A_{F(e m p)}\right)$ and composition (via $A_{\text {surf }}$ ) of the debris jam, and using both terms explains more variability in $\left(C_{D} A_{F}\right)_{\text {calc }}$ than either alone (Table 2.3$)$. In addition, $V$ was highly correlated with $A_{F(e m p)}$, suggesting that they are somewhat interchangeable. In all, to describe $\left(C_{D} A_{F}\right)_{\text {calc }}$, one must have a metric representing the size of the jam and a metric representing the composition of the jam. Our results showed that either $A_{F(\text { (етр) }}$ or V were interchangeable in describing $\left(C_{D} A_{F}\right)_{c a l c}$, and both are metrics of jam size. However, $A_{\text {surf }}$ had a separate impact on $\left(C_{D} A_{F}\right)_{c a l c}$, and we interpret this as $A_{\text {surf }}$ being a metric of the composition of the jam.

\subsubsection{Surface Area and Porosity}

The importance of increased surface area has been widely studied in respect to its increased ecological function (Harmon et al 1986). Hydraulically, the role of wood surface area has been explored in terms of added roughness generally on a reach scale, lumping the effects of wood as single pieces and within jams into overall added resistance. The roughness 
added to a channel affects flood peak time (Gregory et al. 1985) and water level height (Gippel et al 1996). The roughness associated with surface area of single logs has also been investigated experimentally. Adding branches to logs, both Hygelund and Manga (2003) and Gippel et al (1996) reported a decline in $C_{D}$, but for different reasons. While Hygelund and Manga found no increase in the drag force and therefore a decrease in the drag coefficient, Gippel reported an increase in the force concurrent with a larger increase in the frontal area. Greater surface area due to more pieces of woody debris within a jam increases the total roughness, or the total surface of wood interacting with the flow. Such added roughness has the potential to account for the increased resistance. Studies on wind through trees have shown that the greater the volumetric porosity (the proportion of the total dimensions filled by leaves and branches) the greater the drag (Grant and Nickling 1998). Open space, or porosity, is an indicator of total surface area interacting with the flow. The degree to which a structure is porous can affect the local hydraulics by increasing or decreasing roughness and hydraulic resistance.

Debris jams are inherently porous objects due to the presence of irregularly shaped wood pieces which range in size. Conceptually, medium pieces can "fill the holes" created by the large ones and small pieces do the same for medium pieces. While some of the void space can be filled by soil and leaf litter, not all of it is. This discrepancy represents a basic assumption many make when modeling debris jams for real-world applications: that enough sediment and fine organic matter has essentially filled all of the holes making the jam nonporous (Shields and Gippel 1995). Our results indicate that debris jams are highly porous structures. Our experimental design allowed quantification of the difference in $\mathrm{F}_{\mathrm{D}}$ between a natural jam and one that has close to zero porosity. The differences observed represent 
potential errors studies introduce when modeling a natural jam as a single, non-porous object. By assuming solid debris jams, previous studies have over estimated $C_{D}$, and thus overestimated the drag force exerted on natural debris jams.

\subsubsection{Theoretical Predictions between Debris Jam Types}

The rate at which surface area increases relative to volume depends on jam composition. Since jams are complex structures which amass a wide range of pieces, the relationship between $A_{\text {surf }}$ and $V$ is a continuum. Based on the classification of wood piece size and the composition of the jams we studied, we have grouped jams into three types: (i) natural jams with complete accumulations including the key member, SWD, MWD and LWD; (ii) partial jams lacking SWD with a framework of accumulated MWD and LWD; and (iii) key member jams with only one or multiple large trunks.

Differences in jam type can be defined by a relationship between $\left(C_{D} A_{F}\right)_{c a l c}$ and the volume and surface area combination, and we present these relationships as a contour plot (i.e., $\left(C_{D} A_{F}\right)_{c a l c}$ contours, Figure 2.9$)$. While $\left(C_{D} A_{F}\right)_{c a l c}$ will vary with discharge, values presented are for a bankfull event during which the flow either just overtops the jam or almost overtops it. Therefore, while $\left(C_{D} A_{F}\right)_{c a l c}$ is independent of velocity in this situation, it does represent a limited range of flow conditions. However it is these flow conditions in which most restoration projects are interested because of the capability of the high flows to cause geomorphic change and instability of the structure.

The $\left(C_{D} A_{F}\right)_{c a l c}$ contour plot has three distinct regions, roughly corresponding to the three jam types. In the range of $A_{\text {surf }} V$ corresponding to key member jams found in this study, small increases in surface area result in large changes in drag. As pieces are added to a 
key member, surface area increases quickly relative to volume, leading to an increase in $\left(C_{D} A_{F}\right)_{\text {calc. }}$ As wood pieces, in particular SWD, are added to a partial jam, surface areas become extremely large, although the increase in $\left(C_{D} A_{F}\right)_{c a l c}$ from partial to natural jam will be relatively minor in comparison to the increase in $\left(C_{D} A_{F}\right)_{\text {calc }}$ from key member to partial jam. In terms of volume, these generalized relationships dictate the sensitivity of a particular jam type to the addition of material. While the drag on key members is highly sensitive to an increase in material, drag on natural jams is much less responsive to changes in material.

We used two previous studies to test our approach to calculating $\left(C_{D} A_{F}\right)_{c a l c}$ based on $A_{\text {surf }}-V$ relationships. Wallerstein et al. (2001) report the prototype dimensions of single log elements used in a flume along with $F_{D}$ for near bankfull flows. From their data we backcalculated the $\left(C_{D} A_{F}\right)_{\text {calc }}$ for the modeled logs. Their single-log model is within the $A_{\text {surf }} V$ space as we found for our key members. However, our predicted values of $\left(C_{D} A_{F}\right)_{\text {calc }}$ were 2 to 4 times greater than those measured by Wallerstein et al. (2001). For example, at a $A_{\text {surf }}-V$ combination of $31.0 \mathrm{~m}^{2}$ and $8.5 \mathrm{~m}^{3}$ Wallerstein et al. measured a $\left(C_{D} A_{F}\right)_{\text {calc }}$ of $14.6 \mathrm{~m}^{2}$ whereas our approach predicted a $\left(C_{D} A_{F}\right)_{c a l c}$ of $70.7 \mathrm{~m}^{2}$. . Differences between the drag on a single debris element in the flume and field were investigated by Hygelund and Manga (2003). Using simulated single logs, they measured $F_{D}$ to calculate $C_{D}$. For the largest of the "logs" used (length $=1.8 \mathrm{~m}$ and diameter $=0.17 \mathrm{~m})$, the $\left(C_{D} A_{F}\right)_{\text {calc }}$ measured ranged between $0.8 \mathrm{~m}^{2}$ to $1.0 \mathrm{~m}^{2}$. These values exceeded our predicted value of $0.5 \mathrm{~m}^{2}$ and although these measurements were taken in the field, the conditions differed from those at our study site (low flows, fine bed material, non-natural wood elements). While the agreement is not perfect, it is important to note that our model contours are based on limited data collected at the field scale on natural jams. Aside from our study, no others have quantified the drag force 
on natural debris jams, and so we were not able to test our predictions for partial or natural jams.

\section{Implications of Findings}

The results from this study are applicable to restoration initiatives. A recent call for a watershed approach to river restoration with a major focus on the restoration of process (Wohl et al. 2005) requires an understanding of the current processes and those needed to achieve the stated goal. Generally the addition of in-stream structures (LWD and boulders) does not restore process and instead focuses on the restoration of form. Such a strategy has resulted in high rates of failure (Shields et al. 2004; Larson et al. 2001). An understanding of the structure and composition of natural jams and how these translate to their function can be applied to restoration strategies.

The very nature in which jams form, as accumulations through time, means that their character continually changes with season and variations in discharge (Lienampker and Swanson 1986) as well as through space (Kraft and Warren 2003) and with channel geomorphology (Piegay and Gurnell 1997). While the large logs at the core of jams have been shown to persist for decades to centuries (Murphy and Koski 1989; Collins and Montgomery 2002), the accumulation of smaller debris is more dynamic (Harmon et al 1984). Inputs of wood into rivers and standing biomass have been shown to vary widely depending on factors such as location in watershed (Bilby and Ward 1989), land-use, and disturbance history (Gregory and Davis 1992). Therefore, debris jam composition is closely linked to fluvial and riparian processes at both the watershed- and reach- scale. Our results show that jam composition has an important influence on the local channel hydraulics. The 
size and number of wood pieces influence the porosity which we found to have a control on the velocities upstream, adjacent and downstream of the jam, the shear stress distribution, and the drag force.

These hydraulic adjustments have implications in the creation of habitat surrounding the debris jam. Velocity adjustments provide areas of low flows in close proximity to high flows thereby resulting in hydraulic complexity. High shear stress cores forming scour holes and areas of deposition provide geomorphic complexity. The interaction of both the hydraulic and geomorphic complexity enhances the habitat value (Zalewski et al. 2003; Lepori et al. 2005).

Based on the results from this study, we propose a process-based restoration of natural debris jams. Utilization of available woody material present either on the floodplain or within the channel, will result in a more dynamic design allowing for the natural accumulation. Such a strategy will not only insure the long-term maintenance of debris jam structures, but also allow for continued functioning as their hydraulic function changes. The results from this study allow us to begin to predict how the different structures and compositions of debris jams will dictate the hydraulic, geomorphic and ecologic changes.

\section{Conclusion}

The effect of large woody debris accumulations has had a significant presence in the academic literature in the past two decades. Through numerous studies, we have gained a solid understanding of the morphological changes and ecological benefits of debris jams. Several of these studies have catalogued the total volume of wood, the number of pieces and their size distribution. We understand how these characteristics vary spatially, with land use 
history and current management. Other studies have linked the total wood loading with sediment retention, scour, and pool depth. Such reach-scale associations black-box the mechanistic relationship between wood pieces and their function. This study has begun to define such a relationship. We investigated three jams during high flow conditions to determine what effects the different sizes and amounts of woody pieces had on the local hydraulics. Our single-jam model allowed us to isolate the results. We found a correlation between jam volume, the character of the pieces within the jam and the total drag force. Implications for our findings extend to restoration initiatives where a restoration of process may allow for more sustainable $\log$ structures. 
Table 2.1:

Volume, surface area, and total number of individual pieces on each jam for each stage of removal

\begin{tabular}{|c|c|c|c|c|c|c|c|c|c|c|}
\hline \multirow{3}{*}{ Volume $\left(\mathrm{m}^{3}\right)$} & \multicolumn{2}{|c|}{ JAM 1} & \multicolumn{4}{|c|}{ JAM 2} & \multicolumn{4}{|c|}{ JAM 3} \\
\hline & Natural & Partial & Key Member & Wrapped & Natural & Partial & Key Member & Wrapped & Natural & Key Member \\
\hline & & & & & & & & & & \\
\hline Leaf Litter & $0.72(6)$ & 0 & 0 & $N / A$ & $0.18(6)$ & 0 & 0 & $N / A$ & $0.05(9)$ & 0 \\
\hline Soil & $0.08(1)$ & 0 & 0 & $N / A$ & $0.19(6)$ & $0.04(2)$ & 0 & $N / A$ & 0 & 0 \\
\hline SWD & $0.73(6)$ & 0 & 0 & $N / A$ & $0.15(5)$ & $0.05(2)$ & 0 & $N / A$ & $0.02(3)$ & 0 \\
\hline MWD & $2.58(19)$ & $1.81(19)$ & 0 & $N / A$ & $0.46(16)$ & $0.38(16)$ & 0 & $N / A$ & $0.09(16)$ & 0 \\
\hline LWD & $3.43(27)$ & $2.64(27)$ & 0 & $N / A$ & $0.55(18)$ & $0.54(21)$ & 0 & $N / A$ & $0.16(27)$ & 0 \\
\hline Key Member(s) & $5.16(41)$ & $5.16(54)$ & $5.16(100)$ & $N / A$ & $1.44(49)$ & $1.44(59)$ & $1.44(100)$ & $N / A$ & $0.26(45)$ & $0.26(100)$ \\
\hline TOTAL VOLUME & 12.70 & 9.61 & 5.16 & 11.62 & 2.97 & 2.45 & 1.44 & 2.12 & 0.58 & 0.26 \\
\hline \multicolumn{11}{|l|}{ Surface Area $\left(\mathrm{m}^{2}\right)$} \\
\hline SWD & $292.9(51)$ & 0 & 0 & $N / A$ & $67.0(56)$ & $28.5(38)$ & 0 & $N / A$ & $7.9(35)$ & 0 \\
\hline MWD & $166.2(29)$ & $103.2(50)$ & 0 & $N / A$ & $32.2(27)$ & $25.7(34)$ & 0 & $N / A$ & $5.5(24)$ & 0 \\
\hline LWD & $70.3(12)$ & $59.4(29)$ & 0 & $N / A$ & $14.7(12)$ & $14.4(20)$ & 0 & $N / A$ & $3.5(16)$ & 0 \\
\hline Key Member(s) & $44.0(8)$ & $44.0(21)$ & $44.0(100)$ & $N / A$ & $6.2(5)$ & $6.2(8)$ & $6.2(100)$ & $N / A$ & $5.6(25)$ & $5.6(100)$ \\
\hline $\begin{array}{c}\text { TOTAL } \\
\text { SURFACE AREA }\end{array}$ & 573.4 & 207.4 & 44.0 & 38.6 & 120.2 & 74.8 & 6.2 & 4.8 & 22.5 & 5.6 \\
\hline \multicolumn{11}{|l|}{ \# of pieces } \\
\hline SWD & $13681(95)$ & $32(8)$ & 0 & $N / A$ & $2560(93)$ & 755 (84) & 0 & $N / A$ & $527(91)$ & 0 \\
\hline MWD & $687(5)$ & $303(77)$ & 0 & $N / A$ & $190(6)$ & $129(14)$ & 0 & $N / A$ & $43(7)$ & 0 \\
\hline LWD & $69(0)$ & $54(14)$ & 0 & $N / A$ & $15(1)$ & $14(2)$ & 0 & $N / A$ & $6(1)$ & 0 \\
\hline Key Member(s) & $2(0)$ & $2(1)$ & $2(100)$ & $N / A$ & $2(0)$ & $2(0)$ & $2(100)$ & $N / A$ & $1(1)$ & $1(100)$ \\
\hline TOTAL \# & 14439 & 391 & 2 & $N / A$ & 2767 & 900 & 2 & $N / A$ & 577 & 1 \\
\hline
\end{tabular}


Table 2.2:

Drag force and the drag force equation variables

\begin{tabular}{|c|c|c|c|c|c|c|c|}
\hline & $F_{D(x)}(k N)$ & $\mathrm{F}_{\mathrm{D}(\mathrm{y})}(\mathrm{kN})$ & $\mathrm{F}_{\mathrm{D}}(\mathrm{kN})$ & $A_{F(e m p)}\left(m^{2}\right)$ & $\mathrm{U}_{\mathrm{Ap}}\left(\mathrm{m} \mathrm{s}^{-1}\right)$ & $\left(C_{D} A_{F}\right)_{\text {calc }}\left(m^{2}\right)$ & $\mathrm{C}_{\mathrm{D}}$ \\
\hline \multicolumn{8}{|l|}{ JAM 1} \\
\hline Natural (B) & 62.7 & 0.4 & 62.7 & 14.6 & 1.10 & 103.6 & 7.1 \\
\hline Partial (C) & 23.9 & 3.6 & 24.2 & 8.8 & 1.05 & 43.5 & 5.0 \\
\hline Key Member (D) & 19.9 & 0.7 & 19.9 & 6.7 & 1.00 & 39.8 & 5.9 \\
\hline \multicolumn{8}{|l|}{ JAM 2} \\
\hline Wrapped (A) & 18.2 & 2.1 & 18.3 & 6.3 & 1.00 & 36.6 & 5.8 \\
\hline Natural (B) & 15.0 & 0.4 & 15.1 & 6.3 & 0.98 & 31.3 & 4.9 \\
\hline Partial (C) & 14.4 & 0.4 & 14.4 & 3.8 & 1.00 & 28.8 & 7.7 \\
\hline Key Member (D) & 11.6 & 0.4 & 11.6 & 3.0 & 1.01 & 22.7 & 7.5 \\
\hline \multicolumn{8}{|l|}{ JAM 3} \\
\hline Wrapped (A) & 10.1 & 0.4 & 10.1 & 2.7 & 0.82 & 29.9 & 11.1 \\
\hline Natural (B) & 7.6 & 1.9 & 7.8 & 2.7 & 0.78 & 25.5 & 9.4 \\
\hline Key Member (D) & 0.2 & 0.7 & 0.8 & 1.3 & 0.80 & 2.1 & 1.7 \\
\hline
\end{tabular}


Table 2.3:

Multivariate linear regression model results

\begin{tabular}{|c|c|c|c|c|c|}
\hline \multirow[b]{2}{*}{$\begin{array}{c}\text { Model } \\
\text { Run }\end{array}$} & \multirow[b]{2}{*}{$\begin{array}{l}\text { Independent } \\
\text { variables }\end{array}$} & \multicolumn{2}{|c|}{$\left(C_{D} A_{F}\right)_{\text {calc }}$} & \multicolumn{2}{|c|}{$F_{D}$} \\
\hline & & Coefficient & Sig. & Coefficient & Sig. \\
\hline \multirow[t]{3}{*}{1} & V & -2.5 & 0.30 & -580.1 & 0.65 \\
\hline & $A_{\text {surf }}$ & 0.06 & 0.17 & 53.3 & $0.04^{* *}$ \\
\hline & $A_{F(e m p)}$ & 6.90 & $0.01^{* *}$ & 2564.8 & $0.04^{\star *}$ \\
\hline \multirow[t]{2}{*}{2} & V & -1.09 & 0.64 & 783 & 0.64 \\
\hline & $A_{F(e m p)}$ & 7.31 & $<0.01^{* *}$ & 2951.9 & $0.07^{* *}$ \\
\hline \multirow[t]{2}{*}{3} & $\mathrm{~V}$ & 4.67 & $0.09^{*}$ & 2084.6 & $0.08^{*}$ \\
\hline & $A_{\text {surf }}$ & 0.08 & 0.28 & 60.9 & $0.06^{*}$ \\
\hline \multirow[t]{2}{*}{4} & $A_{\text {surf }}$ & 0.04 & 0.28 & 49.6 & $0.02^{* *}$ \\
\hline & $A_{F(e m p)}$ & 5.28 & $<0.01^{* *}$ & 2189.4 & $<0.01^{* *}$ \\
\hline
\end{tabular}


Figure 2.1:

Study site along the Indian River, Adirondack Mountains, New York
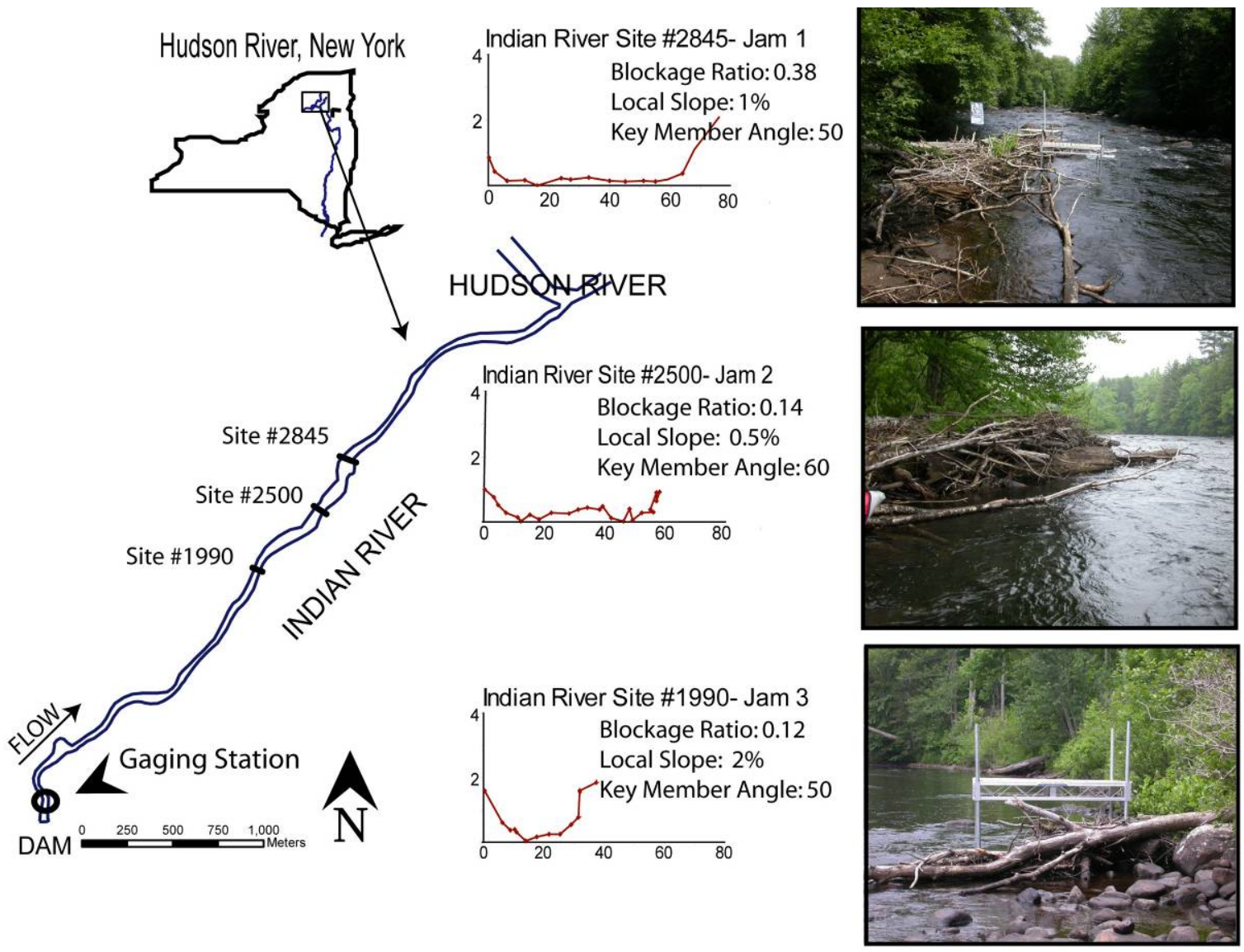
Figure 2.2:

Schematic of the control volume defined by the local hydraulic effects of a debris jam

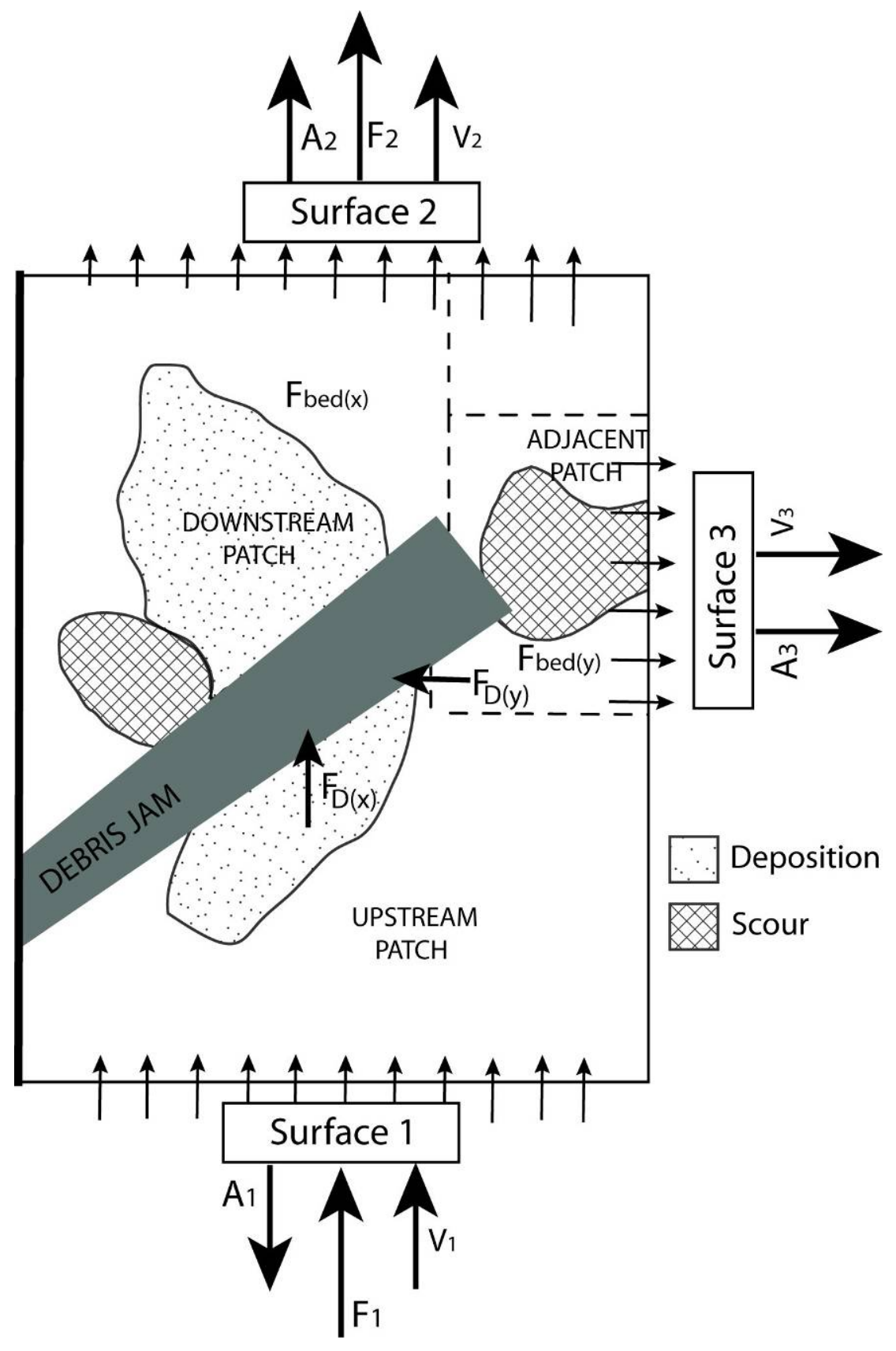




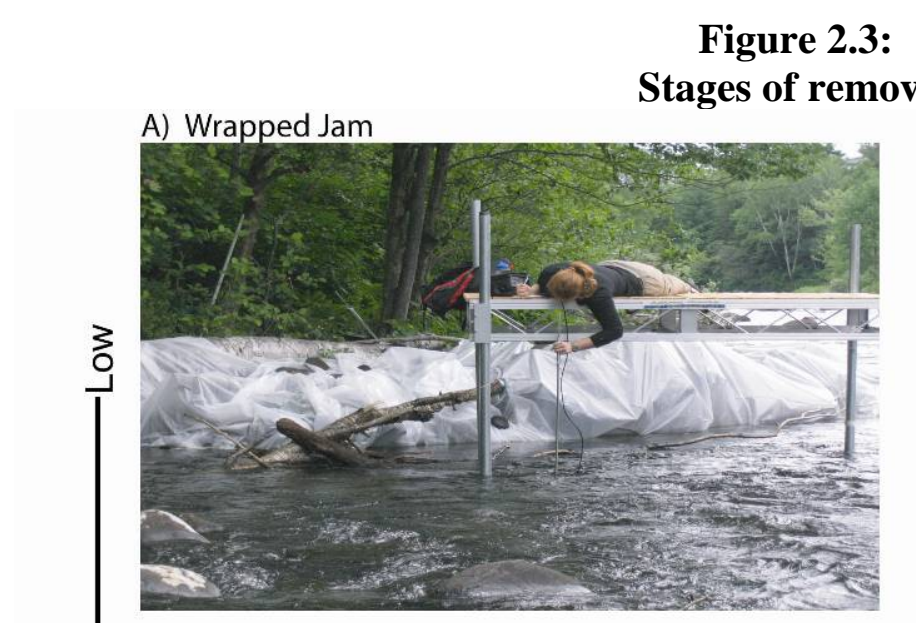

Treatment: Wrap natural jam with plastic wrap keeping as much of the natural shape as possible. Jam Structure: Single, non-porous object

Goal: 1) Simulate non-porous object

2) Represent hypothetical end member in evolution of a jam

Application: Jams 2 and 3

\section{Treatment: None}

Jam Structure: LWD and MWD racked onto the key member(s); SWD, soil and leaf litter occupy spaces among LWD and MWD

Goal: 1) Assess those jams formed completely by natural processes

2) Determine the natural porosity of jams

Application: Jams 1,2 and 3

C) Partial Jam

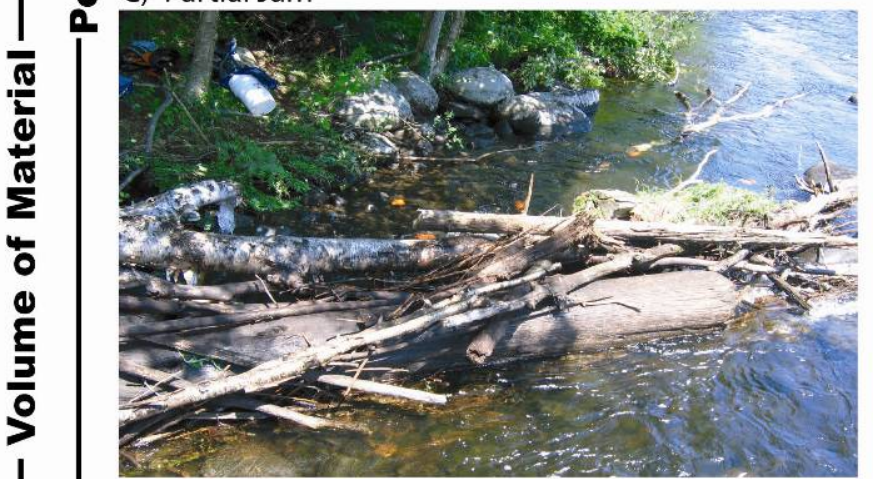

Treatment: Remove SWD, soil, leaf litter and any large unstable pieces

Jam Structre: Key member(s) with a LWD and MWD framework

Goal: 1) Assess the role of the small debris and organic matter in both jam structure and local hydraulics

2) Assess the role of a largely porous jam through a framework of LWD and MWD

Application: Jams 1 and 2

Treatment: Remove remaining accumulated woody debris.

Jam Structure: Key member(s)

Goal: 1) Assess the hydraulic influence of the key member(s)

2) Determine the role of all accumulated material

Application: Jams 1,2 and 3 
Figure 2.4:

Surface area and volume relationships as defined by stage of removal

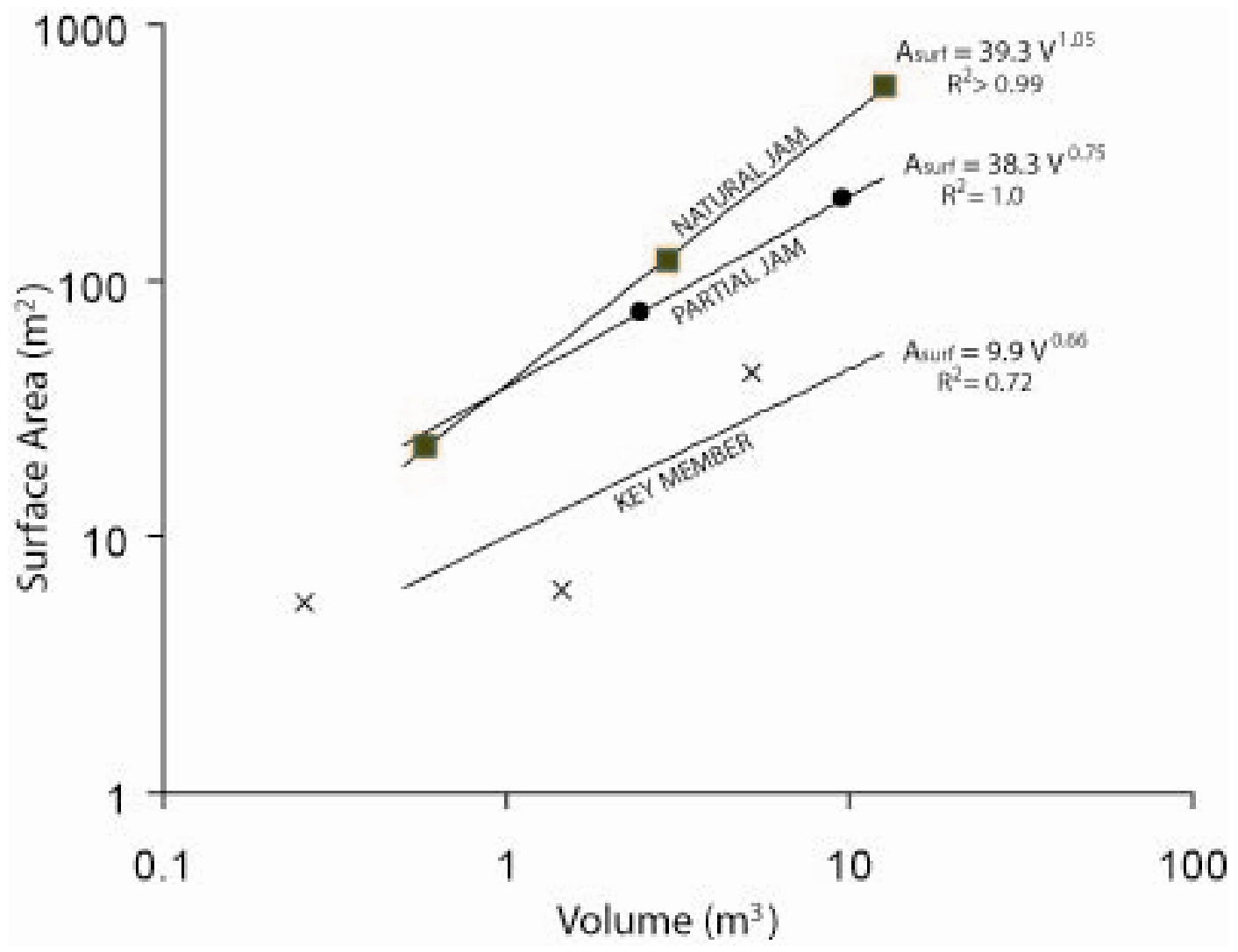


Figure 2.5:
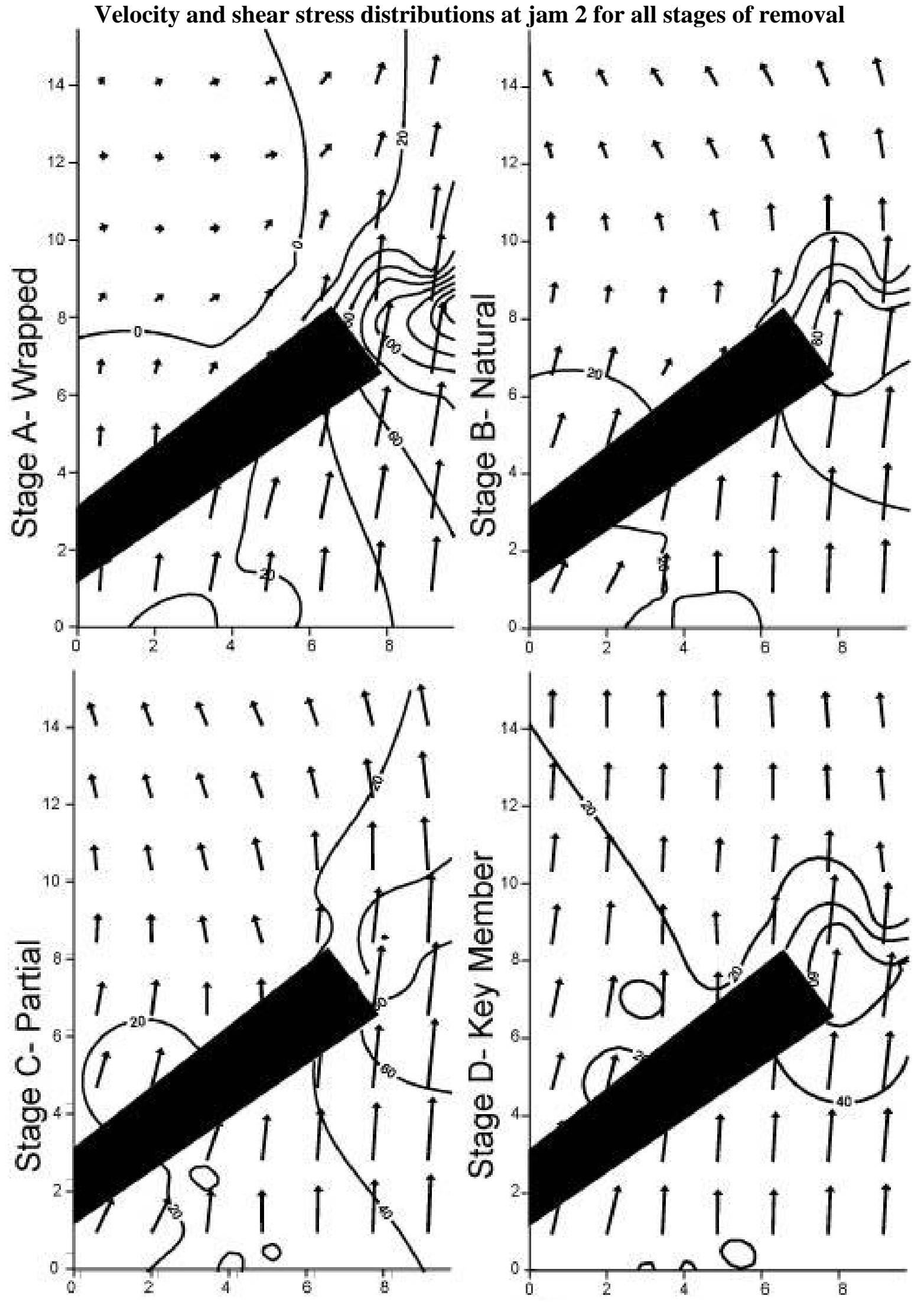
Figure 2.6:

Spatially divided mean velocity and shear stress values for each stage at both low and high flow conditions for jam 2
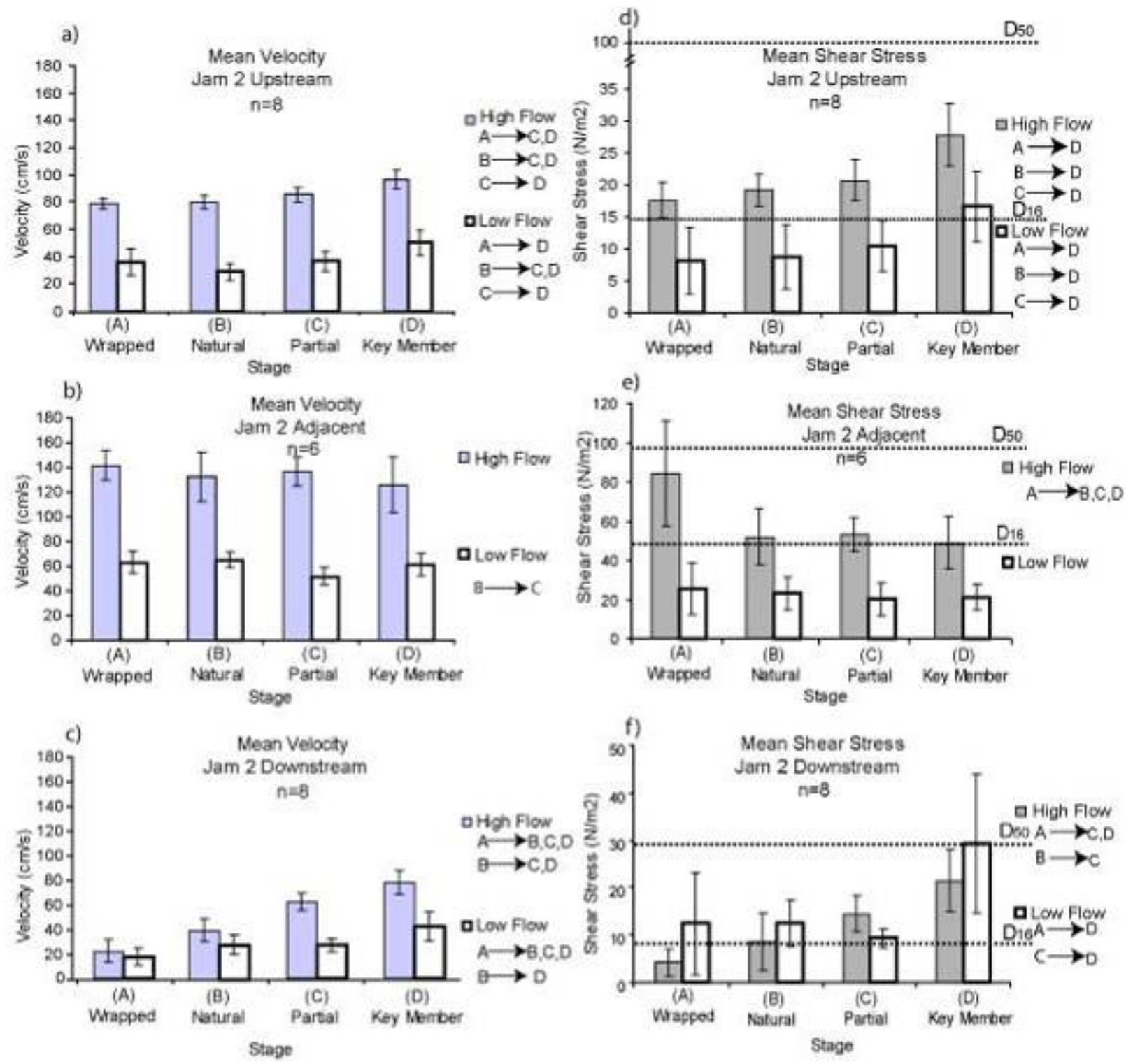
Figure 2.7:
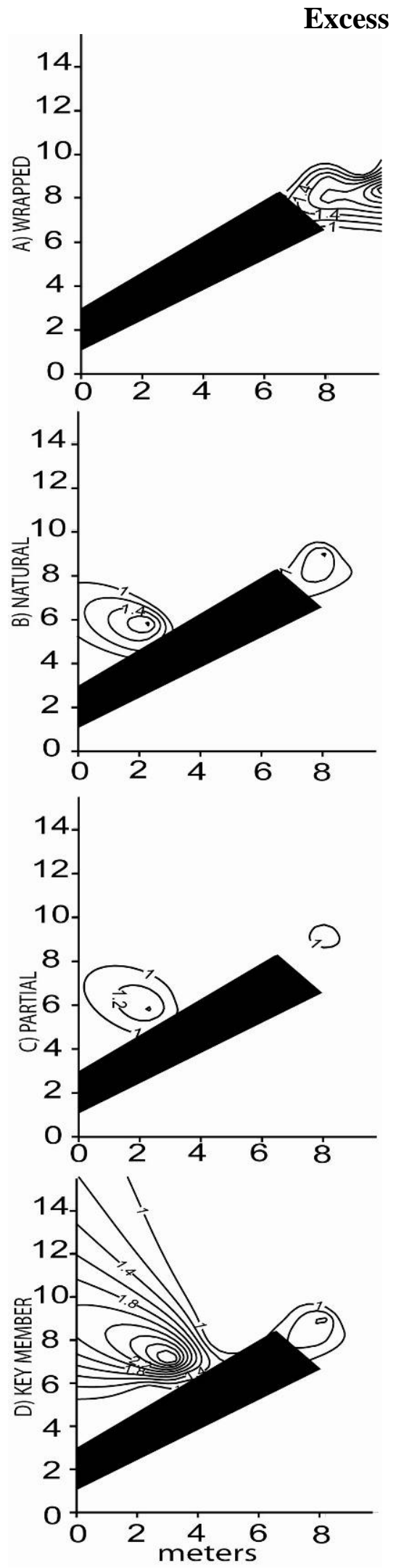
Figure 2.8

Proportion of $\left(C_{D} A_{F}\right)_{c a l c}$ made up by $A_{F(e m p)}$ and $C_{D}$ for jams 1 and 2
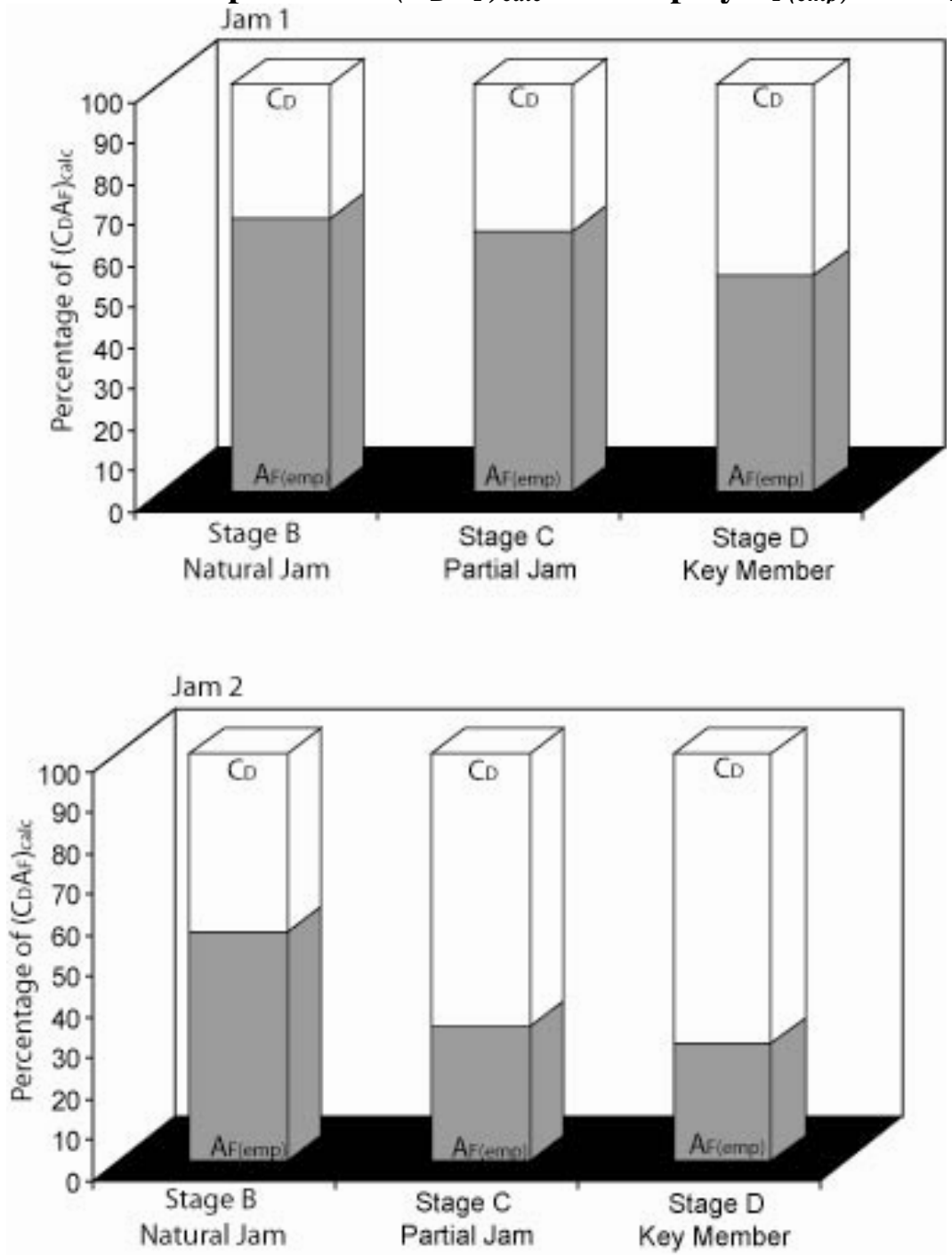
Figure 2.9:

Contour plot of $\left(C_{D} A_{F}\right)_{c a l c}$ based on the $A_{\text {surf }}-V$ relationship for each stage of

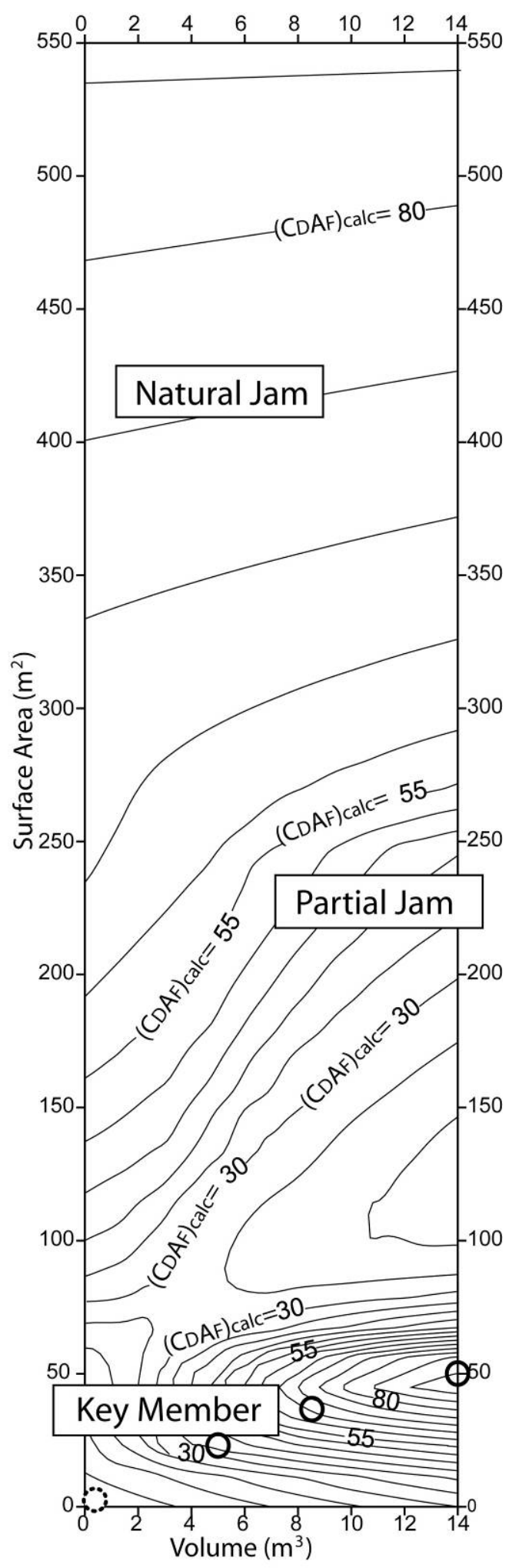
removal 


\section{CHAPTER III:}

\section{DEBRIS JAM EVOLUTION}

\section{Introduction}

The dramatic growth in river restoration projects over the last 10 years (Bernhardt et al 2005) has outpaced the capability of research and monitoring to provide important feedbacks, severely limiting the scientific foundation for restoration. The fourteen billion dollar industry is projected to continue to grow and become a prominent feature in environmental policy. These trends have prompted researchers to encourage an interdisciplinary agenda working towards synthesizing research efforts with their application thereby creating a sustainable and successful restoration industry (Palmer et al. 2005; Lake 2001; Kondolf 1995). While coordination within and among disciplines will ensure a longterm relationship between science and restoration, efforts to provide meaningful solutions to specific problems provide the basis for this relationship. One of the most prominent goals for restoration projects is the enhancement or creation of habitat. The most widely-used tool in restoration projects whose goals include improving in-stream habitat is large woody debris (Bernhardt et al 2005).

Wood structures are installed either as single logs, rootwads, or multiple pieces in the form of jams (D'Aoust and Millar 2000) for a variety of applications including bank stabilization, habitat enhancement and geomorphic complexity. Where the transport and 
supply of wood are abundant, wood has the tendency to aggregate, accumulating to form debris jams (Kraft and Warren 2003). This natural phenomenon has been adapted into woodstructure design. The complex form of debris jams is more hydraulically efficient in causing morphologic change (Richmond and Fausch 1995) and provides better cover for fish (Monzyk et al 1997) than does a single log or rootwad. Additionally, jams can be used to retain wood and organic matter protecting downstream structures and enhancing the ecological integrity of the stream (Bilby and Likens 1980).

The use of wood in restoration relies on the fact that by introducing a roughness element to a river channel, it is possible to fundamentally affect the localized hydraulics thereby causing geomorphic change and influencing ecologic processes. The successful implementation of wood structures in river restoration projects has proven that proper manipulation of fluvial processes is possible. We can generalize the influence on the localized hydraulics and provide enough confidence in the fact that an eroding bank will be protected as flow is deflected towards the channel centerline (eg Brooks et al 2001). Furthermore, we can assure the stability of an engineered structure during a 100-year flood to some degree of accuracy (eg D'Aoust and Millar 2000). Unaccounted for changes, such as local scour around a wood structure or the accumulation of woody material, regularly cause either structural breakdown or overall project failure because of the structures functional loss (D’Aoust and Millar 2000; Frissell and Nawa 1992; Larson et al 2001).

A general lack of project monitoring (Bernhardt et al 2005) has inhibited a thorough understanding of why restoration structures may fail or succeed therefore prohibiting future developments. Since wood-based restoration is based on the adaptation of a natural phenomenon, researchers and designers should further focus on understanding the natural 
dynamics of wood. The ability to incorporate the variability of wood dynamics may assure the long-term success and maintenance of wood-based restoration projects. Previous research efforts have focused on general trends of wood dynamics at the reach- or watershed-scale (Gurnell et al 2002) relating things such as land-use controls on wood loadings (Gregory and Davis 1992), geomorphological controls on jam formation (Petit et al 2005) and type (Abbe and Montgomery 2003) and hillslope and channel gradient on input and output processes (Keller and Swanson 1979). These trends translate to increased channel roughness altering the reach-scale hydraulics resulting in decreased sediment sizes (Buffington and Montgomery 1999), slower peak travel times (Gregory et al 1985) and lower water stages (Gippel et al 1996). While these findings are important, their scalability to a more local focus (ie patch scale) which serve as the foundation for restoration projects is still unknown and currently limited to work done on the hydraulics of single-log models (Wallerstein et al 1997; Gippel et al 1996; Manga and Kirchner 2000).

Therefore there exists a gap in the fundamental understanding of the debris jam, the controls on its initiation and accumulation of woody debris, and how this process affects the local hydraulics. It is this gap which may lead to a greater ability to use wood in restoration by providing managers with the capability of predicting how structures will change through time, assuring structural maintenance and greater cost-effectiveness. Abbe and Montgomery (2003) proposed that the recruitment and stabilization of a large log induces local channel changes which promote the recruitment of additional wood. The accumulation of wood then promotes further channel changes, affecting further accumulation. Based on this hypothesis, there exists a feedback by which the accumulation of wood affects the hydraulics which in turn affects further accumulation of wood. The following paper expands on this hypothesis 
proposing a model of debris jam evolution defined here as the accumulation of woody debris through time progressing from the recruitment of a single-log to a heterogeneous structure and mediated by the supply of wood and changing local hydraulics.

The paper is organized as follows: 1) It establishes what we know about the initiation and accumulation of wood to form a debris jam reviewing the literature and highlighting what gaps exist. 2) It presents a conceptual model for the evolution of a single debris jam. 3) It introduces a case study which provides insight into what may control the at-a-jam evolution of a debris jam and relate these controls to the change in the localized hydraulics. 4) Recommendations are made as to how this idea of jam evolution can be adapted to restoration and to work within the watershed context in order to ensure successful project implementation.

\section{Evolution}

\subsection{Key Member Dynamics}

\subsubsection{Key Member Stability}

Initiation of the jam begins with the recruitment and stabilization of the "key member" (Abbe and Montgomery 2003), a relatively large tree trunk that may or may not contain branches and a rootwad which serves as the accumulation of additional wood pieces (Figure 3.1). The stability of a piece of wood best defines its role as the key member (See Table 3.1). Stabilization requires the equalization of forces so that the resisting forces exceed the drag forces. Variables such as the size and shape, the presence of a rootwad or branches (Meleason et al 2005), and the wood density affect the ability for a piece of wood to stabilize and serve as a key member by adding resistance or increasing the probability that it will 
become lodged against another stabilizing element such as a boulder. Upon recruitment of a wood piece, adjustments to both the bed and the position of the wood piece, generally occur within the first large flow event (Wallerstein et al 2001). Alteration of the key member's angle to flow helps to equalize forces. Angle to flow seems to be the most stable at a downstream angle of around 30 degrees (Gippel et al 1996; Cherry and Beschta 1989; Bilby and Ward 1989), but the presence of a rootwad or a boulder could prevent this natural adjustment. Stabilization of a wood piece in order to serve as a key member is simply a function of the hydraulics of a single wood piece. Various studies have investigated this topic providing an in-depth understanding of balance of forces on the key member (Gippel 1995; Shields and Gippel 1995)

\subsubsection{Key Member Recruitment}

Key members may be from the adjacent bank or may be transported from upstream and become lodged on a bank or rock during a high flow event. Recruitment of key members is dominated by local inputs (Wallerstein et al 1997) and is a function of length of eroded bank (Wyzga and Zawiejska 2005; Angradi et al 2004), lateral channel mobility (Thevenet et al 1998), and riparian composition, topography, and width (Bilby and Bisson 1998; Robison and Beschta 1990). A key member must withstand high flows and be resistant to decay and fragmentation over annual to decadal timescales. Therefore, these pieces are generally the largest available in a reach. Abbe and Montgomery (2003) found that the diameter of the key member dictated its ability to act as a key member (ie stabilizing) more than the length, yet both determine the efficiency in the capture of material. Qualifications for key members are channel dependent. While some studies have found that the majority of key pieces have 
rootwads (Collins and Montgomery 2002), Lienampker and Swanson (1986) reported that less than $20 \%$ of the key members had them.

The differences in key member sizes and characteristics indicate that the qualifications of woody debris to serve as a key member are variable. The greater the channel width and stream power (defined by the water discharge and slope as the loss of potential energy per unit weight of water), the larger the piece size needed (Nakamura and Swanson 1993). Yet rootwads, branches and high density wood aid in the stabilization of woody debris, resulting in smaller key members than would be defined solely by channel characteristics.

\subsection{Wood Availability}

The accumulation of wood into a debris jam is a relatively random process that is difficult to predict because of the stochastic nature of wood input and transport. If a stable key member exists, the first control on the accumulation of wood into a jam is the availability of woody debris within or adjacent to the channel.

\subsubsection{Watershed-Scale: Wood Loadings}

Much attention has been paid to the volume of wood or density of wood, called the wood loading (Table 3.1), in a variety of geographic locations and under diverse watershed conditions (Gippel et al 1996; Gurnell et al 1995). While regional patterns in wood loading have been observed (Hering et al 2000), forest age, composition and landuse history are more explanatory variables. High loadings of wood have been reported for old-growth forests.

Evans et al (1993) found that ancient native and 120-year old native forests had 1-2 orders of 
magnitude greater volumes of wood than forests 10-12 years old. Landuse histories therefore play a role in the amount of wood available. Recovery patterns of a riparian forest from clear-cutting depend on the succession of species (Murphy and Koski 1989; Sturtevant et al. 1997; Meleason and Hall 2005;) and can be fairly high immediately post-disturbance as leftover debris remains (Swanson et al 1984). Additionally, those forests dominated by coniferous trees provide more wood than do hardwood forests (Harmon et al 1986).

The greatest riparian impact on wood delivery to the channel occurs immediately adjacent to the stream (Marsh et al 2001). While landslides will deliver a large pulse of wood to a stream potentially from distant sources, the frequency of occurrence is rare (Martin and Benda 2001). In fact, Robison and Beschta (1990) put together a probability model predicting that $50 \%$ of the wood in a river comes from within $50 \mathrm{ft}$. of the edge of the channel and all in-channel wood comes from within $200 \mathrm{ft}$ of the river.

Wood loadings are often reported as volume or mass per unit area (Table 3.1). This masks the frequency and size distributions of wood pieces in a reach which may be just as important, if not more so, to the build-up of debris jams. For example, Webb and Erskine (2003) found that over $75 \%$ of the logs within a channel were less than $0.3 \mathrm{~m}$ in diameter, but made up less than $10 \%$ of the total volume. Since the input of the key members is a local phenomenon, the presence of these pieces is generally dominated by the local forest conditions and may be well represented by adjacent riparian conditions. However, the remainder of wood found on jams is controlled by a variety of other factors which may contribute to its size and distribution.

Those factors affecting wood loading (forest age, composition and management history) have been found to influence the size of wood pieces. Richmond and Faush (1995) 
and Ralph et al (1994) observed on average smaller piece sizes in disturbed watersheds. Hillslope topography can influence in-channel piece sizes (McDade et al 1990) where slope was shown to influence both diameter and length. Gentler slopes provided smaller diameters while steeper slopes produced shorter lengths because of breakage (McDade et al 1990). Gurnell et al (2000) and Berg et al (1998) both report distributions of length in the western United States, one from an old-growth forest and one from a fairly young one (Figure 3.2a). While the shape of the distributions is similar, the old-growth population had longer pieces. A comparison of two studies in old-growth forests, one of hardwoods (Webb and Erskine 2003) and one of spruce (Murphy and Koski 1989), suggests that the difference in composition does carry over to the piece-size distributions (Figure 3.2b). Hering et al (2000) and Berg et al (1998) also provide piece-size distributions for watersheds both with a mixture of management strategies, one in a coniferous forest in California and one from a variety of studies of deciduous forests from Central Europe. Although the forest composition varies between these two studies, their piece-size distributions are very similar (Figure 3.2c). Therefore, while those landscape-specific factors which have been shown to control wood loadings do influence piece-size distributions, the relationship is not clear (Evans et al 1993).

The distribution of piece sizes, whether presented as diameters or lengths are often skewed towards the finer fractions (Figure 3.2). The range of these distributions reported in the literature is dictated by the sampling methods and the goal of the study. For the majority of studies on wood dynamics, woody debris is defined by a minimum piece size diameter of $10 \mathrm{~cm}$ and length of $1 \mathrm{~m}$, thereby not accounting for pieces smaller than $10 \mathrm{~cm}$. Wallace et al (2000) focused on fine wood in small streams in North Carolina and found that $98 \%$ of the pieces present within the channel had diameters smaller than $10 \mathrm{~cm}$. Given that the 
distributions of wood pieces are heavily skewed towards the smaller fractions, the lack of data on small wood pieces may mask the role of smaller material in debris jam evolution.

\subsubsection{Reach-Scale: Wood Loadings and Fluvial Transport}

While the adjacent forest conditions provide a first-order control on the amount of wood and its size distribution, the influence of upstream fluvial inputs on wood loadings increases with watershed area as the ability to transport wood increases through a watershed (Martin and Benda 2001). Below a certain threshold in watershed size, the material within a reach is primarily a function of lateral inputs. As width and stream power increase relative to piece size, a greater proportion of wood can be transported. Below this threshold most wood is immobile and the reach is said to be transport limited. On the other hand, reaches capable of mobilizing all wood are thought to be supply limited (Marcus et al 2002). Gippel et al (1996) found a lack of correlation between the distribution of debris in streams and the distribution of adjacent riparian trees, indicating redistribution of wood by floods.

Braudrick and Grant (2000) showed that log entrainment is primarily a function of piece angle relative to flow direction, presence of a rootwad, density and diameter. While length is not a factor in the mobilization as long as it is less than channel width, it does dictate travel distance (Braudrick and Grant 2001; Hildebrand et al 1998). Additionally, the geomorphology and hydrology of the reach will dictate the mobilization of pieces (Moulin and Piegay 2004) and the distance they are transported (Ehrman and Lamberti 1992). Altered hydrologies and/or geomorphologies can affect the loading of wood within a reach. Downs and Simon (2001) found that incised channels are extremely effective at transporting wood debris with their low width-depth ratio and flashy hydrographs. The hydraulics in disturbed 
channels can overcome the natural resistance of wood to transport out of a reach including resistance from channel irregularities and hydraulic complexity including backwater areas. The lack of wood in these channels highlights the importance of channel roughness in retaining wood thereby influencing reach-scale loadings.

Due to differences in the contribution of upstream and lateral inputs and the controls on fluvial transport, wood loadings within a reach change through a watershed. Reach-scale watershed trends include greater total loadings (Murphy and Koski 1989) and larger piece sizes (Bilby and Ward 1989) with an increase in channel width.

\subsubsection{Jam-Scale: Accumulation of Wood}

As noted above, the amount of material on a jam is first a function of the available wood in a reach which, as mentioned above, has both local riparian and fluvial transport controls. A more direct control is the ability of the wood in the reach to be mobilized and transported within the influence of a key member. Similar to those controls on reach-scale loadings, the ability of a reach to transport wood controls the accumulation of wood into a jam. Marsh et al (2001) found that for reaches in Australia with shear stress values greater than $40 \mathrm{~N} \mathrm{m-2,60-85 \%} \mathrm{of} \mathrm{the} \mathrm{wood} \mathrm{in} \mathrm{a} \mathrm{reach} \mathrm{was} \mathrm{in} \mathrm{a} \mathrm{jam.} \mathrm{Dahlstrom} \mathrm{and} \mathrm{Nillson} \mathrm{(2001)}$ related the variation in the number of pieces on a jam to the differences in stream power. These reasons are why there are fewer jams in large rivers (Bilby and Ward 1989) but those that are on large rivers are larger (Piegay et al 1999).

Once wood is mobilized, the chance it will encounter a key member is a function of the frequency with which it is mobilized, the dominant flow paths, and the proportion of the channel occupied by the key member. The process of transporting wood changes its 
character, removing many of the branches and roots as it encounters other wood pieces or roughness elements and reducing its length (Moulin and Piegay 2004). The ability of larger channels to transport larger pieces also changes the population that is mobile thereby delivering larger and larger pieces to jams. If a piece of wood is half as dense as water $(\sim 500$ $\mathrm{kg} / \mathrm{m} 3$ ), Braudrick and Grant (2001) concluded that as long as its length is less than the channel width, it will mobilize. Larger channels not only have a higher probability of being larger than piece length, but also are more likely to have deeper flows capable of moving pieces with larger diameters. Therefore, it is likely that the composition of a jam or the piece size distribution will change throughout a watershed as well, not just the magnitude and frequency of jams.

The ability to tease out these trends is limited by the lack of data on piece-size distributions. To date, two studies have reported detailed wood piece counts from within jams, Manners et al (In Review) and Jackson and Sturm (2002) (Figure 3.2d). While Manners et al counted all wood pieces in three debris jams, Jackson and Sturm limited their study to those pieces with diameters greater than $10 \mathrm{~cm}$. The majority of the Manners et al. wood pieces are less than $10 \mathrm{~cm}$ again highlighting the need to include these pieces in further studies and prohibiting comparison between these two studies.

Based on the idea that the first-order control on jam accumulation is the availability of wood, it can be deduced that jam formation is also controlled temporally by the inputs of wood either due to vegetation controls or hydrologic ones (Pettit et al 2005). For the smallest wood, ie diameter $<1 \mathrm{~cm}$, and leaves, the input to the channel will coincide with its transport and potential accumulation on a jam (Diez et al 2005). Larger wood pieces not transportable by base flows, on the other hand, depend on the timing of flows. Generally large wood pieces 
lie dormant on the floodplain or within the active channel for most of the year (Piegay 1993). Their mobilization and potential delivery is dependent on a flood event of great enough magnitude to significantly overtop the banks.

\subsection{Retention}

The review of wood availability has highlighted that while our understanding of wood recruitment and transport can adequately describe trends such as wood loading at the watershed and reach scale, the application of this information to the specifics of a single debris jam is still unknown. Mobilization, transport, and delivery of woody debris on a key member or debris jam can be described by probability functions (Martin and Benda 2001). Upon delivery, the means by which wood will be retained and stabilize as part of the jam has not been very well studied. Retention may depend on the presence of an established framework of wood (matrix of large wood pieces on the key member- Table 3.1; Figure 3.1) which may serve as a sieve through which the water may pass, but the woody material may not. The balance of wood pieces able to act as a surface of accumulation for passing material and open space between wood pieces which allows water to pass suggests that the porosity of the jam may dictate the accumulation of wood into a jam (Manners et al In Review). Generally it is assumed that debris jams are non-porous (Shields and Gippel 1995) and may be treated as single solid objects. Investigations into this claim are few, and yet they have found that jams are indeed porous (Manners et al In Review; Monzyk et al 1997; Thevenet et al 2004), and that this porosity may change with season (Haschenburger and Rice 2004). Defining a linear space around debris jams (similar to Figure 3.3), Thevenet et al (2004) quantified that the proportion of air within the space was $90 \%$ and found that this value was 
higher the larger the wood pieces in the jam. Therefore, there may exist a balance between the porosity of a debris jam and the degree to which it alters the local flow fields and the wood delivered to and retained on the jam. High porosity indicates minor interruptions in flow patterns thereby maintaining delivery and transport of wood to the jam but also indicates a lack of wood surface on which wood may be retained. Conversely, low porosity alters flow limiting delivery of wood so that moderate amount of porosity maximizes retention of wood on a jam.

\subsection{Decay and Export}

\subsubsection{Reach-Scale}

Decay, abrasion, and fragmentation all act on pieces in a jam potentially resulting in export from both a jam and the reach (Harmon et al 1986). Many studies have investigated the decay rates of wood pieces in aquatic environments reporting on losses of mass via biological decay (respiration and leaching; for a review see Spanhoff and Meyer 2004). Single exponential decay models can begin to describe the longevity of a piece of woody debris based on biological losses:

$Y_{t}=Y_{0} e^{-k t}$

where $Y_{0}$ is the initial quantity of material, $Y_{t}$ is the amount left at time $t$, and $k$ is the decay rate constant.

Species type and degree of submergence dictate $k$. In general, hardwoods have higher values of $k$ than conifers because of their smaller sizes, higher substrate quality and the climate they are found in (Harmon et al 1986; Hyatt and Naiman 2001). 
Biological decay is not the only factor contributing to the breakdown and export of wood from jams. Triska and Cromack (1980) found that wood in the most advanced stages of decay (ie surface is extensively rotted) are not found in rivers because they are more likely to get washed away. Therefore, while biological decay is important for the loss of mass, physical abrasion and fragmentation are important contributors to the export of wood in a river. Harmon et al. (1986) suggested adding a coefficient for fragmentation so that $k=k_{b}+k_{f}$

where $k$ is the overall decay rate constant, $k_{b}$ is the decay to due the biological breakdown and $k_{f}$ is the decay rate for losses for fragmentation.

A common way of reporting wood decay is the reciprocal of $k$, called the turnover time. Studies reporting turnover times may be from two different sources. Some measure the decay of individual pieces and solve for $k$ (from equation 1) (Webster et al 1999) while others solve for the total amount of material in the area of interest (ie a reach) and divide that number by the flux of material (Diez et al 2000). This latter statistic is equal to residence time (total time of an individual piece in the same reach) if the system is in a steady state (if the fluxes in equal the fluxes out). If we assume that the standing crop of woody debris is in equilibrium on an annual timescale as Wallace et al (2000) measured for a reach in Western North Carolina, then we can use the movement of a population of wood pieces through a reach as a proxy for individual pieces. These two scenarios provide fundamentally different data, the former of which solely represents the biological decay while the other includes fluvial transport and physical breakdown. In fluvial environments, biological decay, physical breakdown and export from a reach are all related, where the greater the decay the higher the chance of fragmentation and therefore the greater the potential for export and on a reach 
scale the relationship between reported turnover times are comparable. For large wood pieces turnover time has been estimated to be on the order of $10^{2}$ years (Swanson and Lienamker 1978; Murphy and Koski 1989) while turnover time decreases for non-key member wood pieces to $10^{0}-10^{1}$ years (Diez et al 2000; Spanhoff and Meyer 2004).

Spanhoff and Meyer (2004) reported a significant relationship between the surface to volume ratio of wood and the breakdown rate. Since piece diameter controls the surface to volume ratio, the loss of wood from a reach can be thought of based on diameter. Diez et al (2000) found that wood pieces with a diameter less than $5 \mathrm{~cm}$ had a turnover time of 1.7-3 years whereas for pieces greater than $5 \mathrm{~cm}$ the number jumped to 75 years. Wallace et al (2000) found a turnover time of 10 years for wood with diameters between 1 and $10 \mathrm{~cm}$.

\subsubsection{Jam-Scale}

Once a debris jam has formed, it may be in a steady-state (see below) and therefore reach-scale turnover times may be applicable. However, additional factors may also control the turnover time of wood in a jam including its location within the jam. Location within a jam may further dictate the degree to which a piece of wood experiences biological decay, physical breakdown and therefore is potentially exported from the jam. The small pieces (ie

diameter $<1 \mathrm{~cm}$ ), which predominate the surface of the jam, will decay quickly (high surface to volume ratio and therefore high $k$ ). The high rate of decay along with their exposure to all flows indicates that they have a high rate of turnover and therefore a low turnover time. Medium to large accumulated wood pieces have slower breakdown rates because of their low surface to volume ratio. These pieces are generally located within the jam where they are not as susceptible to the majority of flows and are physically protected against abrasion and 
fragmentation. Therefore, these pieces will remain on the jam for a longer time period and have higher turnover times than the small pieces on the surface. The key member, with its low surface to volume ratio and therefore highest turnover time, will define the longevity of the jam. By definition, this piece is stable and therefore resistant to major physical breakdown. After a significant lag time ( $\sim 10^{2}$ years), biological decay will weaken the key member enough to make it susceptible to physical fragmentation and export.

\subsection{Relationship to Hydraulics}

The evolution of a debris jam from a single key member to a complete jam is accompanied with a progression of hydraulic changes. With the addition of material, total jam size, volume, and porosity change at different rates. The ability to predict the geomorphic and ecologic changes associated with the changing composition of the jam requires a mechanistic understanding of the relationship between jam composition and structure with local hydraulics. Currently, our ability to make these predictions is limited to single-log models studied in environmentally controlled settings. Many studies have focused on the effect of the position of a log in a channel on the drag coefficient (Wallerstein et al 2002, Hygelund and Manga 2003, and Shields and Gippel 1995). Other studies observed the scour patterns associated with the single log (Cherry and Beschta 1989; Marsh et al 2001). While these studies are a first step and have been corroborated in the field for single logs or key members (Lisle 1986; Meleason et al 2005), their adaptation to complex debris jams is problematic. The assumption that jams can be treated as single solid objects was tested by Manners et al (In Review). They found that such an assumption results in a $20 \%$ overprediction of the drag force on the jam, translating to a $75 \%$ over-prediction in maximum 
shear stress values on the bed. Additionally, the difference between the hydraulics of a single $\log$ or key member and a complete jam was investigated by Manners et al. who found that the increase in the drag force between the key member and the complete jam ranged from a factor of three to two orders of magnitude. Their findings highlight the complex nature of natural jams and the need for more work to be done on the relationship between jam composition and the local hydraulics.

\section{Theoretical Jam Evolution}

We can hypothesize that in a river reach characterized by neither transport or supply limitations, jam evolution is a non-linear process which with time, volume and drag force increases and porosity decreases in four phases (Figure 3.3). Upon recruitment, a key member is adjusted within the first high flow event by changing its angle to flow or a change to the bed, reducing its drag force and resulting in stabilization (I). The location of the key member in the water column and its size relative to the flow depth dictates both the initial drag force and the number of pieces required to establish a framework of large mobile pieces (pieces whose length is great enough to span the key member's bankfull depth and diameter large enough to resist breakage once lodged on the key member). The addition of these large pieces adds a significant amount of volume, but does not decrease porosity greatly (II). Drag force increases during phase II similar to the increases in volume, with slight adjustments

after each incremental addition of wood. Once the porosity reaches a threshold, a function of the ratio between flow able to pass through the jam to the available surface on which wood medium wood pieces $(1 \mathrm{~cm} \leq \mathrm{d}<10 \mathrm{~cm}$ ) can accumulate on, medium pieces mixed in with small wood $(\mathrm{d}<1 \mathrm{~cm})$, leaves and sediment may begin to fill the spaces. These additions are 
gradual and decrease porosity at a faster rate than they add volume (III). It is likely that a jam reaches a stable size and volume where the porosity has been significantly reduced so that water is routed around the jam, inhibiting further accumulation of material. Once in phase IV, the drag force adjusts to the complete jam's volume and porosity and remains constant. After stabilizing, changes are expected in the volume slightly changing both the porosity and volume (IV). These minor fluctuations may be due to the seasonal inputs of leaves and small twigs or the breakdown and fragmentation of small to medium wood pieces. The lifetime of a jam, barring any extreme flood event or significant channel migration, depends on the durability of the key member whereas the character (hydraulic functioning) depends on the dynamics of the smaller pieces.

\section{Case Study: Jam Evolution and the Change in Hydraulics}

Data collected on the evolution of three debris jams on the Indian River in the Adirondack Mountains, New York, provides a basis to evaluate the mechanistic evolution of a debris jam and make predictions about how the sequential accumulation of woody debris relates to the local hydraulics. Three naturally formed debris jams were systematically removed in 2-3 stages representing the stages in the evolution of a debris jam, including the key member (phase I), a framework (phase II) and a complete jam (phase III/IV) (for details

on this process see Manners et al In Review) (Figure 3.4). Each piece of wood removed was measured for its length and diameter. The piece-size distributions in each jam (Figure 3.5) represent those pieces with diameters greater than $1 \mathrm{~cm}$. Additionally, the drag force was quantified during a bankfull event for each phase measured (Table 3.3). 


\subsection{Piece-Size Distributions}

The specific distributions differed in their shape indicating a difference in sorting (Figure 3.5, Table 3.2) quantitatively described by a sorting coefficient:

$$
C_{S}=\sqrt{\frac{P_{84} / P_{16}}{}}
$$

where $C_{S}$ is the sorting coefficient describing the spread of piece sizes, $P_{84}$ is the variable measuring individual piece size representing the $84^{\text {th }}$ percentile of the distribution, and $P_{16}$ is the variable measuring individual piece size representing the $16^{\text {th }}$ percentile of the distribution where $P_{84}$ and $P_{16}$ indicate the value of which $84 \%$ and $16 \%$ of the population are smaller. Diameter $(d)$, volume $(V)$ and surface area $\left(A_{\text {surf }}\right)$ are used to describe the piece size populations. For sediment sorting, it is conventional to characterize populations as "poorly sorted" if their sorting coefficient is greater than 1. For all three parameters used, sorting coefficients exceeded 1.0 ranging from 1.47 to 4.83 , indicating that there existed a wide range of sizes of wood pieces on all three jams, yet the degree to which these populations were sorted differs.

Diameters had the smallest sorting coefficients, all of which were very similar (jam 1 $=1.50$, jam $2=1.47$, jam $3=1.69)$. Both surface area and volume distributions had high $C_{S}$ values because they are a function of both length and diameter. Surface area $C_{S}$ values were the same for jams 1 and 3 (2.24) and slightly higher for jam 2 (2.74). The range in $C_{S}$ values for volume was greater. Jam 2 had the highest $\mathrm{C}_{\mathrm{S}}$ (4.83), then jam 3 (3.16) and jam 1 (2.98). The similarities in $C_{S}$ within each of the three parameters are highlighted in the curves where all three jams have similar shapes (Figure 3.5). Their placement along the $\mathrm{x}$-axis is indicative of the percentile values so that $d_{16}, d_{50}$ and $d_{84}$ were all less for jam 2 than they were for jams 1 and 3 (Figure 3.5, Table 3.2). The notable exception is for jam 2 in both surface area and 
volume where the higher percentile of jam 2's distribution cuts to larger values. The greater $V_{84}$ and $\mathrm{A}_{\text {surf84 }}$ values for jam 2 explain the high $C_{S}$ for both parameters.

\subsection{Key Member Effects}

It can be hypothesized that the change in drag force is a function of the compositional state of the jam, where the previous stage dictates the form of the next stage and therefore the magnitude of drag force change. To begin with, the key members of these three jams differed in size and elevation off the bed. Jam 1 had the smallest key member $(\mathrm{d}=18 \mathrm{~cm}$ length $=7.4$ m) which was steeply angled off the bed. The increase in drag force from $0.2 \mathrm{kN}$ as a key member to $10.1 \mathrm{kN}$ as a complete jam contrasts with those changes observed on jams 1 and 2 (19.9 $\mathrm{kN}$ to $62.7 \mathrm{kN}$ and $11.6 \mathrm{kN}$ to $15.1 \mathrm{kN})$ which had larger key members $(\mathrm{d}=25 \mathrm{~cm}$ and length $=7.5 \mathrm{~m}, \mathrm{~d}=50 \mathrm{~cm}$ and length $=13.6 \mathrm{~m}$ respectively) located either on the bed or with a small amount of space.

\subsection{Piece-size Effects}

Jams 1 and 2 were removed in a way to simulate the transition from phase I to phase II, from key member to large wood framework, and phase II to phase IV, from the framework to the complete jam (Figure 3.4 and 3.6). Volume, porosity and drag force were quantified and are represented in a similar manner to figure 3.5 (Figure 3.6). The volume is the total volume of all pieces of wood $\left(\mathrm{m}^{3}\right)$ on the jam for the defined phase. The porosity is a ratio of the space open for flow and the space that is occupied by woody material solved for by:

Porosity $=\frac{\left(V_{C J}-V_{\text {PHASE }}\right)}{V_{C J}}$ 
where $V_{C J}$ is the volume of the complete jam within the bankfull channel and $V_{\text {phase }}$ is the volume of wood found on the jam for the phase in question. Values range from 0 to 1 where higher values represent a structure where water may flow through easily while lower values are structures with little space for water to flow. Both jams 1 and 2 have similar trajectories in their evolutionary path, with increasing volume and drag force accompanied by a decrease of porosity. Drag force and volume are closely linked (Manners et al In Review). The difference between the two jams was the magnitude of change they experience. While it was expected that jam 1 would have greater volume and therefore a greater drag force because of its larger key member, the magnitude of the difference was much greater for jam 1. Given that both of these jams began with relatively similar key member positions, the differences in the drag force from one phase to the next can be attributed to the piece size distributions. From the first to second phases of jam evolution on jam 1 drag force increased $(19.9 \mathrm{kN}-23.9$ $\mathrm{kN})$ but not as significantly as it did between the phase II and phase IV $(23.9 \mathrm{kN}-62.7 \mathrm{kN})$. This is explained by the fact that jam 1 had generally large wood pieces (Table 3.2) which initially created a matrix in which large holes existed, causing only minor increases in the hydraulics. The volume nearly doubled $\left(5.2 \mathrm{~m}^{3}\right.$ to $\left.9.6 \mathrm{~m}^{3}\right)$ and the porosity decreased by $25 \%$ ( 0.77 to 0.57$)$. Jam 1 also had a variety of wood piece sizes which were able to then fill those holes (Table 2), thereby increasing the drag force by a factor of three. From phase II to phase IV, volume increased $30 \%\left(9.6 \mathrm{~m}^{3}\right.$ to $\left.12.7 \mathrm{~m}^{3}\right)$ and was also accompanied by a $25 \%$ decrease in porosity $(0.57$ to 0.43$)$.

Jam 2 on the other hand has smaller pieces, notably smaller diameters in the higher fraction of the distribution (Table 3.2) Therefore, the initial recruitment of wood pieces (phase II) produced a more compact framework where the increase in volume was 
accompanied by a more steady decline in porosity resulting in the gradual increase in drag force (from $11.6 \mathrm{kN}$ to $14.4 \mathrm{kN}$ to $15.1 \mathrm{kN}$ ). From phase I to phase II volume nearly doubled $\left(1.4 \mathrm{~m}^{3}\right.$ to $\left.2.5 \mathrm{~m}^{3}\right)$ with a $10 \%$ drop in porosity $(0.88$ to 0.79$)$. Then from phase II to phase IV volume increased $20 \%$ (2.5 to $3.0 \mathrm{~m} 3$ ) and porosity decreased by less than $10 \%(0.79$ to $0.74)$.

\subsection{Conclusions}

This case study has afforded a mechanistic view of the process of jam evolution and its relationship to the localized hydraulics. The data presented here suggest that debris jam evolution is mediated by key member characteristics and piece-size distributions so that the accumulation of material is dependent on the degree to which a jam has open space through which water can flow and wood pieces will become "filtered" out. While the data from jams 1 and 2 fit the evolution model well, it is not possible to fill in the temporal controls. It can be hypothesized that the time it takes for a debris jam to evolve and make the transition between phases depends on certain environmental factors such as the material present both in the channel and on the floodplains and the magnitude and frequency of mobilization events. Additionally, defining the phases for these natural jams in order to collect the data presented here was somewhat of a subjective exercise requiring good judgment by the researchers. The limited data and the subjective nature of its collection means that while the results are a first step towards defining the mechanisms through which a debris jam evolves, much more work must be done. 


\section{Management and Restoration Recommendations}

In the early part of the last century, a priority of river management strategies was the removal of woody debris from the channels and floodplains because it was thought that wood prohibited fish passage and increased flooding risks. Since Keller and Swanson (1979)'s seminal paper on the geomorphological benefits and Bilby and Liken (1980)'s paper on the ecological benefits of wood, research on the role of woody debris in rivers was popularized accompanying a paradigm shift in management strategies. Current practices seek to restore the natural dynamics of wood in rivers where they may be degraded through changes in landuse or a history of removal. Additionally, the benefits of woody debris are now used as a means of accomplishing management and restoration goals, notably the creation of in-stream habitat. Given that wood will naturally accumulate and form debris jams and that the debris jam is more morphologically and ecologically productive than a single wood element, incorporation of the debris jam into management and restoration plans is generally preferred.

Therefore, the above review of the literature outlining the controls on debris jam evolution can aid managers and restoration practitioners in the design and implementation of wood-based restoration projects. From what we know about the evolution of a debris jam the following are applicable to restoration goals:

1) A key member will accumulate wood and become a debris jam. Wood structures installed as single logs may fail due to the accumulation of additional material through time. If the reach is neither transport nor supply limited, it should be expected that mobile debris will accumulate on the installed structure. 
2) Riparian vegetation is essential for the evolution of a debris jam. Whether a design incorporates the natural recruitment of mobile wood into its design or relies on the delivery of wood for the maintenance of a debris jam, a selfreplenishing wood population is necessary. Restoration goals and practices may need to expand to meet in-stream objectives including riparian restoration and preservation.

3) Upstream conditions dictate the evolution of a debris jam. Wood-based restoration requires the characterization of conditions, both locally and within upstream reaches. Where wood is mobile, upstream inputs exert greater controls than local riparian conditions.

4) Forces are underestimated if a debris jam is treated as a key member. Most of the work done on the hydraulics of wood has focused on single logs similar to a key member. The mechanisms do not scale to a debris jam and the accumulation of material alters the forces on the structure. Not taking these changes into account could result in structural failure or unwanted scour.

5) The evolution of a debris jam may be predictable. Based on the model of jam evolution and supported by the findings of the case study, the current composition of a debris jam may dictate the accumulation and rate of change of the drag force on that debris jam. This predictive ability allows for more precise design of wood structures based on local wood supply. With proper characterization of the wood piece population and hydrologic regime, a wood structure may be designed to accumulate and grow in a predictable way. For example, it is possible to build a structure consisting of a key member and a framework of wood and expect that it 
will accumulate additional wood decreasing its porosity and increasing its volume and the drag force on it. The Nechako Fisheries Conservation Program has been using a similar model for nearly 15 years with promising results (Triton 1996).

\section{Conclusions}

This paper has investigated the dynamics of woody debris in the context of debris jam evolution. The tendency of woody debris to accumulate into a coherent structure has been adapted by the restoration industry because of its effectiveness in causing morphological change and providing ecological benefits. While previous studies have studied the dynamics of woody debris in terms of the controls on its loading values at the watershed- and reachscale, the movement of wood through a watershed, and the hydraulics of individual pieces of wood, there is a deficiency in the dynamics of woody debris as it relates to the debris jam. Based on a review of the literature, better characterization of piece-size distributions, debris jam porosities, and the relationship between jam composition and its hydraulics are needed. A theoretical model of debris jam evolution was proposed and supported with data from three debris jams. The results from the case study suggest that the piece-size distribution of the wood supply acts as a control on the accumulation of material including the degree of change in porosity and drag force. More detailed work must be done in order to understand these complex relationships and the controls on debris jam formation and evolution. 
Term

Accumulation
Angle
Complete Jam
Composition
Debris Jam
Decay
Biological
Physcial
Density
Evolution
Framework
Key Member
Mobile Wood

Porosity

Recruitment

Retention

Small, Medium and Large Wood

Turnover Time

Wood Availability

Woody Debris

Wood Loading

volume

biomass
Table 3.1:

Wood vocabulary

Description

The recruitment of wood pieces to form a jam

Degrees off flow. Perpindicular to flow is zero.

Complete barrrier to water and sediment

Total number of pieces of varying sizes within a jam

hetergeneous structure of logs, branches, root boles, and

twigs of various sizes that have been transported and deposited as discrete accumulations by the river

wood pieces lodged against the key member providing structural integrity

a large stable log which can initiate an accumulation of wood into a debris jam

Wood pieces capable of being transported fluvial generally a function of piece angle relative to flow direction, the presence of a rootwad or branches, piece density and diameter

Ratio of open volume to volume filled with wood

The input of wood due from one of two directions: 1) laterally due to bank erosion, windthrow or landslides 2) upstream due to fluvial transport

The ability for a reach or jam to withold organic material.

Defined by diameter. Differs from one study to the next. Here defined as: $d<1 \mathrm{~cm}$ small, $1 \leq \mathrm{d}<10 \mathrm{~cm}$ medium, $d$ $\geq 10 \mathrm{~cm}$ large

1) Reciprocal of $k$ (loss of mass due to biological decay from a single piece)

2) Total wood/Flux of wood: in a steady state system, its equal to individual wood piece turnover time

Total number of pieces of varying sizes within a reach

Dead wood found within or along a river channel

Reported as volume of wood (m3) per area $(\mathrm{m}-2)$. Common range 0.001 to $0.1 \mathrm{~m} 3-2$

Takes into account density of volume of wood $(\mathrm{kg} \mathrm{m}-2)$
Gurnell et al 2000; Thevenet et al 1998; Abbe and Montgomery 2003; Nakamura and Swanson 1993

Harmon et al 1986

Van Sickle and Gregory 1990

Harmon et al 1986; Thevenet et al 1998; Braudrick and Grant 2000

Abbe and Montgomery 2003

Abbe and Montgomery 2003

Piegay 1993; Piegay and Gurnell 1997

Webb and Erskine 2005

Gregory et al 1985

Abbe and Montgomery 2003; Pettit et al 2005

Braudrick and Grant 2000

Manners et al In Review; Thevenet et al 2004; Monzyk et al 1997

Nakamura and Swanson 1993;

Murphy and Koski 1989; Martin and

Benda 2001; VanSickle and Gregory 1990

Diez et al 2000; van der Nat et al 2003; Speaker et al 1984

Murphy and Koski 1989; Wallace et al 2000; Manners et al In Review

Spanhoff and Meyer 2004

Diez et al 2000; Hyatt and Naiman 2001; Murphy and Koski 1989; Wallace et al 2000

Keller and Swanson 1979; Jackson and Sturm 2002; Gurnell et al 200; Berg et al; Webb and Erskine 2005

Lienamper and Swanson 1987; Gippel et al 1996; Gurnell et al 2002

Keller and Swanson 1979; Swanson et al 1984; Gurnell et al 1995 
Table 3.2:

\section{Wood piece distributions}

\begin{tabular}{|c|c|c|c|}
\hline \multirow[b]{3}{*}{$A_{\text {surf16 }}$} & Jam 1 & Jam 2 & Jam 3 \\
\hline & \multicolumn{3}{|c|}{ Surface Area (Asurf) m2 } \\
\hline & 0.09 & 0.04 & 0.06 \\
\hline$A_{\text {surf50 }}$ & 0.18 & 0.09 & 0.1 \\
\hline$A_{\text {surf84 }}$ & 0.45 & 0.3 & 0.3 \\
\hline \multirow[t]{2}{*}{$\mathrm{C}_{\mathrm{s}}$} & 2.24 & 2.74 & 2.24 \\
\hline & \multicolumn{3}{|c|}{ Volume (V) m3 } \\
\hline $\mathrm{V}_{16}$ & 0.0009 & 0.0003 & 0.0005 \\
\hline $\mathrm{V}_{50}$ & 0.002 & 0.001 & 0.001 \\
\hline$V_{84}$ & 0.008 & 0.007 & 0.005 \\
\hline \multirow[t]{2}{*}{$\mathrm{C}_{\mathrm{s}}$} & 2.98 & 4.83 & 3.16 \\
\hline & \multicolumn{3}{|c|}{ Diameter (d) cm } \\
\hline$d_{16}$ & 4 & 3 & 3.5 \\
\hline$d_{50}$ & 5 & 3.5 & 6 \\
\hline $\mathrm{d}_{84}$ & 9 & 6.5 & 10 \\
\hline $\mathrm{C}_{\mathrm{s}}$ & 1.50 & 1.47 & 1.69 \\
\hline
\end{tabular}


Table 3.3:

Drag force (kN) on each jam for each phase

\begin{tabular}{c|ccc|}
\multirow{2}{*}{ Key Member (Phase I) } & Jam 1 & Jam 2 & Jam 3 \\
\cline { 2 - 4 } Framework (Phase II) & 19.9 & 11.6 & 0.8 \\
& 24.2 & 14.4 & - \\
Complete Jam (Phase III/IV) & 62.7 & 15.1 & 7.8 \\
\cline { 2 - 4 } & &
\end{tabular}


Figure 3.1:

Schematic of the controls on the evolution of a debris jam

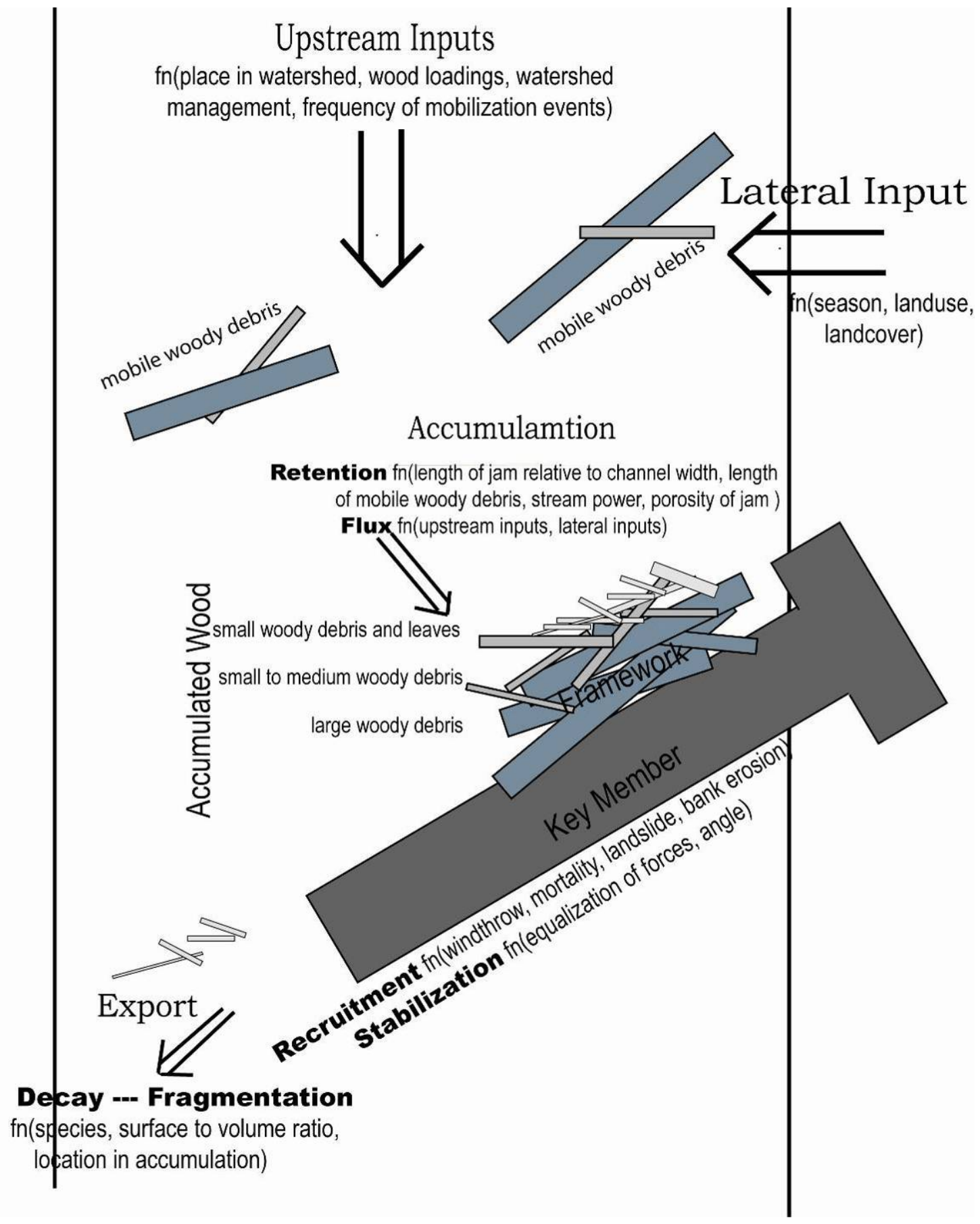


Figure 3.2:

Piece-size distributions from various studies
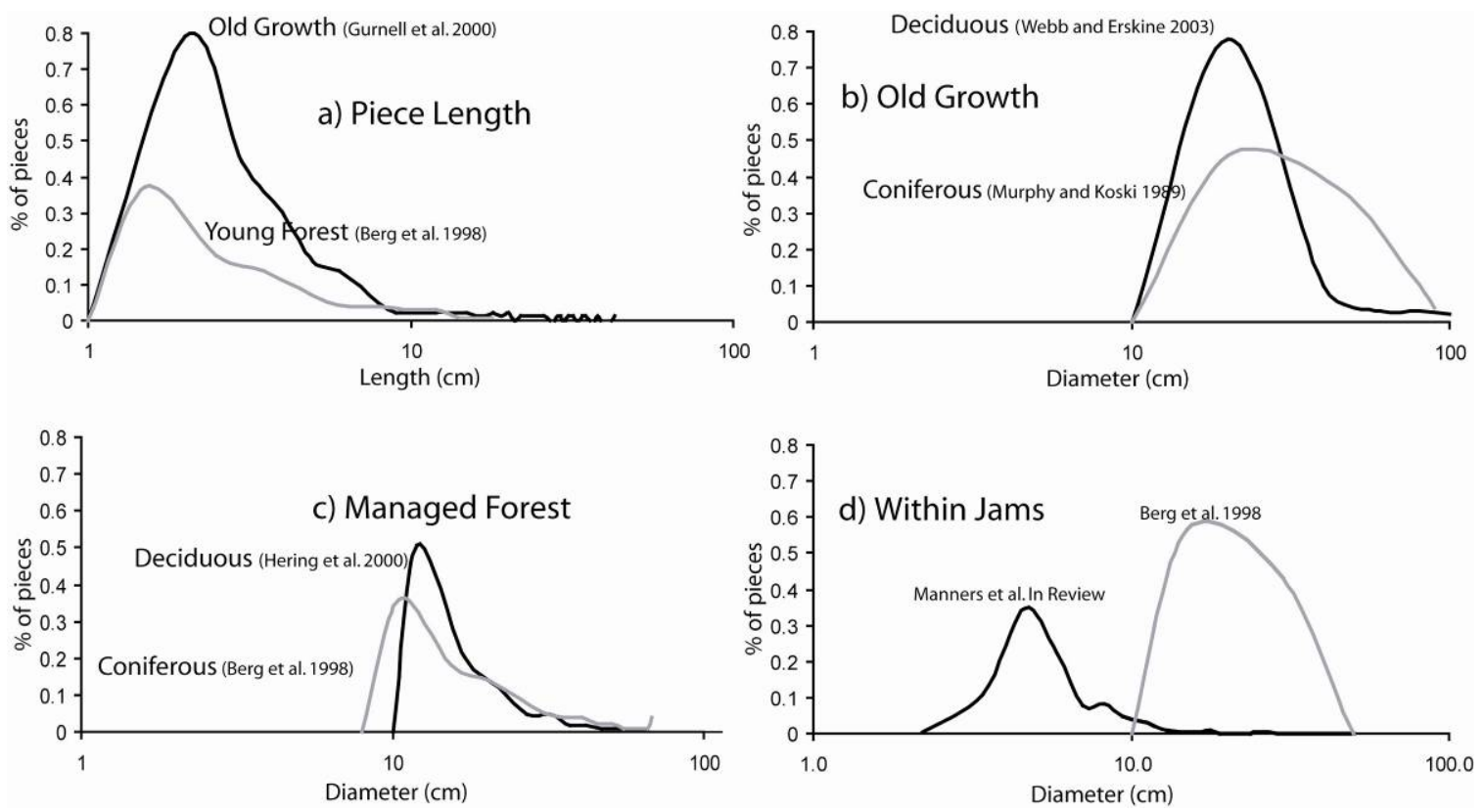
Figure 3.3:

Theoretical evolution of a debris jam

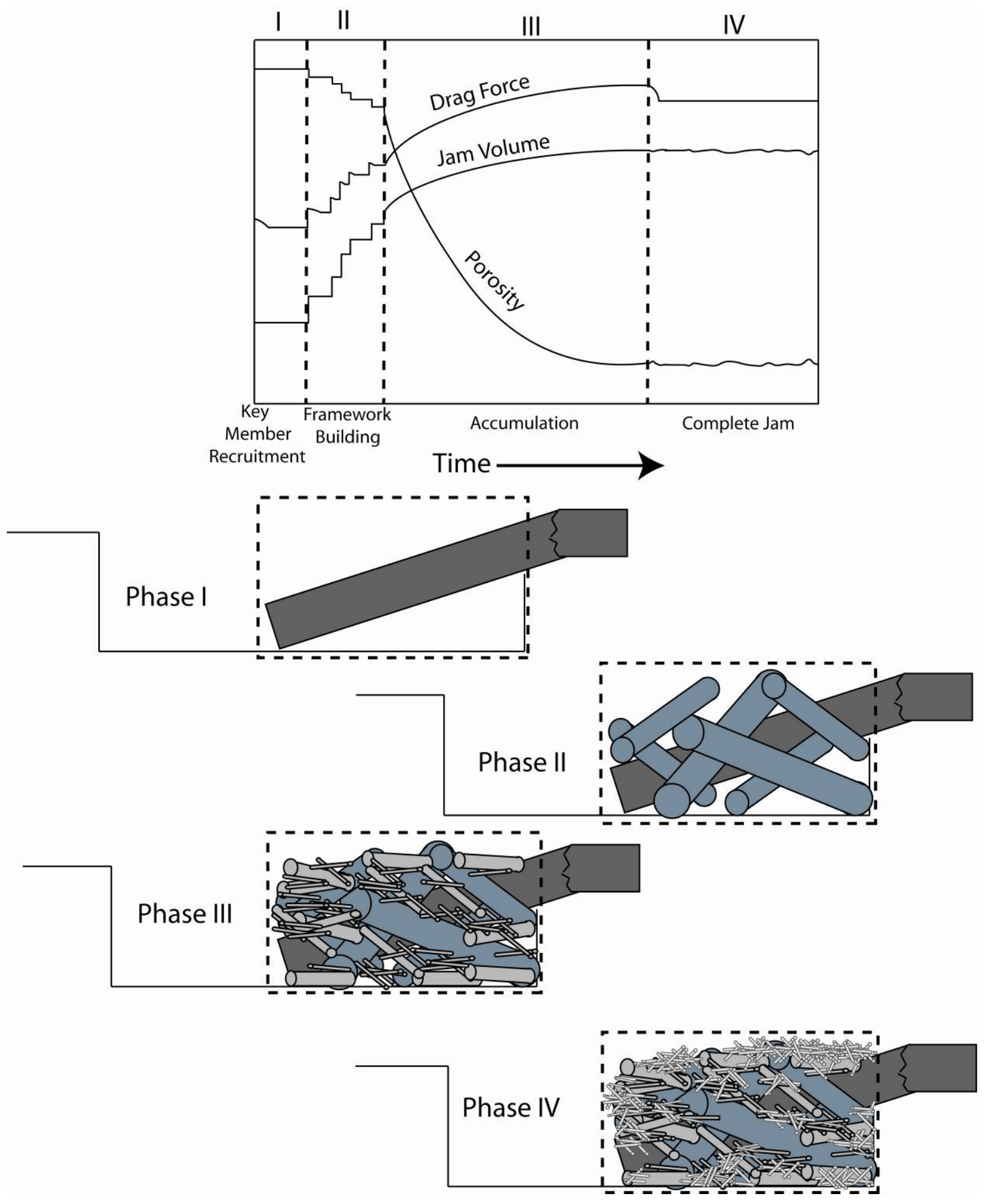


Figure 3.4:

Photographs of jam 1 at the different phases of evolution
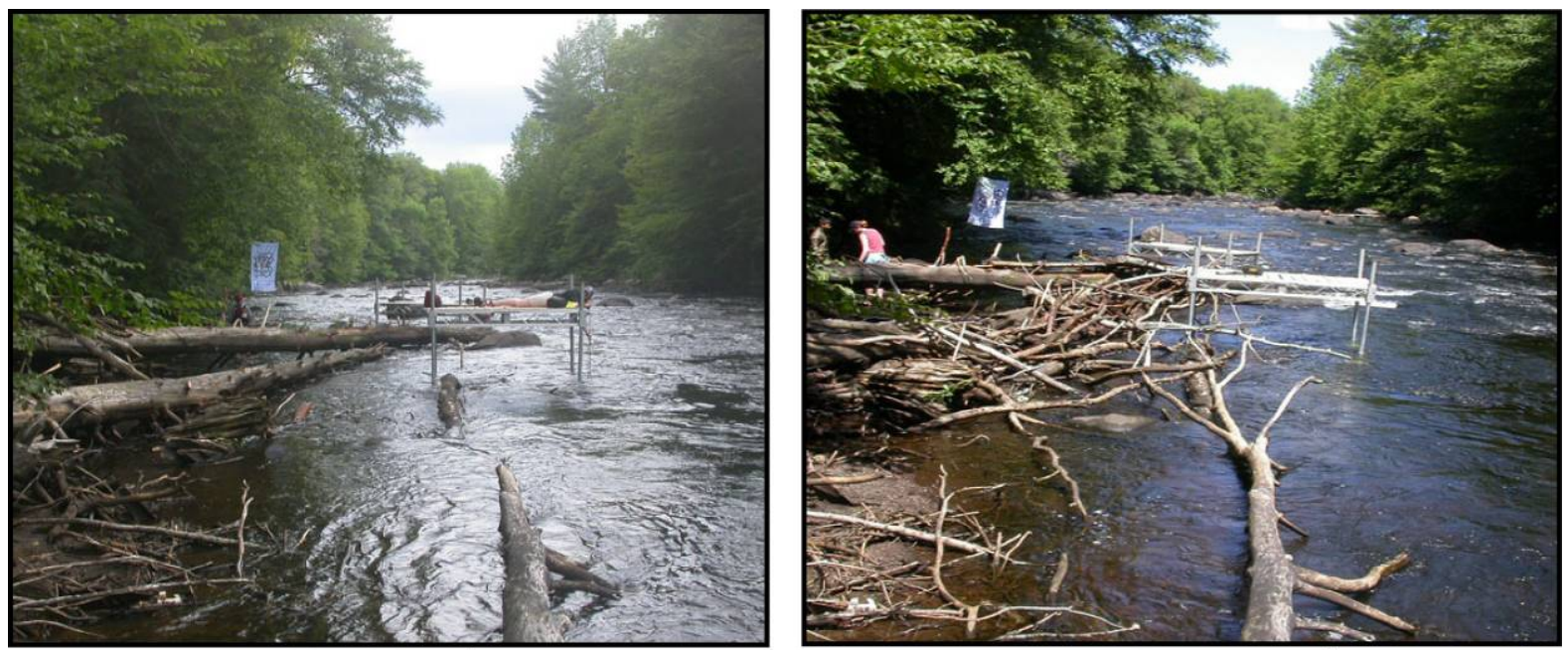

Key Member

Phase I

Complete Jam

Framework

Phase III/IV

Phase II

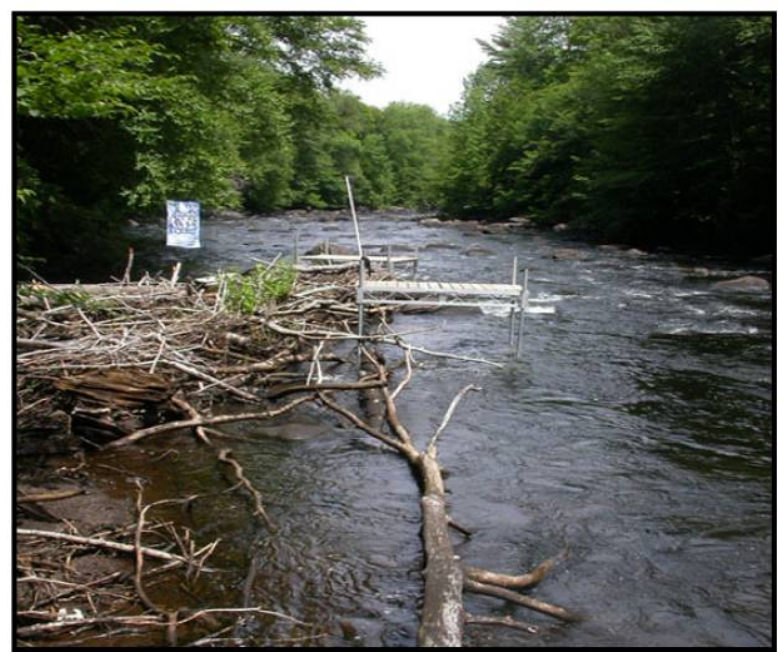


Figure 3.5:

Piece-size distributions for wood pieces with diameter greater than $1 \mathrm{~cm}$ found on the three jams studied on the Indian River

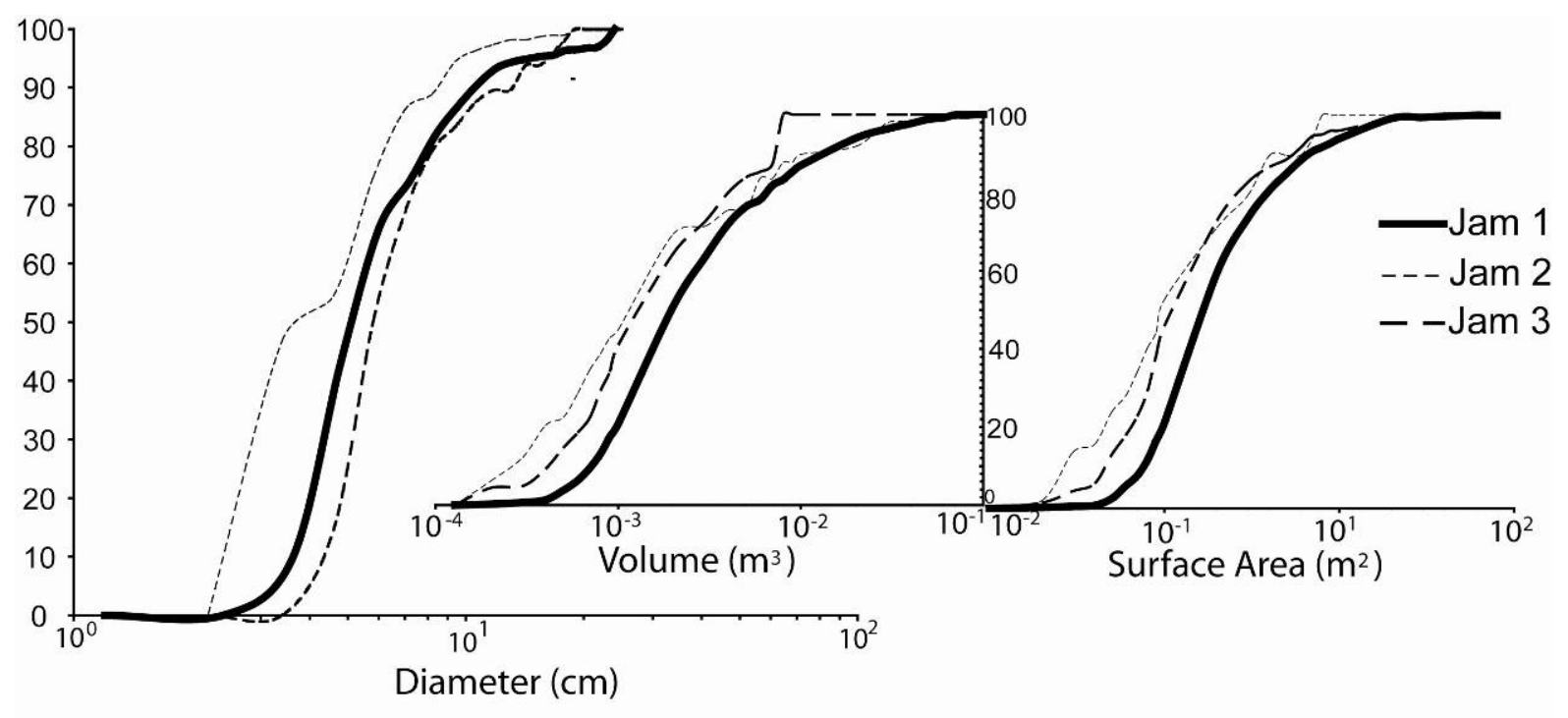


Figure 3.6:

Evolution of jams 1 and 2
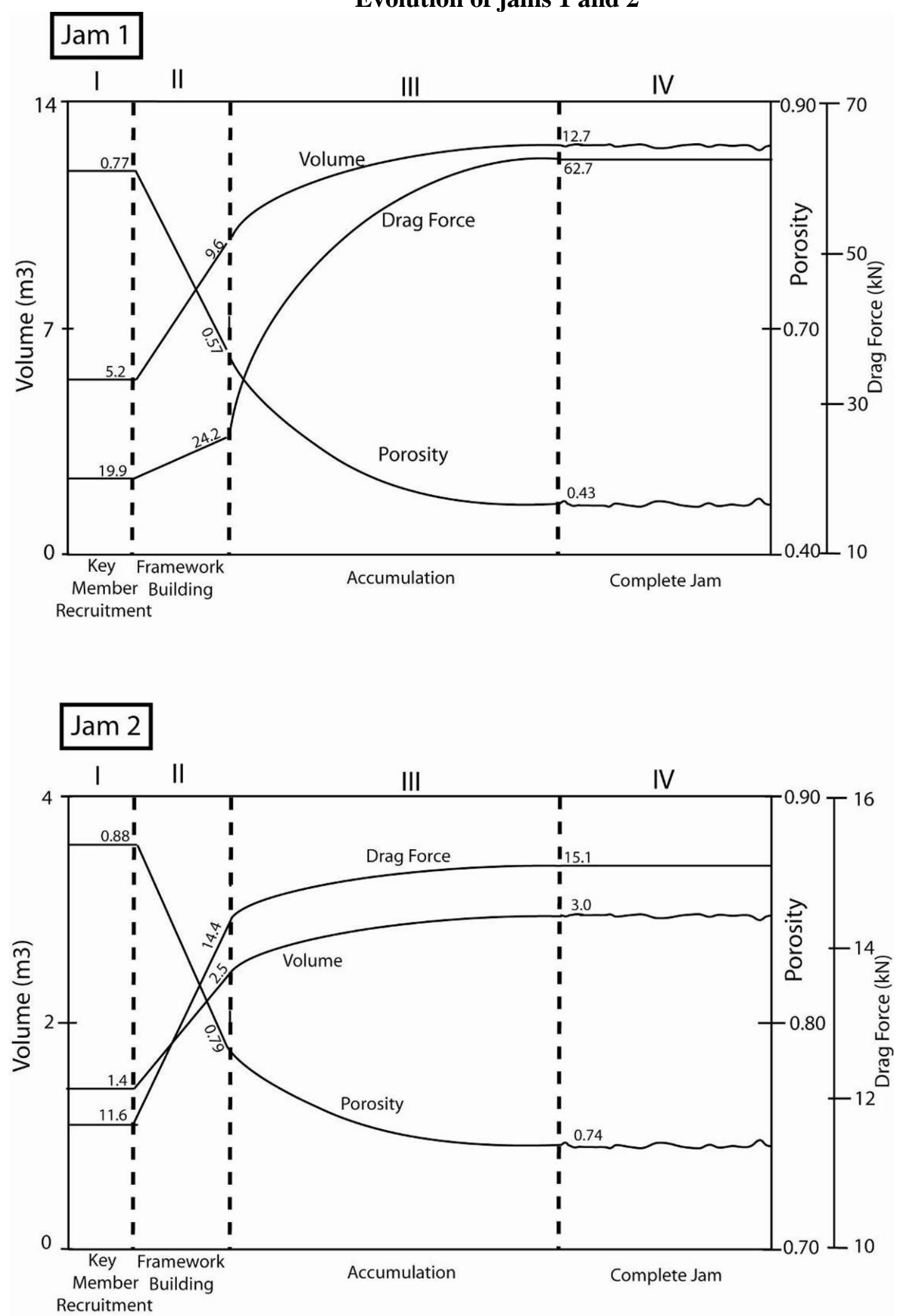


\section{CHAPTER IV:}

\section{SUMMARY OF FINDINGS AND FUTURE RESEARCH DIRECTIONS}

This document is based on the idea that a debris jam is a complex and porous structure formed through the accumulation of a variety of wood piece sizes whose structure and composition are related to its hydraulics. The nature of debris jam formation means that both the composition and hydraulics of a debris jam will change through time. Through a mixture of field-based experiments, modeling, and a literature review, this document adds to our understanding of the natural dynamics of woody debris. By treating debris jams as accumulations of material, instead of single-solid objects, this document provides a unique way of conceptualizing their hydraulics and the controls on their formation and persistence as influential structures in the fluvial environment. The findings of this study are summarized below:

1) Debris jams are porous structures and treating them as single-solid objects overpredicts their drag force by $20 \%$.

2) The difference in the drag force of a key member and a complete debris jam ranges and may be as high as two orders of magnitude difference. The location of the key member with respect to flow mediates this change, so that the drag force on key members close to the bed will have a lower magnitude of change when woody debris accumulates and forms a jam. The findings of the drag on key members are consistent with previous studies which have reported on the hydraulics of single-log models. 
3) Because natural debris jams are poorly described as cylinders due to their irregular, porous, and three-dimensional structure, the frontal area $\left(A_{F(e m p)}\right)$ term in the drag equation loses its meaning. Similarly, the drag coefficient $\left(C_{D}\right)$ previously has been solved for a two-dimensional non-porous object (eg. cylindrical rods), does not describe a debris jam. Back-calculated values of $\left(C_{D} A_{F}\right)_{\text {calc }}$ represented the drag form character of natural debris jams. Using $\left(C_{D} A_{F}\right)_{c a l c}$ acknowledges that both $C_{D}$ and $A_{F(e m p)}$ have a combined effect on drag, but their individual contributions are less important to know and likely to vary considerably between jams.

4) Surprisingly, both $F_{D}$ and $\left(C_{D} A_{F}\right)_{c a l c}$ can be explained by $A_{F(e m p) \text {, but it does not }}$ describe all of the variation as would be the case for a single-log model. In all, to describe $\left(C_{D} A_{F}\right)_{c a l c}$, one must have a metric representing the size of the jam and a metric representing the composition of the jam. Our results showed that either $A_{F(e m p)}$ or $V$ were interchangeable in describing $\left(C_{D} A_{F}\right)_{c a l c}$, and both are metrics of jam size. However, $A_{\text {surf }}$ had a separate impact on $\left(C_{D} A_{F}\right)_{c a l c}$, and we interpret this as $A_{\text {surf }}$ being a metric of the composition of the jam.

5) Wood-piece size in a debris jam dictates the surface area to volume relationship. This association in turn determines the rate at which $F_{D}$ and $\left(C_{D} A_{F}\right)_{c a l c}$ change, so that an increase in the size of a key member will result in a greater increase in drag than an increase in size of a debris jam which includes wood of all sizes and therefore higher surface area.

6) A model of debris jam evolution was proposed based on a review of previous literature. Debris jams evolve from key members to complete jams in four phases defined by the relationship between volume and porosity. Their evolution is mediated 
by the piece-size distributions which feedback on the localized hydraulics. Both key member characteristics (such as location in water column) and piece-size characteristics (such as the sorting) control the rate of change in volume, porosity, and drag force on a debris jam. Data on two natural debris jams that emulate this model support the proposed relationships between structure and hydraulics.

7) The life-span of a debris jam relies on the stability and resilience of its key member while it's the upkeep of its hydraulics (maintaining the same porosity and same drag force) relies on the flux of smaller mobile material. Once a debris jam has accumulated enough material to reduce its porosity enough to route enough water around the structure to prevent further growth, its maintenance relies on the delivery of small wood and leaves. High turnover times due to higher rates of biological decay and export from the jam equalized with the high transport rates of small wood indicates that wood jams are in a steady-state.

In the preceding chapters, I have shown that while we know a good deal about the dynamics of woody debris, there is still a deficiency in our understanding. The mechanisms by which debris jams form, the hydraulics associated with their formation, and the relationship between debris jam structure and hydraulics are not well understood. The findings from this thesis have begun to elicit these mechanisms. Furthermore, the results from this study have raised new questions and provided a new direction for research where a paucity of process-based studies contributes to this gap in understanding. Potential research directions include: 
1) Controls on debris jam formation. Working in a controlled setting, it may be possible to isolate what controls the delivery and retention of woody debris on a key member. Does the piece-size distribution within a reach influence the evolution of a debris jam? Does the existing composition of a debris jam dictate future accumulation of additional wood and the rate of change in drag force? Does porosity mediate this process?

2) Organization of debris within debris jams. The observation of a pattern of accumulation with large mobile wood creating a framework and smaller wood filling in the "holes" suggests that the evolution of a debris jam is a self-organizing phenomena. Collection of data on debris jams across a wide range of geographic settings under different geomorphic and hydrologic conditions may tease out these controls. Specifically, a database of piece-size distributions will help to further our understanding on the organization of woody debris into debris jams

3) Relationship between debris jam composition and hydraulics. This study has suggested a new way of investigating the hydraulics of a debris jam, moving beyond viewing it as a cylinder and incorporating the total volume and surface area of material within the jam. Based on the three debris jams, this study concluded that these variables of jam composition can describe drag force on a debris jam. These findings need to be corroborated by future studies.

4) Predicting geomorphic influences of debris jams. This study mapped out areas of excess shear stress, indicating that the maximum scour will occur at the lowest porosity at the tip of the debris jam. More work needs to be done on the relationship between woody debris jam composition and total scour and deposition. Empirical 
relationships from experimental work would allow for the prediction of the geomorphic effects of a debris jam and how that will shift with the evolution of a debris jam.

5) The effect of pore-size distribution versus total porosity on the drag force. While I have shown that the porosity of a debris jam influences the hydraulics, the values presented in this thesis are rough estimates of total porosity either used as a relative measure of open space, or quantified as the volume of open-space through which water may flow. Work done on flow through porous media, has focused on the influence of the pore-size distributions on the drag where drag is inversely proportional to the cube of the radius of the pore. This suggests that not only is the total porosity important in the determination of the drag force, but also the distribution of the open-space. Data on the piece-size distribution on a jam provides a rough estimate of this. Smaller wood pieces will reduce porosity and therefore have smaller pore sizes than larger wood pieces. Further work should be done to investigate the accuracy of this claim and the control of pore-size distribution on drag force. 
APPENDIX I:

PHOTO-DOCUMENTATION OF THE STAGES OF REMOVAL FOR THE THREE JAMS STUDIED ALONG THE INDIAN RIVER, NEW YORK

\section{Jam 1}

Low Flow
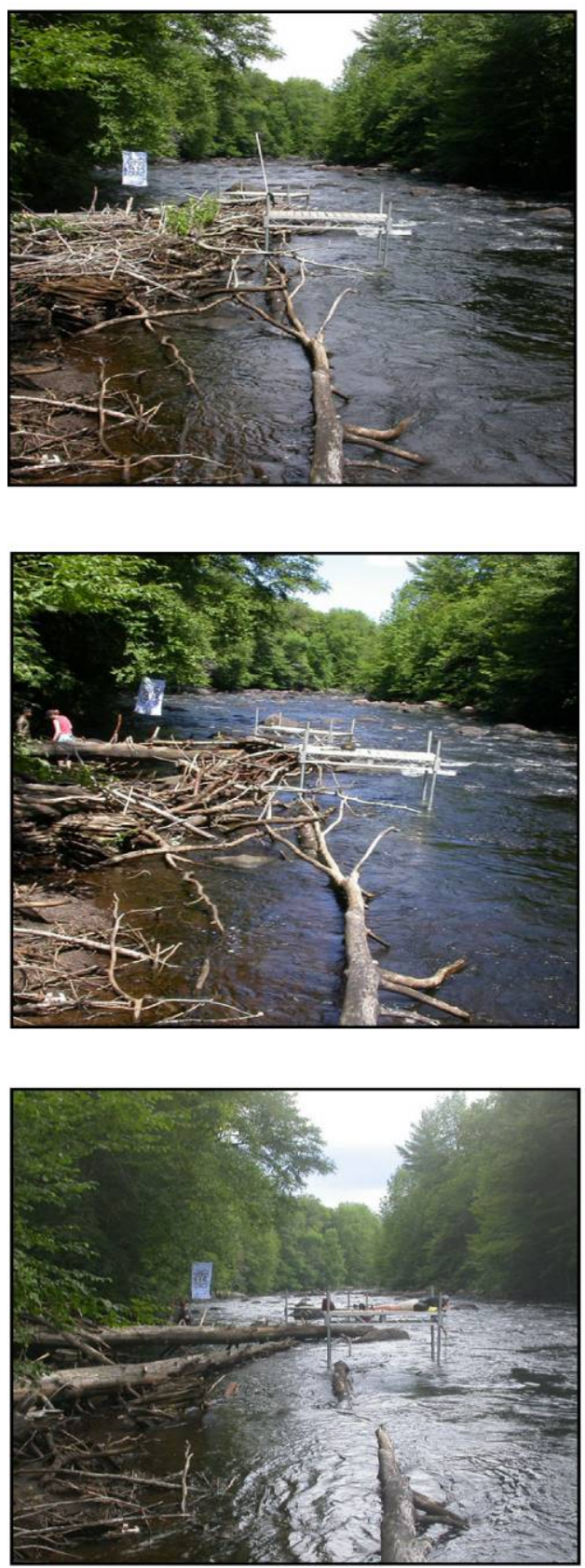

High Flow

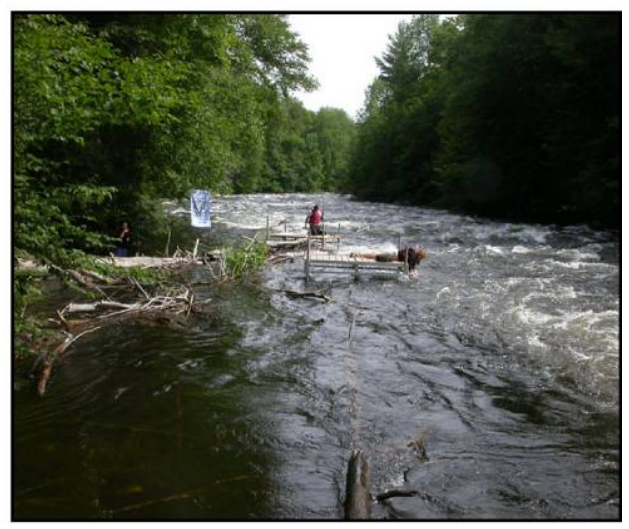

Stage C

Partial Jam

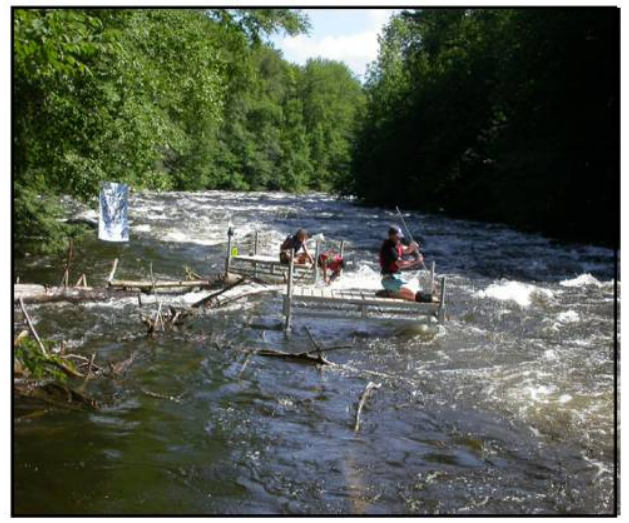

Stage D

Key Member

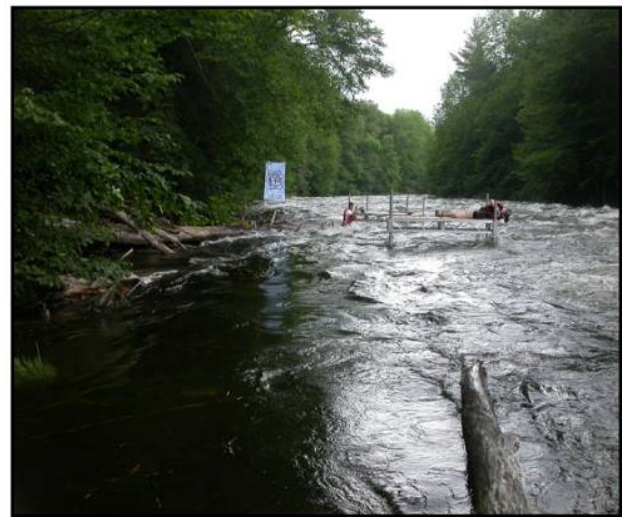




\section{Jam 2}

\section{Low Flow}
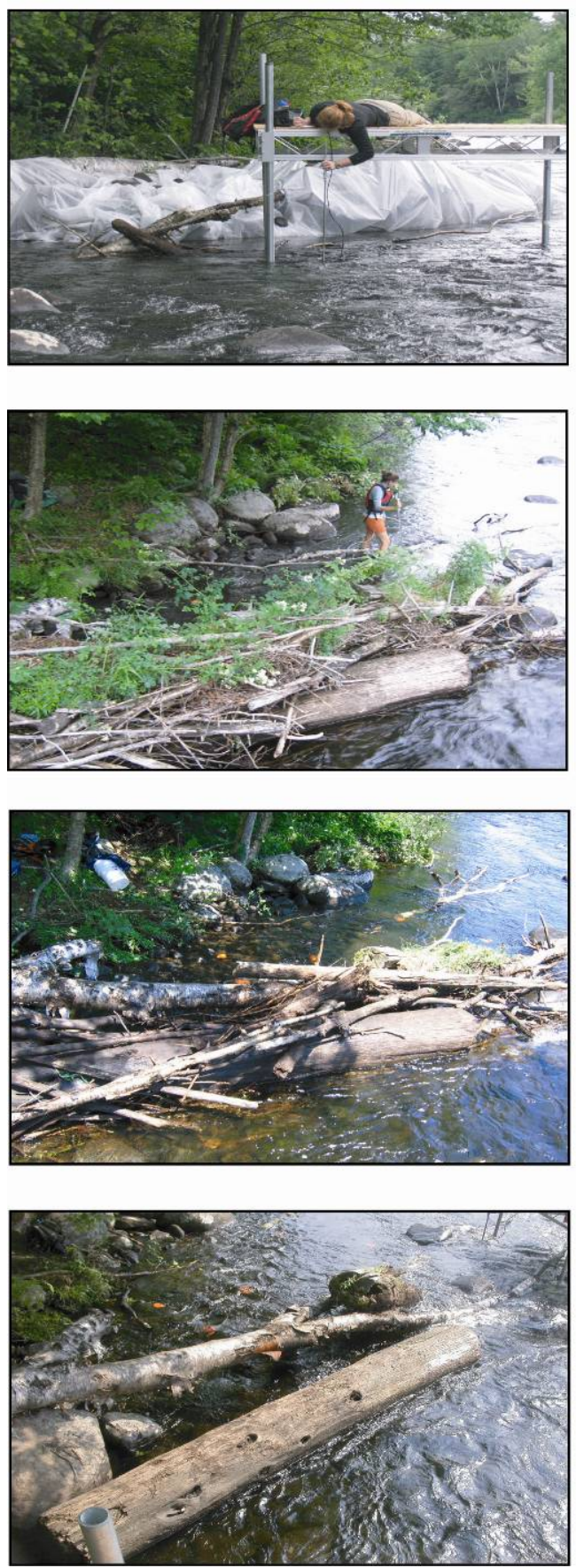

High Flow

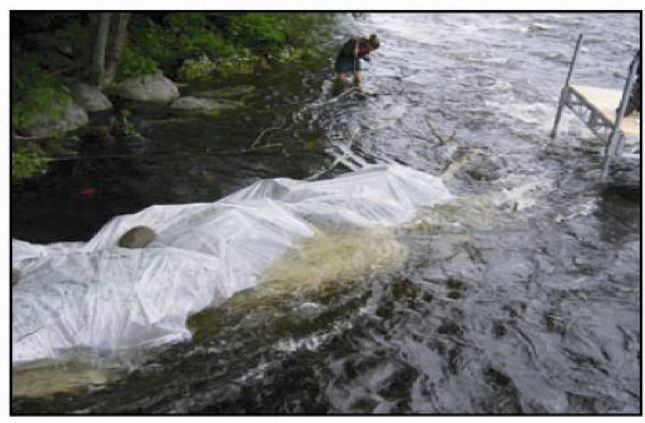

Stage B:

Natural Jam

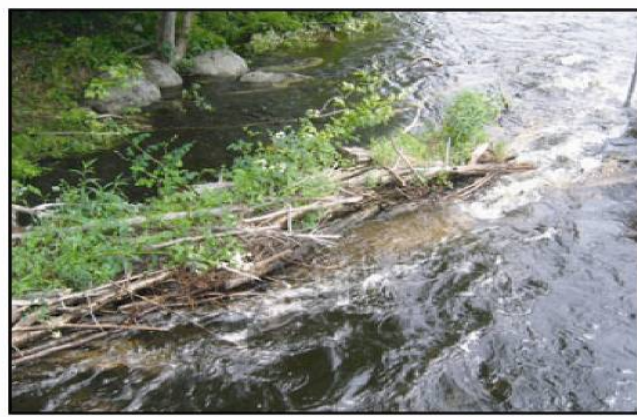

Stage C:

Partial Jam

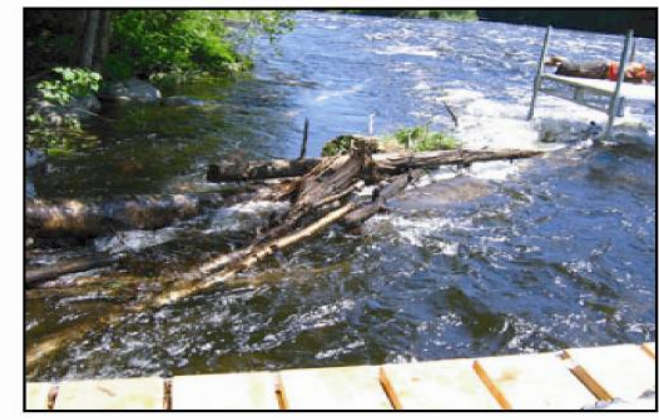

Stage D:

Key Member

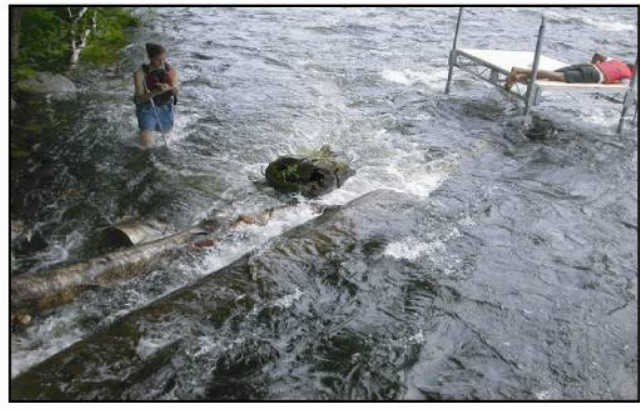




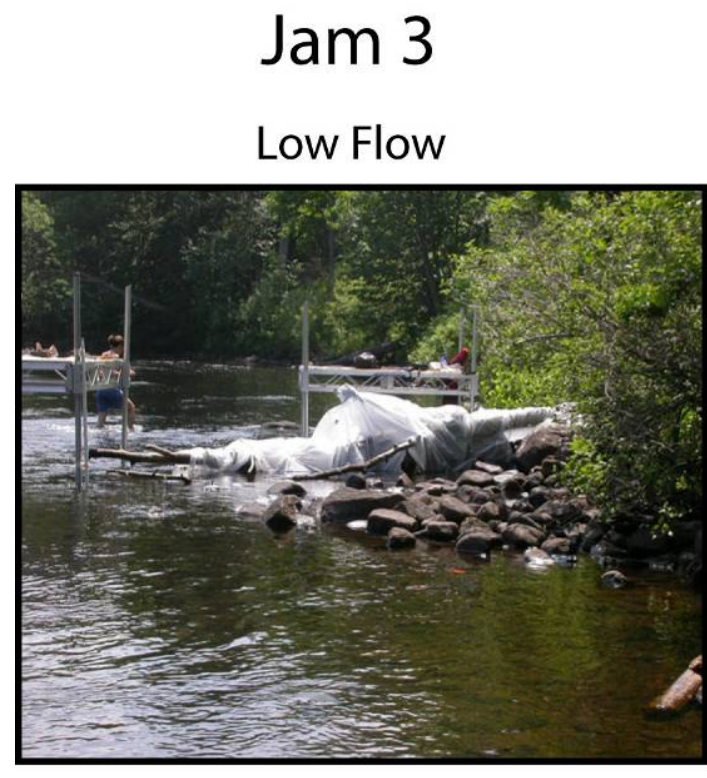

\section{Stage A \\ Wrapped Jam}

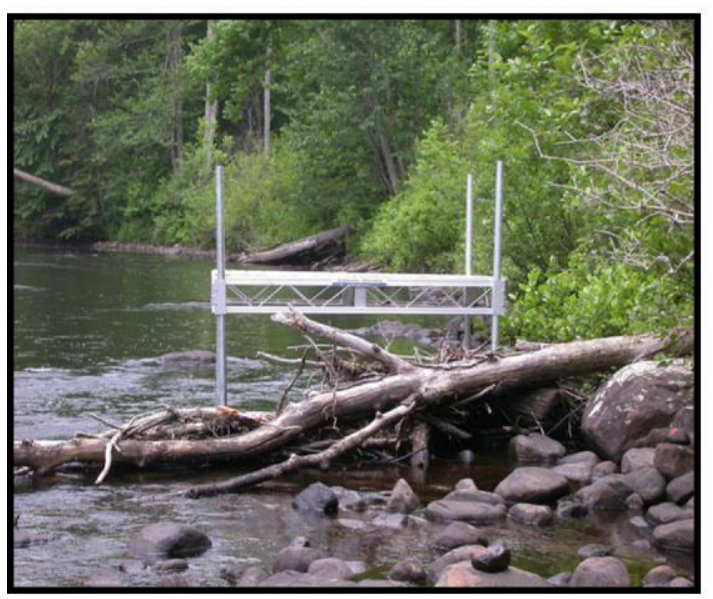

Stage B

Natural Jam

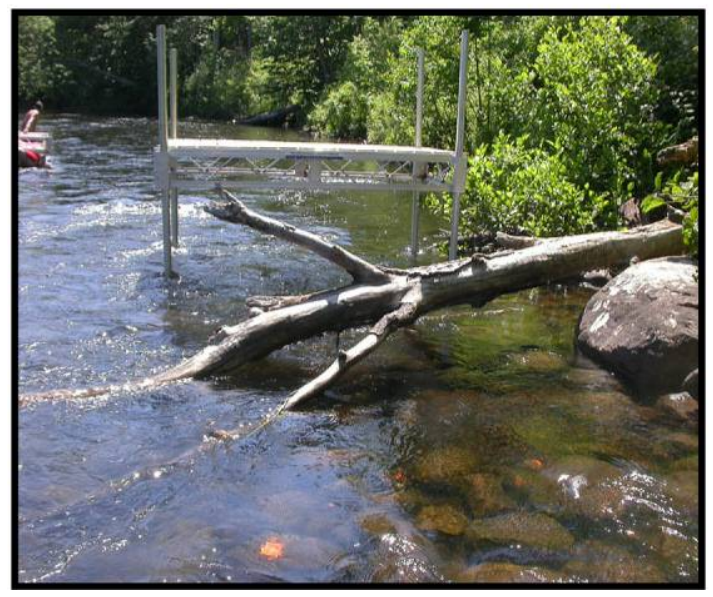

Stage D

Key Member 


\section{APPENDIX II: \\ PEBBLE COUNT DISTRIBUTIONS}

\section{Jam 1}

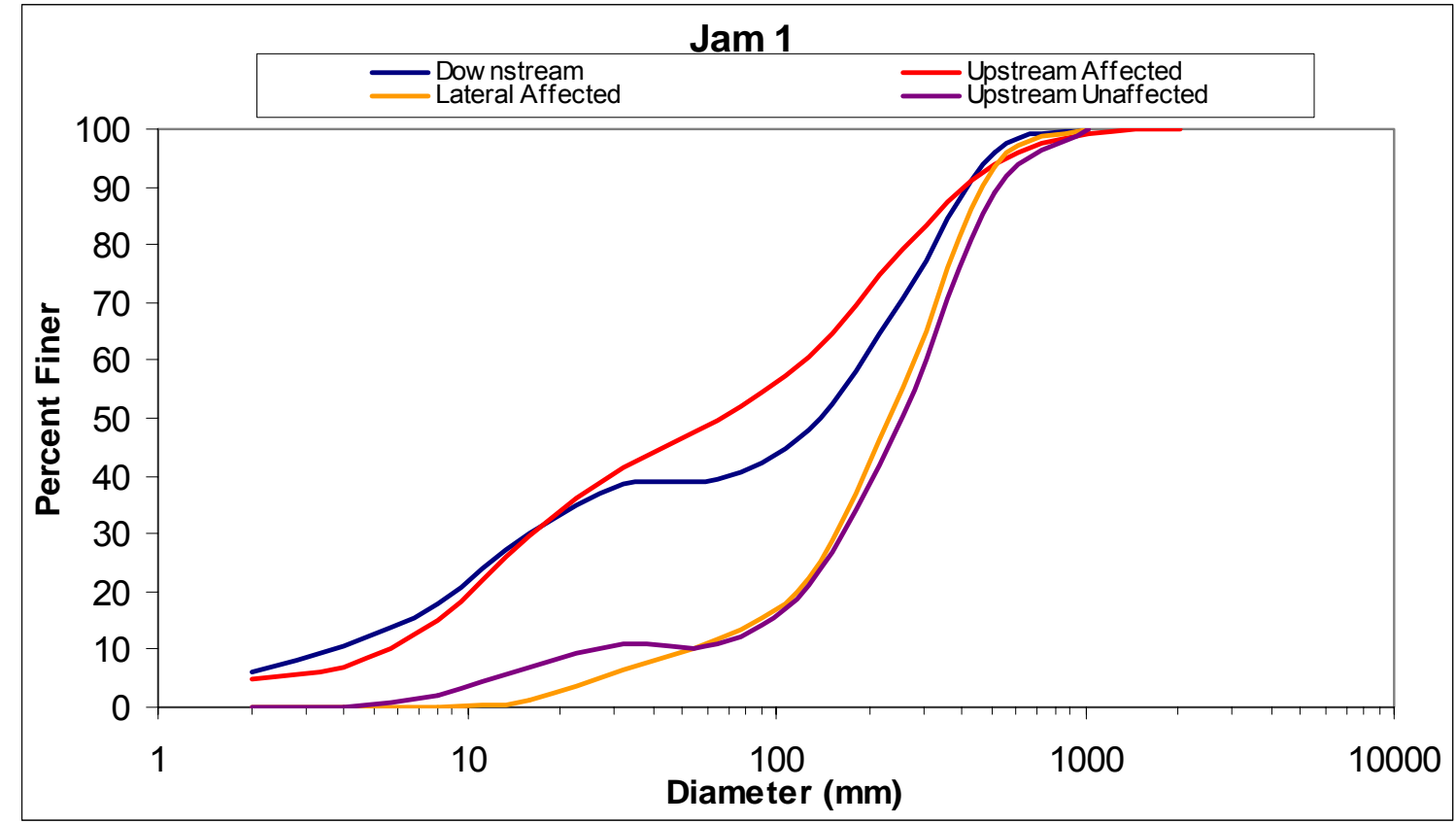

Downstream

\begin{tabular}{|c|c|c|}
\hline D & Count & \%finer \\
\hline 0 & 6 & 0 \\
\hline 2 & 4 & 6 \\
\hline 4 & 7 & 10 \\
\hline 8 & 12 & 18 \\
\hline 16 & 8 & 30 \\
\hline 32 & 1 & 39 \\
\hline 64 & 8 & 40 \\
\hline 128 & 22 & 48 \\
\hline 256 & 24 & 71 \\
\hline 512 & 6 & 96 \\
\hline 1024 & 0 & 100 \\
\hline
\end{tabular}

Upstream Affected
\begin{tabular}{|ccc|}
\hline $\mathrm{D}$ & Count & $\%$ finer \\
0 & 5 & 0 \\
2 & 2 & 5 \\
4 & 8 & 7 \\
8 & 15 & 15 \\
16 & 12 & 30 \\
32 & 8 & 42 \\
64 & 11 & 50 \\
128 & 19 & 60 \\
256 & 15 & 79 \\
512 & 5 & 94 \\
1024 & 1 & 99 \\
2048 & 0 & 100 \\
& & \\
\hline
\end{tabular}

\begin{tabular}{|ccc|} 
Adjacent & & \\
\hline $\mathrm{D}$ & Count & $\%$ finer \\
0 & 0 & 0 \\
2 & 0 & 0 \\
4 & 0 & 0 \\
8 & 1 & 0 \\
16 & 4 & 1 \\
32 & 4 & 7 \\
64 & 8 & 12 \\
128 & 25 & 22 \\
256 & 29 & 55 \\
512 & 4 & 93 \\
1024 & 0 & 100 \\
\hline
\end{tabular}

\begin{tabular}{|ccc|} 
Upstream Unaffected \\
\hline D & Count & $\%$ finer \\
0 & & 0 \\
2 & & 0 \\
4 & 2 & 0 \\
8 & 5 & 2 \\
16 & 4 & 7 \\
32 & & 11 \\
64 & 10 & 11 \\
128 & 29 & 21 \\
256 & 38 & 51 \\
512 & 11 & 89 \\
1024 & 0 & 100 \\
\hline
\end{tabular}


Jam 2

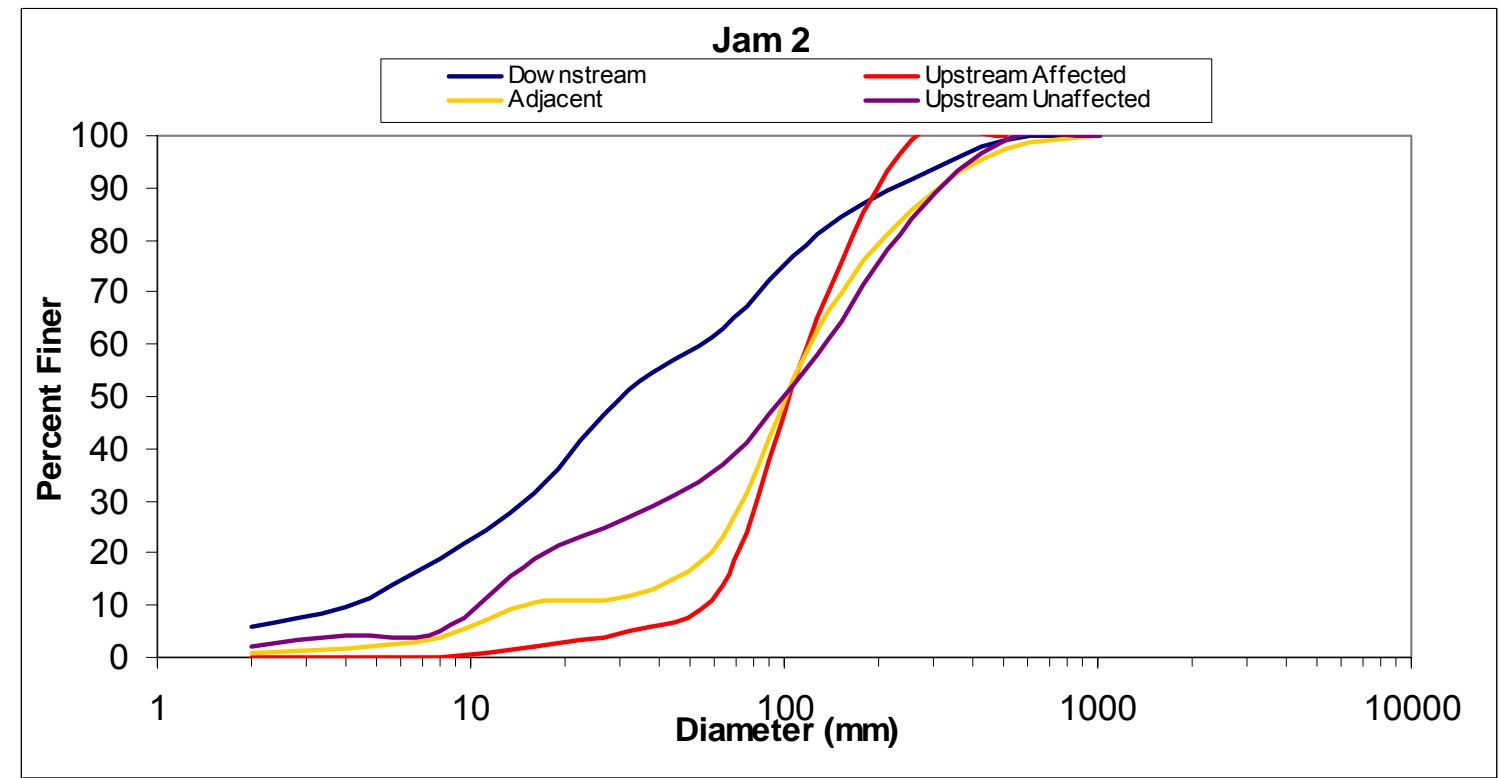

Downstream

\begin{tabular}{|rrrr|}
\hline D & Count & \multicolumn{2}{c|}{$\%$ finer } \\
& 0 & 6 & 0 \\
2 & 4 & 6 \\
4 & 10 & 10 \\
8 & 13 & 19 \\
16 & 21 & 31 \\
32 & 12 & 51 \\
64 & 19 & 63 \\
128 & 11 & 81 \\
256 & 8 & 91 \\
512 & 1 & 99 \\
1024 & 0 & 100 \\
\hline
\end{tabular}

Adjacent

\begin{tabular}{|rrrr|}
\hline D & Count & \multicolumn{2}{c|}{ \%finer } \\
& 0 & 1 & 0 \\
2 & 1 & 1 \\
4 & 3 & 2 \\
8 & 8 & 4 \\
16 & 2 & 10 \\
32 & 14 & 12 \\
64 & 50 & 23 \\
128 & 29 & 63 \\
256 & 15 & 86 \\
512 & 3 & 98 \\
1024 & 0 & 100 \\
\hline
\end{tabular}

Upstream Affected

\begin{tabular}{|rrrr|}
\hline D & Count & \multicolumn{2}{c|}{ \%finer } \\
& 0 & 0 & 0 \\
2 & 0 & 0 \\
4 & 0 & 0 \\
8 & 2 & 0 \\
16 & 3 & 2 \\
32 & 9 & 5 \\
64 & 51 & 14 \\
128 & 34 & 65 \\
256 & 1 & 99 \\
512 & 0 & 100 \\
\hline
\end{tabular}

Upstream Unaffected
\begin{tabular}{|rrrr|}
\hline D & Count & \% finer & \\
& 0 & 2 & 0 \\
& 2 & 2 & 2 \\
4 & 1 & 4 \\
8 & 14 & 5 \\
16 & 8 & 19 \\
32 & 10 & 27 \\
64 & 21 & 37 \\
128 & 26 & 58 \\
256 & 15 & 84 \\
512 & 1 & 99 \\
1024 & 0 & 100 \\
\hline
\end{tabular}




\section{Jam 3}

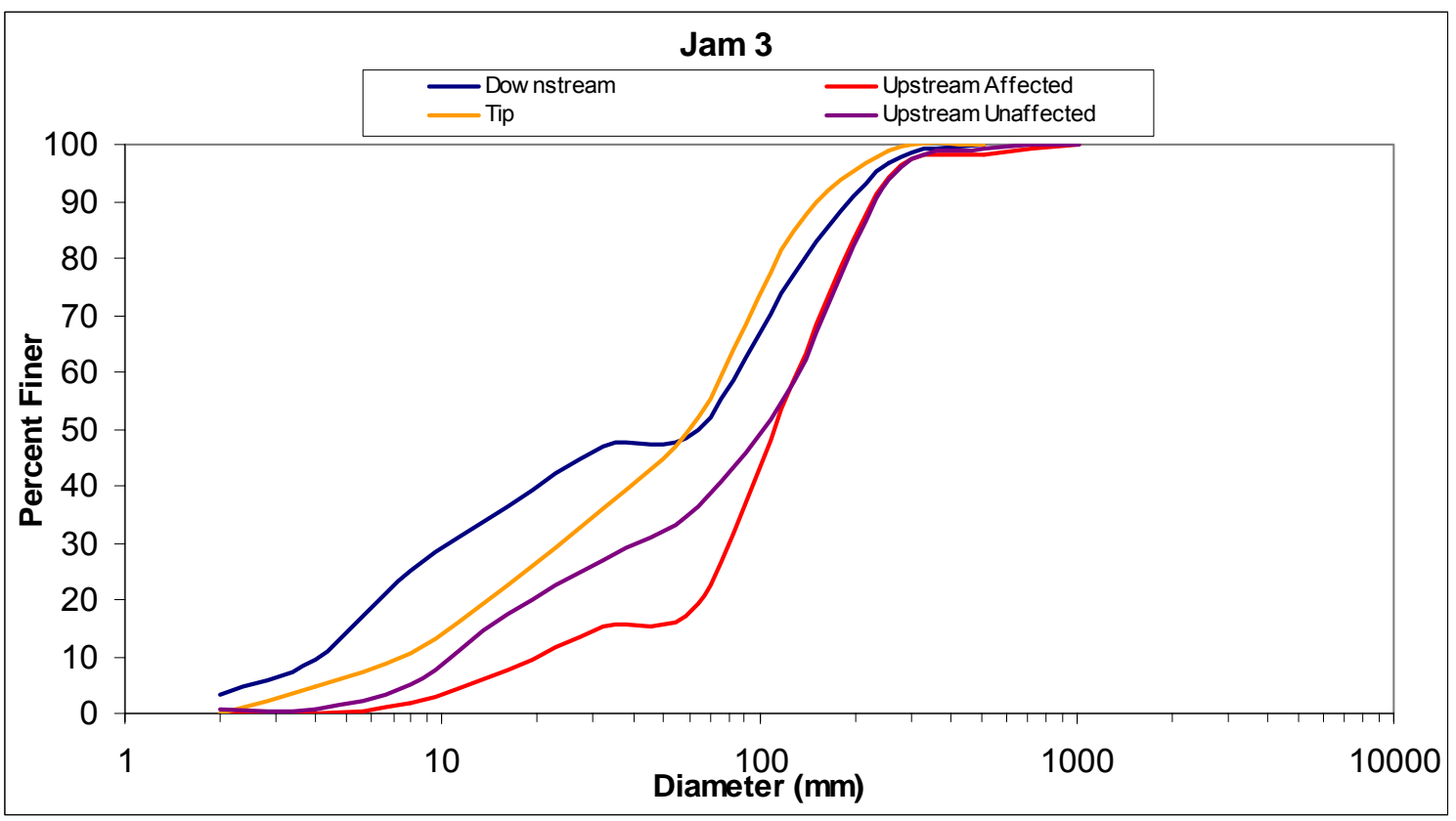

Downstream

\begin{tabular}{|ccc|}
\hline $\mathrm{D}$ & Count & \%finer \\
\hline 0 & 3 & 0 \\
2 & 6 & 3 \\
4 & 15 & 9 \\
8 & 11 & 25 \\
16 & 10 & 36 \\
32 & 3 & 47 \\
64 & 26 & 50 \\
128 & 19 & 77 \\
256 & 3 & 97 \\
512 & 0 & 100 \\
\hline
\end{tabular}

Adjacent

\begin{tabular}{|c|c|c|}
\hline D & Count & $\%$ finer \\
\hline 0 & 0 & 0 \\
\hline 2 & 5 & 0 \\
\hline 4 & 6 & 5 \\
\hline 8 & 13 & 10 \\
\hline 16 & 14 & 23 \\
\hline 32 & 17 & 36 \\
\hline 64 & 35 & 52 \\
\hline 128 & 15 & 85 \\
\hline 256 & 1 & 99 \\
\hline 512 & 0 & 100 \\
\hline
\end{tabular}

Upstream Affected

\begin{tabular}{|crr|}
\hline$D$ & Count & \%finer \\
\hline 0 & 0 & 0 \\
2 & 0 & 0 \\
4 & 2 & 0 \\
8 & 6 & 2 \\
16 & 8 & 8 \\
32 & 4 & 15 \\
64 & 41 & 19 \\
128 & 37 & 59 \\
256 & 4 & 94 \\
512 & 2 & 98 \\
1024 & 0 & 100 \\
\hline
\end{tabular}

Upstream Unaffected

\begin{tabular}{|crc|}
\hline $\mathrm{D}$ & Count & \% finer \\
\hline 0 & 1 & 0 \\
2 & 0 & 1 \\
4 & 5 & 1 \\
8 & 14 & 5 \\
16 & 11 & 17 \\
32 & 11 & 27 \\
64 & 25 & 37 \\
128 & 41 & 58 \\
256 & 6 & 94 \\
512 & 1 & 99 \\
1024 & 0 & 100 \\
\hline
\end{tabular}


$\underline{\text { Pebble Count Percentiles }}$

\begin{tabular}{c|cccc|}
\hline \multirow{2}{*}{ Jam 1 } & \multicolumn{4}{c}{} \\
\cline { 2 - 5 } & Downstream & Adjacent & $\begin{array}{c}\text { Upstream } \\
\text { Affected }\end{array}$ & $\begin{array}{c}\text { Upstream } \\
\text { Unaffected }\end{array}$ \\
\hline \hline $\mathbf{D}_{\mathbf{1 6}}$ & 90 & 90 & 8 & 110 \\
$\mathbf{D}_{\mathbf{5 0}}$ & 250 & 250 & 60 & 280 \\
$\mathbf{D}_{\mathbf{8 4}}$ & 390 & 450 & 350 & 450 \\
$\mathbf{D}_{\mathbf{9 0}}$ & 450 & 500 & 400 & 600 \\
\hline
\end{tabular}

Jam 2

\begin{tabular}{|c|cccc|}
\cline { 2 - 5 } & Downstream & Adjacent & $\begin{array}{c}\text { Upstream } \\
\text { Affected }\end{array}$ & $\begin{array}{c}\text { Upstream } \\
\text { Unaffected }\end{array}$ \\
\hline \hline $\mathbf{D}_{\mathbf{1 6}}$ & 7 & 50 & 70 & 15 \\
$\mathbf{D}_{50}$ & 30 & 100 & 100 & 100 \\
$\mathbf{D}_{\mathbf{8 4}}$ & 175 & 280 & 190 & 280 \\
$\mathbf{D}_{90}$ & 250 & 300 & 220 & 320 \\
\hline
\end{tabular}

Jam 3

\begin{tabular}{|c|cccc|}
\cline { 2 - 5 } & Downstream & Adjacent & $\begin{array}{c}\text { Upstream } \\
\text { Affected }\end{array}$ & $\begin{array}{c}\text { Upstream } \\
\text { Unaffected }\end{array}$ \\
\hline \hline $\mathbf{D}_{\mathbf{1 6}}$ & 6 & 12 & 50 & 15 \\
$\mathbf{D}_{\mathbf{5 0}}$ & 65 & 60 & 110 & 100 \\
$\mathbf{D}_{\mathbf{8 4}}$ & 170 & 130 & 200 & 220 \\
$\mathbf{D}_{90}$ & 200 & 170 & 230 & 270 \\
\hline
\end{tabular}


APPENDIX III:

MAGNITUDE AND DIRECTION OF DEPTH-AVERAGED VELOCITIES AND NEAR-BED SHEAR STRESS VALUES FROM PROFILES TAKEN AT FIXED SAMPLING LOCATIONS FOR EACH JAM

Jam 1

Low Flow

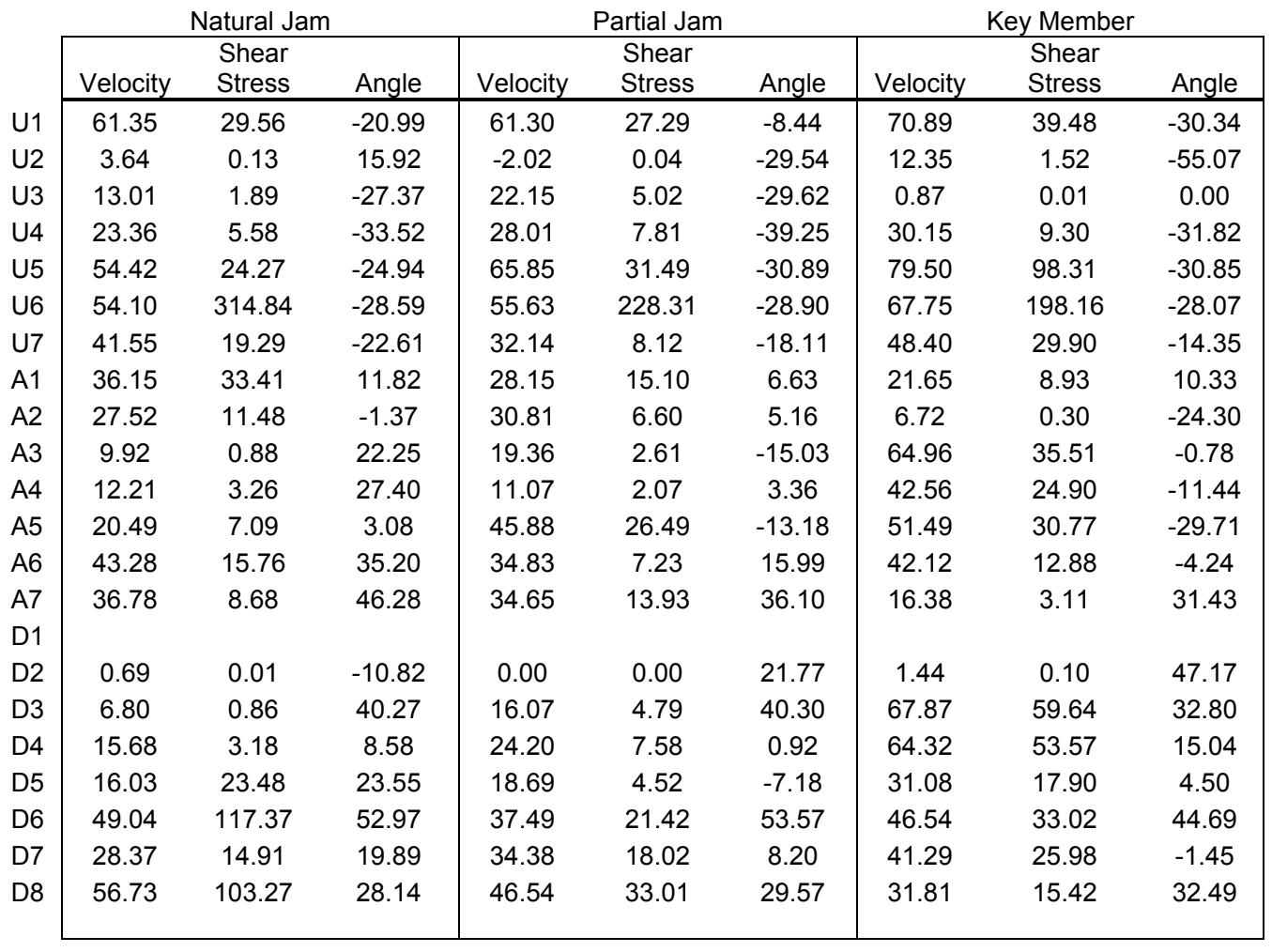




\begin{tabular}{|c|c|c|c|c|c|c|c|c|c|}
\hline \multicolumn{10}{|c|}{ High Flow } \\
\hline & \multicolumn{3}{|c|}{ Shear } & Velocity & $\begin{array}{l}\text { Shear } \\
\text { Stress }\end{array}$ & Angle & Velocity & $\begin{array}{l}\text { Shear } \\
\text { Stress }\end{array}$ & Angle \\
\hline U1 & 127.79 & 56.57 & -14.50 & 139.52 & 76.97 & 36.53 & 110.50 & 44.70 & -35.61 \\
\hline U2 & 49.96 & 9.71 & -21.09 & 66.04 & 18.47 & -24.08 & 115.83 & 49.85 & -34.39 \\
\hline U3 & 43.69 & 7.31 & -10.55 & 51.76 & 10.95 & -5.54 & 65.67 & 16.78 & 4.37 \\
\hline U4 & 45.89 & 8.07 & -16.45 & 57.80 & 13.21 & -19.17 & 92.60 & 34.47 & -28.94 \\
\hline U5 & 88.71 & 28.82 & -27.42 & 124.13 & 64.10 & -8.34 & 146.33 & 82.01 & -31.53 \\
\hline U6 & 80.51 & 33.03 & -28.04 & 130.19 & 90.67 & -31.78 & 170.38 & 159.33 & -33.97 \\
\hline $\mathrm{U} 7$ & 117.66 & 52.21 & 29.93 & 129.47 & 64.21 & -16.14 & 113.93 & 47.53 & -30.42 \\
\hline A1 & 143.00 & 86.00 & -8.30 & 155.82 & 101.71 & -5.12 & 131.89 & 74.47 & -11.23 \\
\hline A2 & 133.26 & 65.03 & -13.13 & 118.28 & 55.13 & -8.18 & 89.26 & 26.89 & -7.75 \\
\hline A3 & 42.32 & 7.20 & 0.78 & 100.95 & 36.68 & -7.94 & 154.27 & 88.69 & -3.71 \\
\hline A4 & 25.09 & 3.30 & -13.07 & 25.28 & 2.68 & 15.11 & 48.00 & 10.09 & -11.84 \\
\hline A5 & 4.38 & 0.09 & 33.15 & 21.76 & 2.12 & -14.23 & 39.63 & 6.31 & -29.12 \\
\hline A6 & 47.06 & 8.56 & -6.85 & 134.98 & 128.87 & 0.02 & 147.05 & 77.82 & 8.94 \\
\hline A7 & 132.25 & 73.27 & 9.60 & 135.71 & 74.04 & 7.17 & 118.32 & 56.28 & 5.74 \\
\hline D1 & 14.61 & 3.96 & 12.03 & 93.85 & 71.97 & 28.41 & 33.18 & 11.00 & 15.69 \\
\hline D2 & 37.86 & 8.71 & -10.87 & 73.22 & 26.33 & 17.66 & 73.73 & 24.48 & -8.32 \\
\hline D3 & 2.85 & 0.04 & -24.21 & 74.60 & 21.65 & 35.86 & 111.15 & 42.64 & 3.61 \\
\hline D4 & 76.43 & 24.36 & 8.96 & 101.38 & 39.99 & 14.73 & 132.04 & 72.70 & -7.23 \\
\hline D5 & 42.43 & 23.31 & -12.30 & 85.99 & 30.83 & 7.06 & 109.90 & 46.99 & 4.66 \\
\hline D6 & 67.88 & 22.64 & 18.44 & 116.28 & 61.38 & -18.02 & 132.36 & 73.74 & -12.06 \\
\hline D7 & 43.71 & 9.39 & 18.41 & 81.07 & 27.41 & 13.91 & 113.29 & 51.59 & -21.95 \\
\hline D8 & 66.55 & 24.02 & 23.99 & 110.07 & 50.52 & 22.58 & 130.90 & 71.44 & 19.15 \\
\hline
\end{tabular}


Jam 2

Low Flow

\begin{tabular}{|c|c|c|c|c|c|c|c|c|c|c|c|c|}
\hline & \multicolumn{3}{|c|}{ Natural Jam } & \multicolumn{3}{|c|}{ Wrapped Jam } & \multicolumn{3}{|c|}{ Partial Jam } & \multicolumn{3}{|c|}{ Key Member } \\
\hline & & Shear & & & Shear & & & Shear & & & Shear & \\
\hline & Velocity & Stress & Angle & Velocity & Stress & Angle & Velocity & Stress & Angle & Velocity & Stress & Angle \\
\hline U1 & 42.64 & 11.74 & 17.32 & 34.98 & 8.42 & 6.52 & 39.86 & 12.61 & & 51.67 & 17.24 & 6.62 \\
\hline U2 & 20.00 & 2.58 & 34.07 & 19.57 & 2.63 & -11.55 & 16.44 & 2.06 & 40.72 & 34.43 & 8.43 & 0.00 \\
\hline U3 & 20.59 & 4.43 & 7.82 & 20.57 & 3.01 & 21.22 & 24.20 & 6.86 & -44.89 & 37.82 & 11.82 & -11.94 \\
\hline U4 & 48.45 & 30.51 & & 69.97 & 31.62 & & 57.42 & 26.17 & & 78.63 & 39.94 & -14.27 \\
\hline U5 & 18.95 & 3.53 & & 29.42 & 4.53 & & 26.75 & 4.36 & & 33.03 & 5.71 & \\
\hline U8 & 29.54 & 9.12 & & 50.39 & 13.94 & & 46.93 & 15.15 & & 65.28 & 23.39 & \\
\hline $\mathrm{T} 1$ & 89.68 & 45.25 & -15.68 & 115.02 & 76.64 & -20.68 & 93.22 & 54.51 & -14.35 & 87.12 & 40.10 & -16.10 \\
\hline T2 & 50.69 & 14.46 & 30.70 & 27.23 & 4.30 & 9.64 & 47.36 & 17.55 & 20.91 & 46.61 & 12.45 & 1.09 \\
\hline T3 & 17.11 & 1.65 & 0.69 & 20.11 & 2.56 & 25.76 & 12.86 & 1.49 & 15.13 & 6.37 & 0.23 & -49.09 \\
\hline T4 & 59.99 & 14.94 & -22.75 & 58.80 & 15.80 & -23.59 & 42.01 & 8.67 & -17.44 & 57.15 & 13.37 & -25.20 \\
\hline T5 & 74.56 & 34.86 & -15.43 & 56.51 & 20.22 & -28.92 & 41.57 & 19.49 & -17.15 & 83.78 & 26.04 & -7.27 \\
\hline D4 & 25.77 & 11.21 & 14.58 & 19.39 & 5.59 & 37.54 & 39.97 & 12.76 & 8.88 & 54.20 & 32.11 & 10.70 \\
\hline D5 & 34.47 & 13.79 & 3.14 & 33.73 & 64.65 & 19.88 & 16.22 & 8.08 & -8.92 & 71.22 & 85.64 & -13.81 \\
\hline D6 & 19.50 & 11.67 & -33.83 & 0.00 & 0.00 & 0.00 & 14.01 & 6.03 & -13.28 & 37.35 & 30.49 & -19.28 \\
\hline D7 & 0.00 & 0.00 & 0.00 & 0.00 & 0.00 & 0.00 & 20.32 & 12.66 & -4.94 & 0.67 & 0.27 & -14.65 \\
\hline D8 & 15.99 & 1.70 & -6.44 & 12.20 & 2.21 & -1.92 & 21.43 & 4.09 & -5.74 & 22.16 & 5.88 & -16.78 \\
\hline
\end{tabular}




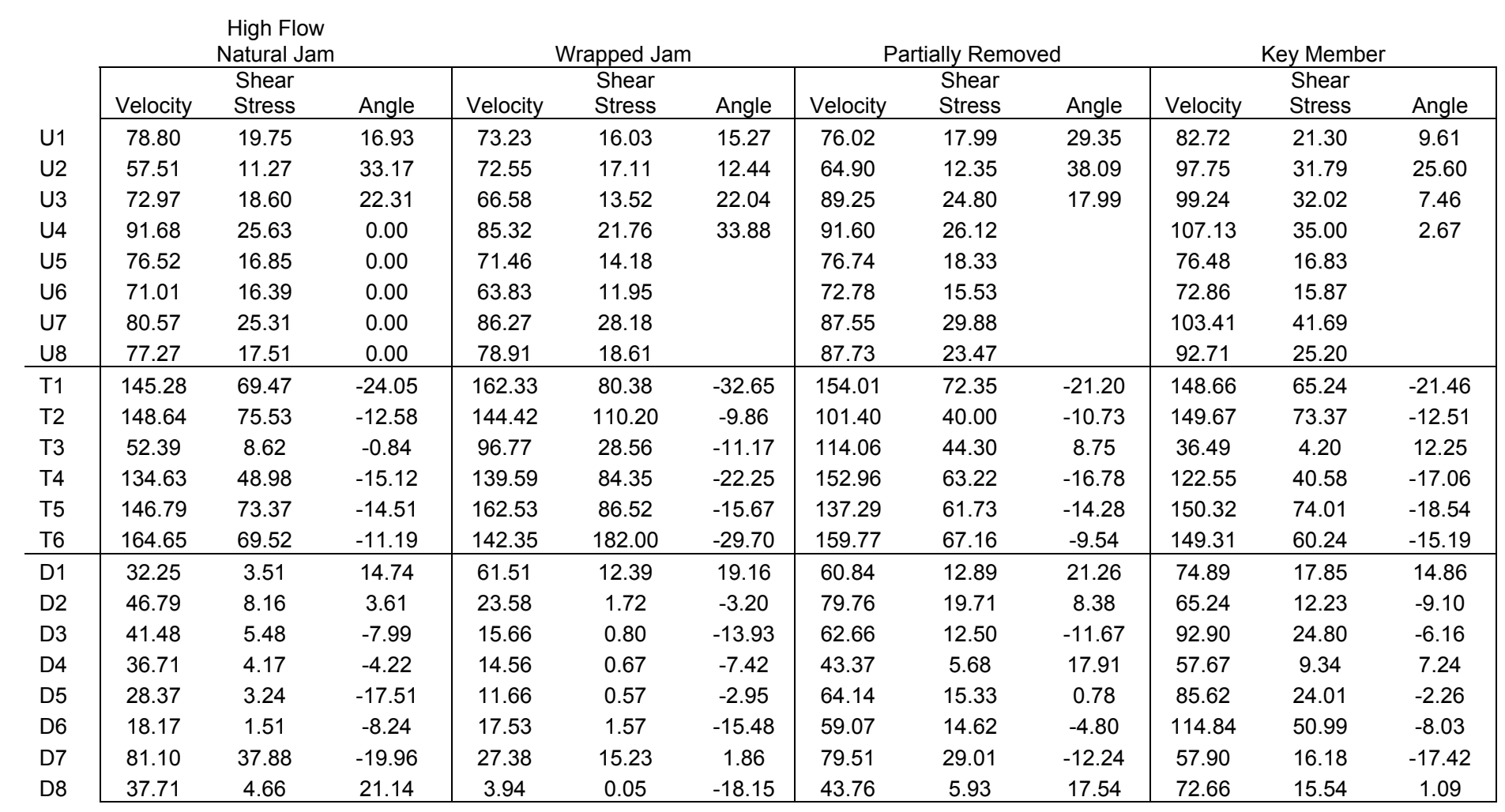




\section{Jam 3}

Low Flow

Natural Jam

Wrapped Jam

Key Member

\begin{tabular}{|c|c|c|c|c|c|c|c|c|c|}
\hline & \multicolumn{3}{|c|}{ Shear } & \multicolumn{3}{|c|}{ Shear } & \multicolumn{3}{|c|}{ Shear } \\
\hline & Velocity & Stress & Angle & Velocity & Stress & Angle & Velocity & Stress & Angle \\
\hline U1 & 23.26 & 3.31 & & 10.95 & 0.71 & & 43.18 & 8.46 & \\
\hline U2 & 18.19 & 2.44 & 11.41 & 4.44 & 0.10 & -24.77 & 37.45 & 7.18 & -14.97 \\
\hline U3 & 6.73 & 0.45 & -57.02 & 3.79 & 0.09 & -52.21 & 31.45 & 5.51 & -22.93 \\
\hline U4 & 4.94 & 0.20 & 54.37 & 8.26 & 0.46 & 57.30 & 20.77 & 2.55 & -26.87 \\
\hline U5 & 4.62 & 0.43 & & 8.93 & 1.81 & & 15.98 & 2.91 & \\
\hline U6 & 12.12 & 3.88 & & 14.39 & 3.30 & & 29.75 & 7.15 & \\
\hline U7 & 0.00 & 0.00 & & & & & 47.80 & 87.83 & \\
\hline U8 & 19.56 & 6.10 & & 15.95 & 2.27 & & 53.57 & 16.99 & \\
\hline $\mathrm{T} 1$ & 32.80 & 3.67 & -9.40 & 33.77 & 4.11 & -12.42 & 48.74 & 7.07 & -23.49 \\
\hline T2 & 27.72 & 3.08 & -2.27 & 17.58 & 1.24 & -17.94 & 39.02 & 4.53 & -16.56 \\
\hline T3 & 40.08 & 6.44 & -5.79 & 48.83 & 8.82 & -11.18 & 50.98 & 7.81 & -11.15 \\
\hline T4 & 34.15 & 4.29 & -34.94 & 37.33 & 5.16 & -42.61 & 61.68 & 10.74 & -23.99 \\
\hline T5 & 40.41 & 7.22 & -35.74 & 53.19 & 11.37 & -28.31 & 70.75 & 13.46 & -15.14 \\
\hline T6 & 35.35 & 4.60 & -17.86 & 52.08 & 9.32 & -29.36 & 74.77 & 15.78 & -32.18 \\
\hline T7 & & & & 61.45 & 13.97 & -36.79 & 57.88 & 9.97 & -25.59 \\
\hline D1 & 1.27 & 0.03 & 45.99 & 3.58 & 0.18 & 28.79 & 12.84 & 1.20 & -16.45 \\
\hline D2 & 0.00 & 0.00 & 0.00 & 0.00 & 0.00 & & & & \\
\hline D3 & 0.10 & 0.00 & 2.54 & -0.04 & 0.00 & 51.86 & 29.76 & 4.51 & -23.60 \\
\hline D4 & 23.67 & 24.18 & -55.96 & -10.65 & 2.90 & 57.29 & 27.08 & 8.19 & -11.90 \\
\hline D5 & 15.59 & 10.49 & -44.50 & 3.85 & 0.64 & -15.65 & 23.55 & 3.31 & -13.47 \\
\hline D6 & 1.49 & 0.04 & -54.50 & 23.41 & 4.49 & -21.68 & 19.40 & 2.24 & -7.42 \\
\hline D7 & 0.00 & 0.00 & 0.00 & 0.00 & 0.00 & & & & \\
\hline D8 & 11.60 & 0.80 & -27.35 & 12.26 & 0.44 & -30.58 & 29.40 & 3.31 & -25.98 \\
\hline
\end{tabular}




\begin{tabular}{|c|c|c|c|c|c|c|c|c|c|}
\hline \multicolumn{10}{|c|}{ Wrapped Jam } \\
\hline \multirow[b]{3}{*}{ U1 } & \multicolumn{3}{|c|}{ Shear } & \multicolumn{3}{|c|}{ Shear } & \\
\hline & Velocity & Stress & Angle & Velocity & Stress & Angle & Velocity & Stress & Angle \\
\hline & 44.62 & 5.36 & & 64.34 & 10.55 & & 90.59 & 21.69 & \\
\hline U2 & 80.94 & 16.84 & 22.98 & 69.15 & 11.97 & 33.99 & 83.99 & 18.30 & 3.20 \\
\hline U3 & 66.82 & 12.03 & 28.06 & 65.00 & 10.77 & 29.62 & 100.66 & 28.43 & 1.08 \\
\hline U4 & 42.35 & 4.78 & 9.75 & 34.61 & 3.11 & 31.02 & 75.11 & 15.50 & 4.92 \\
\hline U5 & 32.00 & 3.31 & & 75.74 & 17.61 & & 60.71 & 12.23 & \\
\hline U6 & 64.34 & 12.13 & & 52.82 & 7.24 & & 77.29 & 16.76 & \\
\hline U7 & 69.35 & 17.72 & & 85.83 & 28.56 & & 95.93 & 34.48 & \\
\hline U8 & 61.97 & 11.13 & & 71.42 & 14.02 & & 87.98 & 21.95 & \\
\hline T1 & 79.85 & 11.86 & -34.93 & 119.65 & 27.25 & -28.69 & 84.85 & 24.39 & -21.14 \\
\hline T2 & 93.56 & 16.70 & -10.21 & 85.54 & 13.93 & -13.23 & 94.50 & 14.05 & -10.90 \\
\hline T3 & 139.11 & 38.96 & -8.54 & 124.07 & 28.60 & -11.19 & 139.56 & 31.17 & 2.67 \\
\hline T4 & 115.48 & 24.81 & -5.38 & 100.27 & 18.68 & -23.55 & 117.85 & 20.62 & -11.77 \\
\hline T5 & 111.42 & 23.10 & -6.61 & 82.15 & 12.25 & -30.56 & 115.53 & 25.75 & -10.40 \\
\hline T6 & 127.87 & 30.42 & -39.87 & 135.04 & 32.39 & 0.80 & 127.87 & 22.57 & -23.88 \\
\hline $\mathrm{T} 7$ & 118.57 & 26.16 & -28.08 & 127.41 & 30.16 & -26.05 & 121.40 & 27.95 & -18.14 \\
\hline D1 & 11.60 & 0.40 & 10.91 & 1.13 & 0.00 & 51.97 & 70.18 & 13.31 & 7.87 \\
\hline $\mathrm{D} 2$ & 19.65 & 1.97 & 6.98 & 19.29 & 1.67 & -21.76 & 93.35 & 36.90 & 8.00 \\
\hline D3 & 39.13 & 5.17 & 1.53 & 7.18 & 0.12 & -20.02 & 81.91 & 17.66 & -4.35 \\
\hline D4 & 20.58 & 1.90 & -11.88 & 6.54 & 0.13 & -52.15 & 81.21 & 18.31 & 5.08 \\
\hline D5 & 7.81 & 0.25 & -24.09 & 12.70 & 0.52 & -21.25 & 88.07 & 19.45 & 7.76 \\
\hline D6 & 38.23 & 4.59 & 5.64 & 32.24 & 2.74 & 1.99 & 73.66 & 14.66 & 0.19 \\
\hline D7 & 54.49 & 19.04 & 8.49 & 3.54 & 0.05 & 54.39 & 28.85 & 2.81 & 2.43 \\
\hline D8 & 62.89 & 9.29 & -15.17 & 130.72 & 40.12 & -21.70 & 79.96 & 13.65 & -4.75 \\
\hline
\end{tabular}


APPENDIX IV:

MEAN VELOCITY AND SHEAR STRESS FOR JAMS 1 AND 3
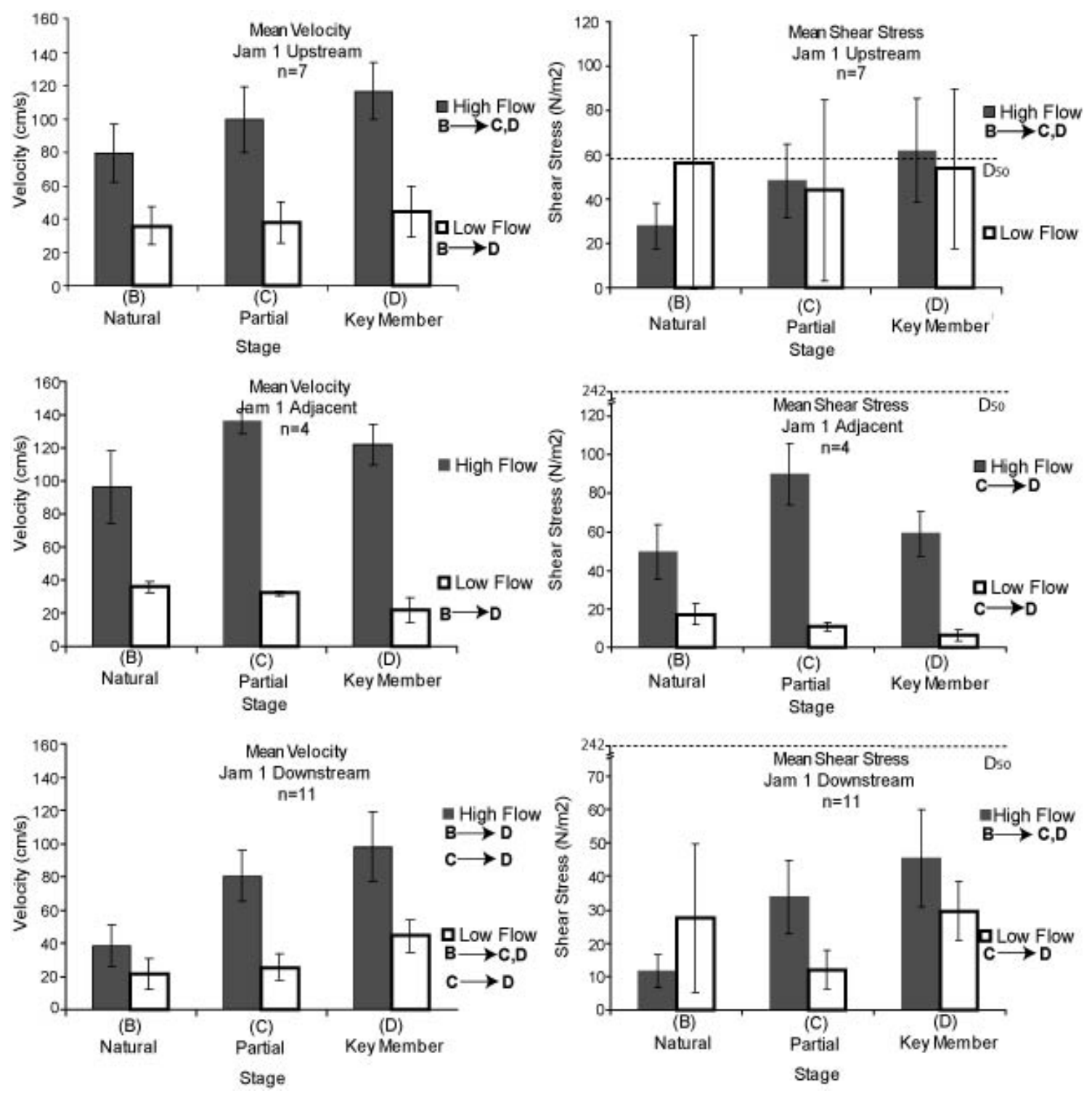

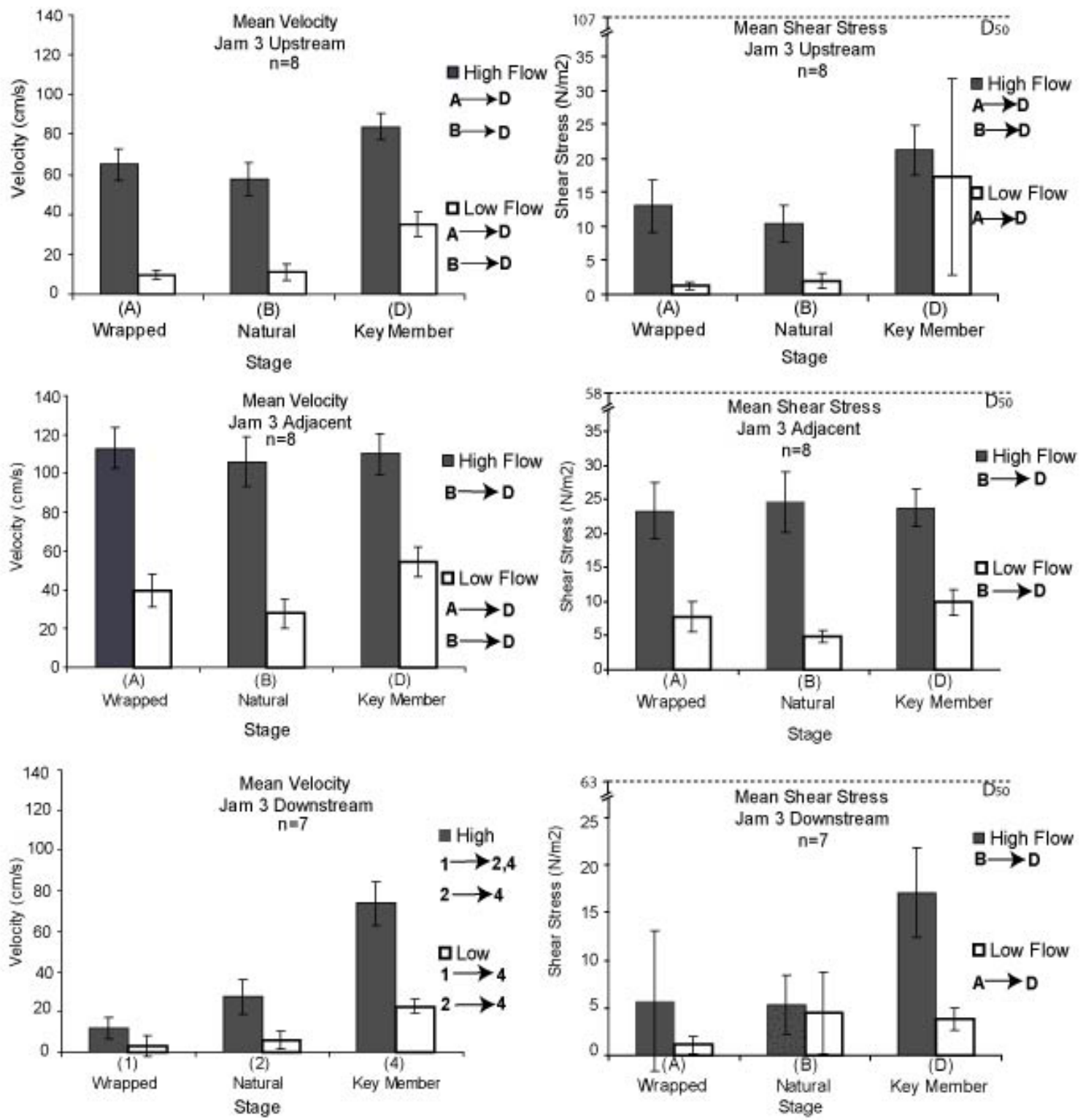
APPENDIX V:

VELOCITY AND SHEAR STRESS DISTRIBUTIONS AROUND JAMS 1 AND 3
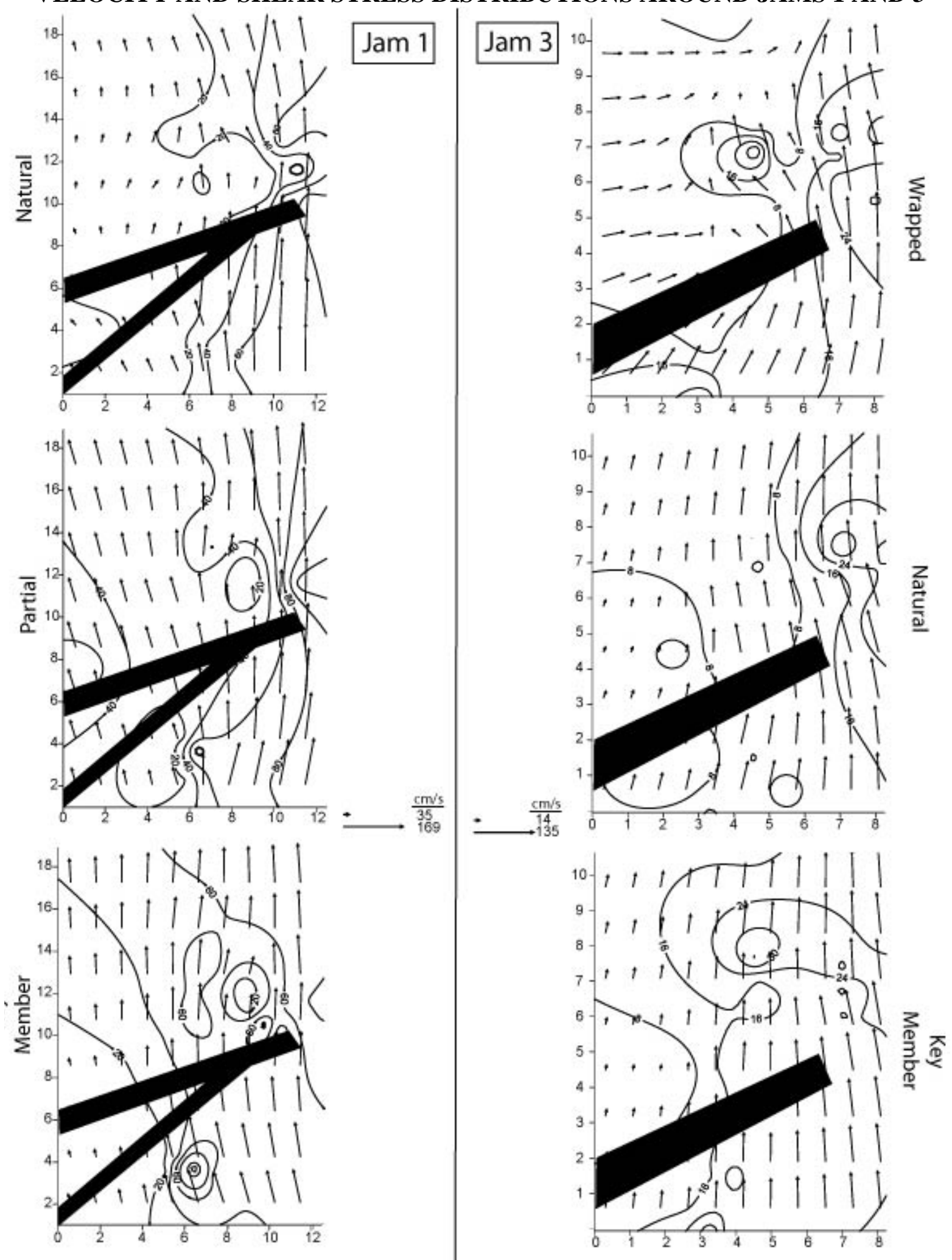


\section{REFERENCES}

Abbe, T. and Montgomery, D.A. (1996), Large woody debris jams, channel hydraulics and habitat formation in large rivers, Reg. Rivers Res. Manage., 12, 201-221.

Abbe, T. Brooks, A.P. and Montgomery, D.R. (2003) Wood in River Rehabilitation and Management, in The Ecology and Management of Wood in World Rivers, edited by S.V. Gregory, K.L. Boyer, and A.M. Gurnell, pp. 367-389, American Fisheries Society.

Abbe, T. and Montgomery, D.R. (2003), Patterns and Processes of wood debris accumulation in the Queets river basin, Washington, Geomorphology, 51, 81-107.

Angradi, T.R., Schweiger, E.W., et al. (2004), Bank stabilization, riparian landuse and the distribution of large woody debris in a regulated reach of the upper Missouri River, North Dakota, USA, River Research and Applications, 20, 829-846.

Berg, N., Carlosn, A., Azuma, D. (1998), Function and dynamics of woody debris in stream reaches in the central Sierra Nevada, California, Can. J. Fish. Aquat. Sci., 55, 1807-1820.

Bernhardt, E., Palmer, M.A., Allan, J.D.,et al. (2005), Synthesizing U.S. River Restoration Efforts, Science, $308,636-637$.

Bilby, R. and Bisson. P. (1998), Function and Distribution of Large Woody Debris, in River Ecology and Management, edited by R. Naiman and R. Bilby, p. 324-346, Springer Velag, New York.

Bilby, R. and Likens, G. (1980), Importance of Organic Debris Dams in the Structure and Function of Stream Ecosystems. Ecology, 61, 1107-1113.

Bilby, R. and Ward, J. (1989), Changes in Characteristics and Function of Woody Debris with Increasing Size of Streams in Western Washington, Trans. Am. Fish. Soc., 118, 368-378.

Brooks, A.P., Abbe, T.B., et al. (2001), Putting the wood back into our rivers: An experiment in river rehabilitation, in Third Australian Stream Management Conference:The value of healthy streams, edited by I. Rutherford, F. Sheldon, G. Brierley and C. Kenyon, p. 73-80, Cooperative Research Centre for Catchment Hydrology, Brisbane,

Braudrick, C. and Grant, G.G. (2000), When do logs move in rivers?, Water Resour. Res., 36, 571-583.

Braudrick, C. and Grant, G.G. (2001), Transport and deposition of large woody debris in streams: a flume experiment, Geomorphology, 41, 263-283.

Buffington, J.M. and Montgomery, D.R. (1999), Effects of hydraulic roughness on surface textures of gravelbed rivers, Water Resour, Res., 35, 3507-3521.

Collins, B.D. and Montgomery, D.R. (2002), Forest Development, Wood Jams, and Restoration of Floodplain Rivers in the Puget Lowland, Washington, Restoration Ecology, 10, 237- 247.

Cherry, J. and Beschta, R.L. (1989), Coarse woody debris and channel morphology. A flume study, Water Resour. Bul., 25, 1031-1036.

D'Aoust, S.G. and Millar, R.G. (2000), Stability of Ballasted Woody Debris Habitat Structures, Journal of Hydraulic Engineering, 126, 810-817.

Daniels, M.D. and Rhoads, B.L. (2004), Effect of large woody debris configuration on three-dimensional flow 
structure in two low-energy meander bends at varying stages, Water Resour. Res., 40, W11302, doi:10.1029/2004WR003181.

Diez, J.R., Larranaga, S. et al. (2000), Effect of removal of wood on streambed stability and retention of organic matter, Journal of the North American Benthological Society, 19, 621-632.

Downs, P. and Simon, A. (2001), Fluvial geomogphological analysis of the recruitment of large woody debris in the Yalobusha River network, Central Mississippi, USA, Geomorphology, 37, 65-91.

Ehrman, T.P. and Lamberti, G.A. (1992), Hydraulic and particulate matter retention in a 3-rd order Indiana Stream, Journal of the North American Benthological Society, 11, 341-349.

Evans, B.F., Townsend, C.R., (1993), Distribution and abundance of coarse woody debris in some southern New Zealand streams from contrasting forest catchments, New Zealand Journal of Marine and Freshwater Research, 27, 227-239.

Frisell, C.A. and Nawa, R.K. (1992), Incidence and causes of failure of artificial habitat structures in streams in western Oregon and Washington, North American Journal of Fisheries Management, 12, 182-197.

Gippel, C.J. O'Neill, Finlayson, B.L. and Schnatz, I., (1996), Hydraulic guidelines for the re-introduction and management of large woody debris in lowland rivers, Reg. Rivers Res. Manage., 12, 223-236.

Gippel, C.J. (1995) Environmental hydraulics of large woody debris in streams and rivers, J, Env.Eng., 121, 388-395.

Grant, P.F. and Nickling, W.G. (1998), Direct field measurement of wind drag on vegetation for application to windbreak design and modeling, Land Degrad. Dev., 9, 57-66.

Gregory, K.J., Gurnell, A.M. and Hill, C.T. (1985), Permanence of Debris Dams Related to River Channel Processes, Hydrological Sciences Journal, 30, 371-381.

Gregory, K.J. and Davis, R.J. (1992), Coarse woody debris in stream channels in relation to river channel management in woodland areas, Reg. Rivers Res. Manage., 7, 117-136.

Gregory, K.J., Davis, R.J. and Tooth, S. (1993), Spatial distribution of coarse woody debris dams in the Lymington Basin, Hampshire, UK, Geomorphology, 6, 207-224.

Gurnell, A.M., Gregory, K.J., Petts, G.E. (1995), The role of coarse woody debris in forest aquatic habitats: implications for management, Aquatic Conservations: Marine and Freshwater Ecosystems, 5, 143166.

Gurnell, A.M., Piegay, H., Swanson, F.J., and Gregory, S.V. (2002), Large wood and fluvial processes, Freshwater Biology, 47, 601-619.

Gurnell, A.M. and Sweet, R. (1998), The distribution of large woody debris accumulations and pools in relation to woodland stream management in a small, low gradient stream, Earth Surf. Processes Landforms, 23, 1101-1121.

Harmon, M.E., Franklin, J.F., Swanson, F.J., et al. (1986), Ecology of coarse woody debris in temperate ecosystems, Adv. Ecol. Res., 15, 133-302.

Haschenburger, J.K and Rice, S.P. (2004), Changes in woody debris and bed material texture in a gravel-bed channel, Geomorphology, 60, 241-267.

Hering, D., Kail, J. et al. (2000), Coarse woody debris quantity and distribution in central European streams, Int. Rev. Hydrobiol., 85, 5-23. 
Hildebrand, R.H., Lemly, D.A., et al. (1998), Design considerations for large woody debris placement in stream enhancement projects, N. Am. J. Fish. Manage., 18, 161-167.

Hyatt, T. and Naimant, R. (2001), The residence time of large woody debris in the Queets River, Washington, USA, Ecological Applications, 11, 191-202.

Hygelund, B. and Manga, M. (2003), Field measurements of drag coefficients for model large woody basins, Geomorphology, 51, 175-185.

Jackson, C.R. and Sturm, C.A. (2002), Woody debris and channel morphology in first and second-order forested channels in Washington's coast ranges, Water Resours. Res., 38, 1177, doi:10.1029/2001WR001138.

Keller, E. and Swanson, F. (1979), Effects of large organic material on channel form and process, Earth Surf. Processes Landforms, 4, 361-380.

Kondolf, M. (1995), Five elements for effective evaluation of stream restoration, Restoration Ecology, 3, 133136.

Kraft, C.E. and Warren, D.R. (2003), Development of spatial pattern in large woody debris and debris dams in streams, Geomorphology, 51, 127-139.

Lake, P.S. (2001), On the maturing of restoration: Linking ecological research and restoration, Ecological Management and Restoration, 2, 110-115.

Larson, M.G., Booth, D.B. and Morley, S.A. (2001), Effectiveness of large woody debris in stream rehabilitation projects in urban basins, Ecological Engineering, 18, 211-226.

Lepori, F., Palm, D., Brannas, E. and Malmqvist, B. (2005), Does Restoration of Structural Heterogeneity in Streams Enhance Fish and Macroinvertebrate Diversity?, Ecological Applications, 15, 2060-2071.

Lienaempker, G. and Swanson, F. (1986), Dynamics of large woody debris in streams in old-growth DouglasFir forests, Can. J. For. Res., 17, 150-156.

Lisle, T.E. (1995), Effects of coarse woody derbris and its removal on a channel affected by the 1980 eruption of Mount St. Helens, Washington, Water Resour. Res., 31, 1797-1808.

Lisle, T.E. (1986), Stabilization of a gravel channel by large streamside obstructions and bedrock bends, Jacoby Creek, northwestern California, Water Resour. Res., 97, 999-1011.

Littell, R.C., Miliken, G.A. and Stroup, W.W. (1996), SAS System for Mixed Models, Cary, NC, SAS Institute Inc.

Manga, M. and Kirchner, J.W. (2000), Stress partitioning in streams by large woody debris, Water Resour. Res., $36,2373-2379$.

Marcs, W.A, Marston, R.A., et al. (2002), Mapping the spatial and temporal distributions of woody debris in streams of the Greater Yellowstone Ecosystem, USA, Geomorphology, 44, 323-335.

Marsh, N., Rutherfor, I. et al. (2001), Predicting pre-disturbance loading and distribution of large woody debris, in Third Australian Stream Management Conference:The value of healthy streams, edited by I. Rutherford, F. Sheldon, G. Brierley and C. Kenyon, p. 391-396, Cooperative Research Centre for Catchment Hydrology, Brisbane, 
Martin, D.J. and Benda, L.E. (2001), Patterns of instream wood recruitment and transport at the watershed scale, Transactions of the American Fisheries Society, 130, 940-958.

McDade, M., Swanson, F.J. et al. (1989), Source distances for coarse woody debris entering small streams in western Oregon and Washington, Can. J. For. Res., 20, 326-330.

Meleason, M.A., Davies-Colley, R. et al. (2005), Characteristics and geomorphic effect of wood in New Zealand's native forest streams, Internat. Rev. Hydrobiol., 90, 466-485.

Meleason, M.A. and Hall, G.M.J. (2005), Managing plantation forests to provide short- to long-term supplies of wood to streams: A simulation study using New Zealand's pine plantations, Environmental Management, 36, 258-271.

Montgomery, D.R., Abbe, T., Buffington, J., Peterson, N.P., Schmidt, K., and Stock, J. (1996) Distribution of bedrock and alluvial channels in forested mountain drainage, Nature, 381, 587-589.

Monzyk, F.R., Kelso, W.E., et al. (1997), Characteristics of woody cover used by brown madtoms and pirate perch in coastal plain streams, Transactions of the American Fisheries Society, 126, 665-675.

Moulin, B. and Piegay, H. (2004), Characteristics and temporal variability of large woody debris trapped in a reservoir on the river Rhone: Implications for river basin management, River Research and Applications, 20, 79-97.

Murphy, M.L. and Koski, K.V. (1989), Input and depletion of woody debris in Alaska streams and implications for streamside management, N. Am. J. Fish. Manage., 9, 427-436.

Nakamura, F. and Swanson, F.J. (1993), Effects of coarse woody debris on morphology and sediment storage of a mountain stream system in western Oregon, Earth Surf. Processes Landforms, 18, 43-61.

Palmer, M., Bernhard, E., Allan, J.D., Lake, P.S., et al. (2005) Standards for ecologically successful restoration, Journal of Applied Ecology, 42, 208-217.

Pettit, N.E., Naiman, R.J., Rogers, K.H., Little, J.E. (2005), Post-flooding distribution and characteristics of large woody debris piles along the semi-arid Sabie River, South Africa, River Research and Applications, 21, 27-38.

Piegay, H. (1993), Nature, mass, and preferential sites of coarse woody debris deposits in the Lower Ain Valley (Mollon Reach), France, Regulated Rivers: Research and Management, 8, 359-372.

Piegay, H. and Gurnell, A. (1997) Large woody debris and river geomorphological pattern: examples from S.E. France and S. England, Geomorphology, 19, 99-116.

Piegay, H. Thevenet, A, Citterio, A. (1999), Input storage and distribution of large woody debris along a mountain river continuum, the Drome River, France, Catena, 35, 19-39.

Ralph, S.C., Poole, G.C. et al. (1994), Stream channel condition and in-stream habitat in logged and unlogged basins in western Washington, Can. J. Fish. Aquat. Sci, 51, 37-51.

Richmond, A.D. and Fausch, K.D. (1995), Characteristics and function of large woody debris in subalpine Rocky Mountain streams in northern Colorado, Canadian Journal of Fisheries and Aquatic Science, $52,1789-1802$.

Roberson, J.A. and Crowe, C.T. (1997), Engineering fluid mechanics, Boston, Houghton Mifflin.

Robison, E.G. and Beschta, R.L. (1990), Identifying trees in riparian areas that can provide coarse woody debris to streams, Forest Science, 36, 790-801. 
Shields, F.D and Gippel, C. (1995), Prediction of Effects of Woody Debris Removal on Flow Resistance, J.Hydraul. Eng., 121, 341-354.

Shields, F.D., Morin, N. and Cooper, C.M. (2004), Large woody debris structures for sand-bed channel, J.Hydraul. Eng., 130, 208-217.

Smith, R.D., Sidle, R.C., Porter, P.E. and Noel, J.R. (1993), Effects of experimental removal of woody debris on channel morphology of a forest, gravel-bed stream, Earth Surf. Processes Landforms, 18, 455-468.

Spanhoff, B. and Meyer, E. (2004), Breakdown rates of wood in streams, Journal of the North American Benthological Society, 23, 189-197.

Sturtevant, B.R., Bissonette, J.A. et al. (1997), Coarse woody debris as a function of age, stand structure, and disturbance in boreal Newfoundland, Ecological Applications, 7, 702-712.

Swanson, F.J., Bryant, M.D. et al. (1984), Organic Debris in Small Streams, Prince of Wales Island, Southeast Alaska, General Technical Report PNW-166, 1-12.

Thevenet, A., Citterio, A., Piegay, H. (1998), A new methodology for the assessment of large woody debris accumulations on highly modified rivers (examples of two French Piedmont rivers), Regulated Rivers: Research and Management, 14, 467-483.

Triska, F.J. and Cromack, K. (1980), The role of wood debris in forests and streams, in Forests: fresh perspectives from ecosystem analysis, edited by R.H. Waring, p. 171-190, Oregon State University Press, Corvallis, Oregon.

Triton Environmental Consultants, Ltd. (1996), In-stream habitat complexing 1988-1990, Nechako Fisheries Conservation Program Technical Report No. RM90-3.

Wallace, J.B., Webster, J. et al. (2000), Small wood dynamics in a headwater stream, Verh. Internat. Verein. Limnol., 27, 1361-1365.

Wallerstein, N., Thorne, C.R. and Doyle, M.W. (1997), Spatial distribution and impact of large woody debris in northern Mississippi, in Proceedings of the Conference on Management of Landscapes Disturbed by Channel Incision, edited by S.S.Y Wang, E.J. Langendoen and F.D. Shields, Jr., pp. 145-150, The University of Mississippi, Oxford, Mississippi.

Wallerstein, N., Alonso, C., Bennett, S, and Thorne, C. 2001. "Distorted froude-scaled flume analysis of large woody debris." Earth Surf. Processes Landforms, 26, 1265-1283.

Wallerstein, N., Alonso, C., Bennett, S., and Thorne, C. 2002. "Surface Wave Forces Acting on Submerged Logs." J. Hydraul. Eng., 128(3), 349-353.

Wallerstein, N. 2003. "Dynamic model for constriction scour caused by large woody debris." Earth Surf. Processes Landforms, 28, 49-68.

Webb, A.A and Erskine, W.D. (2005), Natural variability in the distribution, loading and induced scour of large wood in sand-bed forest streams, River Research and Applications, 21, 169-185.

Webster, J.R., Benfield, E.F. et al. (1999), What happens to allochthonous material that falls into streams? A synthesis of new and published information from Coweeta, Freshwater Biology, 41, 687-705.

Wilcock, P.R. 1996. "Estimating local bed shear stress from velocity observations." Water Resour. Res., 32, 3361-3366. 
Wohl, E., Angermeier, P.L., Bledsoe, B., Kondolf, G.M., et al. (2005), River restoration, Water Resour. Res., 41, W10301, doi:10.1029/2005WR003985.

Wolman, M.G. (1954), Method of sampling coarse river bed material, EOS Trans. AGU, 35, 951-956.

Wolman, M.G. and Miller, J.P. (1960), Magnitude and frequency of forces in geomorphic processes, $J$. Geol,.68, 54-74.

Wyzga, B. and Zawiejska, J. (2005), Wood storage in a wide mountain river: case study of the Czarny Dunajec, Polish Carpathians, Earth Surf. Processes Landforms, 30, 1475-1494.

Zalewski, M., Lapinska, M., Bayley, P.B. 2003. Fish Relationships with Wood in Large Rivers, in The Ecology and Management of Wood in World Rivers, edited by S.V. Gregory, K.L. Boyer, and A.M. Gurnell, pp. 195-211, American Fisheries Society. 